\title{
Follow-up and management of valvular heart disease patients with prosthetic valve: a clinical practice guideline for Indian scenario
}

\author{
Devendra Saksena $^{1} \cdot$ Yugal K. Mishra ${ }^{2} \cdot$ S. Muralidharan ${ }^{3} \cdot$ Vivek Kanhere $^{4} \cdot$ Pankaj Srivastava $^{5} \cdot$ C. P. Srivastava ${ }^{6}$. \\ VHD India consensus committee
}

Published online: 28 January 2019

(C) The Author(s) 2019

\begin{abstract}
Purpose Valvular heart disease (VHD) patients after prosthetic valve implantation are at risk of thromboembolic events. Followup care of patients with prosthetic valve has a paramount role in reducing the morbidity and mortality. Currently, in India, there is quintessential need to stream line the follow-up care of prosthetic valve patients. This mandates the development of a consensus guideline for the antithrombotic therapy in VHD patients post prosthetic valve implantation.

Methods A national level panel was constituted comprising 13 leading cardio care experts in India who thoroughly reviewed the up to date literature, formulated the recommendations, and developed the consensus document. Later on, extensive discussions were held on this draft and the recommendations in 8 regional meetings involving 79 additional experts from the cardio care in India, to arrive at a consensus. The final consensus document is developed relying on the available evidence and/or majority consensus from all the meetings.

Results The panel recommended vitamin $\mathrm{K}$ antagonist (VKA) therapy with individualized target international normalized ratio (INR) in VHD patients after prosthetic valve implantation. The panel opined that management of prosthetic valve complications should be personalized on the basis of type of complications. In addition, the panel recommends to distinguish individuals with various co-morbidities and attend them appropriately.

Conclusions Anticoagulant therapy with VKA seems to be an effective option post prosthetic valve implantation in VHD patients. However, the role for non-VKA oral therapy in prosthetic valve patients and the safety and efficacy of novel oral anticoagulants in patients with bioprosthetic valve need to be studied extensively.
\end{abstract}

Keywords Valvular heart disease $\cdot$ Prosthetic valves $\cdot$ Anti-Coagulation

\begin{tabular}{|c|c|c|}
\hline \multicolumn{3}{|c|}{ Abbreviations } \\
\hline \multicolumn{2}{|c|}{ AACE } & American Association of Clinical \\
\hline \multicolumn{2}{|c|}{ AATS } & American Association for Thoracic Surgery \\
\hline \multicolumn{2}{|c|}{$\mathrm{ACC}$} & American College of Cardiology \\
\hline \multicolumn{3}{|c|}{$\begin{array}{l}\triangle \quad \text { Yugal K. Mishra } \\
\text { dryugal@yahoo.com }\end{array}$} \\
\hline 1 & \multicolumn{2}{|c|}{ Department of Cardiac Surgery, Bombay Hospital, Mumbai, India } \\
\hline 2 & \multicolumn{2}{|c|}{ Manipal Hospital, New Delhi, India } \\
\hline \multicolumn{3}{|c|}{ GKNM Hospital, Coimbatore, India } \\
\hline \multicolumn{3}{|c|}{ Chirayu Health Centre, Bhopal, India } \\
\hline 5 & \multicolumn{2}{|c|}{ Divine Heart \& Multi-speciality Hospital, Lucknow, India } \\
\hline 6 & Nara & a Hrudayalaya, Jaipur, India \\
\hline
\end{tabular}

\section{Abbreviations}

AATS American Association for Thoracic Surgery

$\mathrm{ACC}$
ACCF American College of Cardiology Foundation

ACCP American College of Chest Physicians

AE Adverse events

AF Atrial fibrillation

AHA American Heart Association

APA Antiplatelet agent

AR Aortic regurgitation

AS Aortic stenosis

AS-Echo American Society of Echocardiography

AVR Aortic valve replacement

BMS Bare-metal stent

CABG Coronary artery bypass graft

CAD Coronary arterial disease

CHF Congestive heart failure

CHV Chitra prosthetic heart valve

CKD Chronic kidney disease

CNS Central nervous system

CSI Cardiological Society of India 


\begin{tabular}{|c|c|}
\hline DES & Drug-eluting stent \\
\hline DVR & Dual valve replacement \\
\hline DVT & Deep venous thrombosis \\
\hline EACTS & $\begin{array}{l}\text { European Association for Cardio- } \\
\text { Thoracic Surgery }\end{array}$ \\
\hline EAE & European Association of Echocardiography \\
\hline EHRA & European Heart Rhythm Association \\
\hline ESC & European Society of Cardiology \\
\hline FFP & Fresh frozen plasma \\
\hline GCPR & Good clinical practice recommendations \\
\hline $\mathrm{HF}$ & Heart failure \\
\hline IACTS & $\begin{array}{l}\text { Indian Association of Cardiovascular- } \\
\text { Thoracic Surgeons }\end{array}$ \\
\hline ICD & Implantable cardioverter-defibrillator \\
\hline IE & Infective endocarditis \\
\hline INR & International normalized ratio \\
\hline JAPI & $\begin{array}{l}\text { Journal of The Association of Physicians } \\
\text { of India }\end{array}$ \\
\hline LMWH & Low molecular weight heparin \\
\hline LV & Left ventricular \\
\hline MACE & Major adverse cardiac event \\
\hline MAV & Mechanical aortic valve \\
\hline MI & Myocardial infarction \\
\hline MR & Mitral regurgitation \\
\hline MRI & Magnetic resonance imaging \\
\hline NSAIDS & Nonsteroidal anti-inflammatory drugs \\
\hline NYHA & New York Heart Association \\
\hline OAT & Oral anticoagulation therapy \\
\hline PCC & Prothrombin complex concentrates \\
\hline PCI & Percutaneous coronary intervention \\
\hline POAF & Postoperative atrial fibrillation \\
\hline POC & Point-of-care \\
\hline PSM & Patient self-management \\
\hline PT & Prothrombin time \\
\hline PVE & Prosthetic valve endocarditis \\
\hline PVI & Pulmonary vein isolation \\
\hline QOL & Quality of life \\
\hline $\mathrm{RCT}$ & Randomized controlled trials \\
\hline RHD & Rheumatic heart disease \\
\hline SCAI & $\begin{array}{l}\text { Society for Cardiovascular Angiography } \\
\text { and Interventions }\end{array}$ \\
\hline STS & Society of Thoracic Surgeons \\
\hline TAVI & Transcatheter aortic valve implantation \\
\hline TEE & Transesophageal echocardiography \\
\hline TIA & Transient ischemic attack \\
\hline TPA & Tissue plasminogen activator \\
\hline TR & Therapeutic range \\
\hline TTE & Transthoracic echocardiography \\
\hline TTR & Target therapeutic range \\
\hline TVR & Tricuspid valve replacement \\
\hline UFH & Unfractionated heparin \\
\hline VHD & Valvular heart disease \\
\hline VKA & Vitamin $\mathrm{K}$ antagonist \\
\hline
\end{tabular}

VTE Venous thromboembolism

\section{Executive summary}

I. Anticoagulation

A. Anticoagulants in mechanical prosthesis

A1. Vitamin K antagonists (VKA) therapy with a target international normalized ratio (INR) range of 2.0 to 3.0 is recommended in patients with mechanical aortic valve replacement (AVR) without risk factors (grade A, EL 2).

A2. VKA therapy with a target INR range of 2.5 to 3.5 is recommended in patients with mechanical AVR with risk factors - atrial fibrillation (AF), previous thromboembolism, left ventricular (LV) dysfunction, or hypercoagulable conditions (grade A, EL 2).

A3. In mechanical mitral valve replacement (MVR), VKA therapy with a target INR range of 2.5 to 3.5 is recommended in patients with and without additional thromboembolic risk factors (grade A, EL 2).

A4. With mechanical valves in both the aortic and mitral position, a target INR range of 2.5 to 3.5 is recommended (grade A, EL 2).

A5. VKA therapy in combination with antiplatelet therapy (aspirin 75 to $150 \mathrm{mg}$ ) is recommended for long-term management with mechanical valve prosthesis (grade A, EL 1).

A6. If required warfarin dose is $>10 \mathrm{mg}$, it is recommended to change to acenocoumarol; add aspirin if the patient is not already on aspirin (grade C, EL 4)

B. Anticoagulants in bioprosthesis

B1. VKA therapy is recommended in bioprosthetic AVR and MVR, with a target INR range of 2.0 to 3.0 over no VKA therapy for 3 months (grade B, EL 3). $\mathrm{B} 2$. In patients with dual bioprosthetic valve replacement (aortic, mitral), VKA therapy is recommended for 3 months with a target INR range of 2.0 to 3.0 (grade B, EL 3).

B3. After bioprosthetic AVR or MVR, long-term aspirin at a dose of 75 to $150 \mathrm{mg} /$ day is recommended after withdrawal of VKA therapy (grade A, EL 2)

C. Anticoagulants in transcatheter aortic valve implantation

C1. Antiplatelet agents either alone or in combination with anticoagulants are recommended after 
transcatheter aortic valve implantation (TAVI) (antiplatelet agents long term) (grade A, EL 2)

\section{Bridging anticoagulants}

D1. It is not recommended to interrupt VKA therapy during minor dental procedures (cleaning), dermatological procedures and cataract surgery due to minimal bleeding (grade A, EL 2).

D2. In patients with low thrombotic risk (bileaflet AVR without AF and no other risk factors for stroke), it is recommended to interrupt VKA therapy without bridging (grade B, EL 3).

D3. Bridging anticoagulation is recommended in patients with high risk of thromboembolism during temporary interruption of VKAs (grade B, EL 3).

D4. When interruption of VKA therapy is required, it is recommended to stop for 2-4 days before the procedure. After stopping VKA therapy, INR should be checked after 2 days and maintained $<2$. The VKA therapy should be restarted $12-24 \mathrm{~h}$ after surgery (grade A, EL 2).

D5. The reversal of VKA therapy during emergency surgeries can be achieved by administration of fresh frozen plasma (FFP). FFP requirement depends on the PT/INR value, liver function tests, and body weight of the patient (grade A, EL 2).

D6. Interruption of VKA therapy with bridging anticoagulants is recommended for not more than 2 days in case of elective major surgeries (grade A, EL 3)

E. Cardiac catheterization in patients with prosthetic valves

E1. Patients with low bleeding risk and undergoing coronary angiography with the radial approach may not require modification in VKA; however, in patients at high risk, bridging therapy is recommended (grade A, EL 1).

E2. VKA therapy may be reduced or withheld and bridging is considered for patients with the femoral approach in the electrophysiological procedure (grade A, EL 2).

E3. In patients who are at low risk of thromboembolic events, undergoing pulmonary vein isolation (PVI), VKA dose should be adjusted to maintain INR $<2$ and regular dose to be commenced after implantation (grade A, EL 2).

E4. In patients who are at very low risk of thromboembolic events undergoing cardiac implantable electronic devices, change in VKA therapy is not required; however, the dose should be titrated to achieve target INR $<2$ (grade A, EL 2)
II. Initiation, monitoring and factors affecting anticoagulation

A. Point-of-care INR testing

A1. The practice of patient self-management (PSM) of anticoagulation with patient self-monitoring is recommended (grade B, EL 1).

A2. Use of point-of-care (POC) devices can be alternated with the conventional laboratory testing to reduce hospital visits and the cost of the treatment (grade B, EL 1).

B. Loading dose, dose adjustments, and frequency of INR monitoring

B1. The initial recommended dosages of VKAs are warfarin, $5 \mathrm{mg}$ and acenocoumarol, $2 \mathrm{mg}$. However, individualization of VKA dose depending on age, bleeding risk, medication compliance history, and anticipated drug interactions is also recommended (grade A, EL 2).

B2. After baseline INR is determined, the next INR can be obtained after the patient has received two or three doses. Then after, the frequency of INR monitoring should be decided according to the value of INR (grade C, EL 4).

B3. INR checking should be as follows: first, at discharge; second, $48 \mathrm{~h}$; third, after 1 week of discharge; then after the frequency should be decided depending on INR value at first week (grade C, EL 4) (PT/INR reports $48 \mathrm{~h}$ after discharge as patient will be in the loading phase at the time of discharge. The fluctuation of INR for a week before the revisit after discharge not desirable).

B4. In patients with stable INR for 3 months with no dose adjustment, it is recommended to consider INR monitoring in every 12 weeks (grade A, EL 1). However, in the case of subtherapeutic or supratherapeutic INR, the frequency of monitoring should be increased until it stabilizes again. It should be monitored 1-2 monthly in high thrombotic risk patients (grade C, EL 4).

B5. In most asymptomatic fluctuations, the dose adjustment should be done by calculating the weekly or monthly dose of VKAs (grade C, EL 4).

B6. For patients taking VKAs with previously stable therapeutic INRs who present with a single out-of-range INR of $\leq 0.5$ below or above therapeutic INR, it is recommended continuing the current dose and testing the INR within 1 to 2 weeks with no routinely administering bridging with heparin (grade A, EL 2).

B7. If INR falls below the target in high-risk patients, an increase in VKA dose or unfractionated heparin (UFH) may be considered (grade C, EL 4) 
C. Factors affecting VKA therapy

Pharmacogenetics

C1. If the patient did not achieve target INR in spite of high dose of warfarin, pharmacogenetics testing may be considered, provided that it is easily available and costeffective (grade C, EL 4).

Drug-drug interaction

C2. It is recommended to avoid drugs that inhibit or enhance the activity of cytochrome P450 during the VKA therapy (grade A, EL 1).

C3. It is recommended to educate patients on drug interaction with over the counter drugs and antibiotics, and need for frequent monitoring INR when they are used (grade B, EL 3).

C4. Amiodarone, if needed, should be used with caution along with VKA therapy (grade A, EL 1).

C5. Nonsteroidal anti-inflammatory drugs (NSAIDs) should not be used with VKAs, if at all NSAIDs are needed, paracetamol may be considered with close supervision (grade A, EL 1).

Drug-food interaction

C6. Patients are advised to maintain constant vitamin $\mathrm{K}$ composition in their diet to avoid fluctuation of VKA therapy (grade C, EL 4).

C7. Patient in special situations such as fasting, VKA therapy should be carefully monitored (grade B, EL 2).

D. Anticoagulation in special patient populations Pregnancy

D1. Women with valve replacement should be advised to plan their pregnancy and inform the surgeon if the period is missed (grade C, EL 4).

D2. Women of childbearing age should be warned about the teratogenic and harmful effects of VKAs, especially in early pregnancy (grade C, EL 4).

Before 36 weeks of gestation

D3. Oral VKA therapy is recommended throughout pregnancy in patients with daily warfarin dose requirement of $\leq 5 \mathrm{mg}$ (or equivalent acenocoumarol dose) with target INR of 3 (grade B, EL 3).

D4. Subcutaneous UFH with activated partial thromboplastin time (aPTT) monitoring should be considered if warfarin dose is $>5 \mathrm{mg}$ (also for equivalent acenocoumarol dose) (grade B, EL 3).
D5. Low dose (75-150 mg) aspirin is recommended in second and third trimester (only in high-risk patients or all patients or in stable patients to reduce INR by 0.5 ) (grade C, EL 4).

\section{At 36 weeks of gestation}

D6. If the patient is hospitalized, VKA may be substituted with UFH. If not, VKA therapy should be discontinued prior to admission for delivery (grade C, EL 4).

D7. When hemostasis is adequate, VKA therapy should be restarted on day 1 at maintenance dose along with heparin (grade C, EL 4).

Elderly population

D8. Frequent renal tests and observation for adverse effects with concomitant medications are recommended in elderly patients considering them as high-risk patients for developing hemorrhagic complications (grade B, EL 3).

\section{Cancer}

D9. In patients with chemotherapy, VKA therapy should be closely monitored (grade A, EL 2).

Renal impairment

D10. Renal impairment patients should be closely monitored (grade B, EL 3).

III. Management of prosthetic valve complications

A. Thromboembolic events

A1. Transthoracic echocardiogram (TTE) is recommended for the diagnosis of thromboembolic events (grade A, EL 2).

A2. Treatment with tissue plasminogen activator (tPA) and heparin is recommended in patients with stroke; other vascular occlusions should be managed by surgery (grade C, EL 4).

A3. In anticoagulant patients with thromboembolic events, daily aspirin ( 75 to $81 \mathrm{mg}$ ) is recommended with an increase in the target INR range (mechanical AVR: 2.5-3, mechanical MVR: 3-4) (grade C, EL 4).

A4. In patients with bioprosthetic valve, who are only on aspirin, addition of VKAs can be considered (grade B, EL 3).

A5. Measures to increase patient compliance (patient education) are recommended in all patients with thromboembolic events (grade C, EL 4). 
B. Thrombosis of prosthetic valves

B1. TTE is recommended in patients with suspected prosthetic valve thrombosis to assess hemodynamic severity and resolution of valve dysfunction (grade B, EL 3). Cinefluoroscopy can be considered as an additional tool for diagnosis of prosthetic valve thrombosis (PVT) (grade C, EL 4).

B2. Transesophageal echocardiogram (TEE) is recommended to assess thrombus size and valve motion (grade B, EL 3).

$\mathrm{B} 3$. UFH is recommended in a very small and nonobstructive thrombus burden of left-sided PVT. If not treated, fibrinolytics are recommended (grade B, EL 3). B4. In patients with left-sided PVT, with thrombus burden, $\leq 0.8 \mathrm{~cm}^{2}$ fibrinolytics are recommended over surgery (grade B, EL 3).

B5. Emergency surgery is recommended in case of leftsided PVT with a mobile or large thrombus $>0.8 \mathrm{~cm}^{2}$. Fibrinolytics can be considered in patients with contraindications to surgery (grade B, EL 3).

B6. The right-sided thrombosis can be treated with fibrinolytics if no contraindications to fibrinolytics are present. If fibrinolytic therapy is successful, intravenous (IV) UFH is recommended until the patient achieves an INR of 3.0 to 4.0 for aortic prosthetic and 3.5 to 4.5 for mitral prosthetic valves (grade B, EL 3)

\section{Bleeding complications}

$\mathrm{C} 1$. In absence of active bleeding and INR in the range of 4.5-10.0, it is recommended withholding VKA with serial INR determination, and resuming when INR is therapeutic (grade B, EL 3).

$\mathrm{C} 2$. In absence of active bleeding, and $\mathrm{INR}>10$, it is recommended withholding VKA and administering FFP and should be hospitalized (grade C, EL 4).

C3. For patients with VKA-associated active bleeding, withhold VKA, and administer FFP. It is also recommended to administer vitamin $\mathrm{K} 1$ as slow IV infusion if uncontrolled (grade A, EL 2)

D. Prosthetic valve endocarditis (PVE)

Diagnosis

D1. TTE is recommended in suspected infective endocarditis (IE), in the case of negative TTE in suspected PVE, TEE is recommended. If initial examinations are negative, repetition of TTE/TEE is recommended within 710 days in patients with high suspicion of IE. Modified Duke Criteria should be used in evaluating a patient with suspected IE (grade B, EL 3).
Prophylaxis

D2. Antibiotic prophylaxis is recommended for certain dental procedures like gingival or periapical (root) procedures with perforation of the mucosa, and also for infected gastrointestinal and urogenital tract procedures (grade C, EL 4).

Antithrombotic

D3. It is recommended to discontinue VKA, in patients on VKA for a prosthetic valve who develop IE, until it is clear that invasive procedures will not be required and the patient has stabilized without signs of central nervous system (CNS) involvement. When the patient is deemed stable without contraindications or neurologic complications, reinstitution of VKA therapy is recommended (grade B, EL 3)

IV. Follow-up evaluations and management of concomitant cardiac disease

A. Heart failure

A1. Antithrombotics are recommended in valve replacement patients with stage A heart failure (HF) (grade A, EL 1). Angiotensin-converting enzyme (ACE) inhibitors and $\beta$ blockers could be beneficial if added in older patients (grade B, EL 3).

A2. ACE inhibitors and $\beta$ blockers along with antithrombotics are recommended in patients with stage B, C HF (grade A, EL 1). Moreover, spironolactone and digoxin can be added if congestive failure supervenes despite regular medications (grade A, EL 2).

A3. In patients with stage D HF, other interventions including cardiac transplant are recommended (grade D, EL 4)

\section{B. Coronary artery disease}

B1. Bare metal stents are recommended over drug-eluting stents in patients with valve replacement to lower bleeding risk (grade D, EL 4)

C. Atrial fibrillation

C1. Prophylactic amiodarone is recommended as a routine therapy for high-risk patients undergoing cardiac surgery in absence of a contraindication (grade A, EL 1). C2. Amiodarone at a dose of 100-200 mg daily for 3 months with dosage monitoring along with $\beta$ blockers is recommended for transient perioperative AF (grade A, EL 2) 
D. Follow up cardiac evaluation

D1. First postoperative visit to a cardiac specialist should be within 1 month of discharge (grade A, evidence level 4). D2. The timings of echocardiographic examination: first, at pre-discharge; second, at 1 month; then yearly; and should be done at any time when symptoms occur (grade C, EL 4). D3. The patient should be followed up by TTE and/or TEE in case of clinical symptoms or signs of prosthetic valve dysfunction (grade C, EL 4).

D4. Echocardiographic testing is recommended for (a) unexplained cardiac symptoms, (b) annually in all patients with congestive heart failure $(\mathrm{CHF})$. Moreover, echocardiography is indicated whenever there is an episode of thromboembolism (grade C, EL 4).

D5. Mechanical heart valve patients should undergo annual follow up in presence of a change in clinical status (grade C, EL 4)

\section{E. CT and MRI scan-post valve implantation}

E1. Magnetic resonance imaging (MRI) examination (3 T or less) is safe in patients with a prosthetic heart valve or annuloplasty ring or sternal wire (grade C, EL 3).

E2. MRI examination for patients with risk of endocarditis and valve dehiscence should be decided in consultation with a radiologist (grade D, EL 4).

\section{Introduction}

Valvular heart disease (VHD) is one of the common causes of cardiac morbidity and mortality [1]. The burden of VHD is growing worldwide due to the high incidence of rheumatic heart disease (RHD), especially in developing countries, and due to the increase in degenerative etiologies in industrialized nations $[2,3]$. Prevalence of VHD in industrialized countries is estimated at $2.5 \%$ [2]. Data on the burden of RHD in India comes from hospital data (20-50\%), population-based studies (2.2-1.6\%), and school surveys $(0.67-4.54 \%)$ [4]. The pattern of valve involvement is mitral $(54.4 \%)$, aortic $(17.8 \%)$, both mitral and aortic $(18.0 \%)$, tricuspid $(9.7 \%)$, or pulmonary $(0.04 \%)$. Overall, RHD contributes $63.4 \%$ to the prevalence of VHD [5]. This pattern of VHD in India is in contrast to the developed countries, where the most frequently involved valve type is aortic with degenerative etiology [6, 7]. Surgical valve repair or replacement using either a mechanical or bioprosthetic valve is a common solution practiced globally to manage or treat VHD.

The worldwide annual rate of valve replacement is projected around 275,000 to 370,000 , of which $55 \%$ are mechanical heart valves and $45 \%$ are bioprosthesis heart valves [8, 9]. In India, this number is estimated to be in excess of 10,000 [10]. Globally, the prosthetic valve implantations are increasing at a rate of 5$7 \%$ per year with bioprosthesis valves gaining favor over mechanical heart valves; $8-11 \%$ versus $3-5 \%$ per year respectively [11]. This increase may be attributed to increasing rate of valve replacement surgery in the elderly, in whom bioprosthetic is preferred, and to technological advances in bioprosthesis compared to mechanical device development [12-14].

Globally, valve repair rate for isolated mitral valve disease from 2000 to 2007 has increased from 51 to $69 \%$. However, this rate is still much lower than the $90 \%$ or higher rates achieved by some institutions [15-17]. Additionally, the repair rate among the elderly has remained much lower than their younger counterparts [18]. Valve repair surgery has some short-term advantages such as minimal morbidity and mortality, better survival, superior preservation of left ventricular (LV) function, and less valve-related complications over valve replacement surgery [19]. Furthermore, evidence indicates that along with short-term benefit, patients with valve repair also have an extra advantage toward the long-term survival compared to valve replacement patients [18, 20]. Management of patients with valve repair necessitates antithrombotic therapy for the first 3 months following surgery [21], which is a highrisk period for thromboembolism. Anticoagulation therapy has no extra advantage over antiplatelet therapy in valve repair patients, and anticoagulation therapy may lead to major bleeding complications [22]. Nonetheless, the efficacy of anticoagulants in patients with valve repair needs to be confirmed in randomized controlled trials (RCTs).

\section{Rationale}

An expert analysis of evidence related to drugs, devices, and procedures for diagnosis, management, and prevention of disease, direct toward improvement in the quality of care. Evaluation of data on the benefits and risks of these therapies can optimize patient outcomes and favorably affect costs by focusing resources on the most effective strategies.

Patients with prosthetic valves require lifelong follow-up and anticoagulant therapy. Failure in attaining appropriate follow-up care can lead to life-threatening complications. In order to alleviate morbidity and mortality in these patients, the Indian Association of Cardiovascular-Thoracic Surgeons (IACTS) has set forth to develop guidelines for follow-up care of patients with prosthetic valves, specifically gathering the evidence and formulating the recommendations with Indian perspective.

\section{Methodology}

The current Good Clinical Practice Recommendations (GCPR) from the IACTS for the follow-up and management of VHD patients with a prosthetic valve in India is developed by an "expert panel" of cardiologists and cardiothoracic 
surgeons across the country with vast experience in managing prosthetic valve patients.

A national panel with 13 members reviewed the literature and collected the evidence. Literature search was carried out electronically in the medical search engine "PubMed" and Google Scholar for relevant reports published between 1990 and October 2017. The main search strategy included the following keywords: valvular heart disease, prosthetic valves, anticoagulation with no limitation of time, and India (to identify specific evidence). Also, a manual search was made from key non-indexed journals. Abstracts written only in English were included. Evidence from RCTs and non-RCTs, retrospective and uncontrolled studies, reviews and metaanalyses were considered for framing the GCPR. When evidence was scant for specific areas, existing recommendations from national and international guidelines for the management of prosthetic valve patients were carefully analyzed.

Expert panel members reviewed the draft guideline along with the proposed GCPR, and a series of discussions were made to arrive at a consensus on each GCPR. Later on, extensive discussions were held on this draft and the recommendations in 8 regional meetings involving 79 additional experts to arrive at a consensus. The final consensus document is developed relying on the available evidence and/or majority consensus from all the meetings. When evidence is weak or does not exist for certain areas, the consensus opinion of the expert panel has been relied upon. Recommendations were graded as per the American Association of Clinical Endocrinologists (AACE) guidelines (Table 1) [23].

\section{Anticoagulation}

Prosthetic valve implantation requires postoperative prophylactic anticoagulation to preclude thrombotic events, which are the common cause of morbidity and mortality after surgery in patients with VHD. A paramount risk of thromboembolic

\section{Table 1 Grading of recommendations}

\section{Strength of recommendation}

A Strong recommendation

B Intermediate recommendation

C Weak recommendation

D No evidence-based recommendation

Scale of scientific support (evidence level)

1 At least one randomized controlled trial (RCT) or meta-analysis of RCTs

2 At least one non-randomized/non-controlled, prospective epidemiological study

3 Cross-sectional or observational or surveillance or pilot study

$4 \quad$ Existing guideline or consensus expert opinion on extensive patient experience or review events is observed during the first 3 months after surgery for both mechanical and bioprosthetic devices. Nevertheless, mechanical valves exhibit lifetime thrombotic risk. Atrial fibrillation $(\mathrm{AF})$, which is common in VHD, necessitates lifelong anticoagulation in the majority of patients; especially if it involves mitral valve. Moreover, patients on anticoagulants are always at risk of thrombosis and bleeding complications if the target international normalized ratio (INR) levels are not maintained. Restrictions on certain physical activities that are advised subsequently after surgery to reduce chances of bleeding accidents compromise lifestyle of the young patients. These considerations emphasize the importance of addressing proper anticoagulation techniques to minimize postoperative thrombotic complications while maintaining acceptable levels of risk related to bleeding.

\section{Anticoagulants in mechanical prosthesis}

Apart from the inherent thrombogenic characteristics of the intravascular prosthetic material, mechanical valves impose abnormal flow conditions within their components, with zones of low flow and areas of high-shear stress. These can cause platelet activation and lead to valve thrombosis and thromboembolic events.

\section{The studies comparing lower and higher INR targets}

The difference in outcomes between lower and higher INR targets in patients with valve replacement is controversial. The AREVA trial has failed to demonstrate or exclude a beneficial or detrimental effect of higher versus lower INR (3.0 to 4.5 vs. 2.0 to 3.0 ), achieved with Vitamin $\mathrm{K}$ antagonist (VKA), on thrombosis or hemorrhage in patients who predominantly had aortic valves [24]. LOWERing the INtensity of oral anticoaGulant Therapy in patients with bileaflet mechanical aortic valve replacement (AVR) (LOWERING-IT) trial compared INR target of 1.5 to 2.5 to the conventional 2.0 to 3.0 in low-risk bileaflet mechanical aortic valve patients who are on daily oral coumadin therapy without aspirin. The trial proposed that low INR target is safe and feasible for lowrisk patients. However, the study had a low quality of evidence owing to imprecision due to only four thrombotic events [25]. The German Experience with Low-Intensity Anticoagulation (GELIA) trial has shown the difference in the clinical outcomes by INR target for aortic versus mitral prostheses following coumadin anticoagulation. Thromboembolism following AVR was significantly lower than after mitral valve replacement (MVR). In the end, the trial support re-examination of the intensity of anticoagulation in patients with the St. Jude Medical valve. However, there was a trend toward fewer thromboembolic events in AVR patients with a higher INR in the trial [26]. A prospective study after evaluating 4202 patients with a mechanical valve, $\mathrm{AF}$, or myocardial infarction 
(MI) reports that the optimal anticoagulation for patients with mechanical heart valve prostheses was achieved with an INR of 2.5 to 2.9 , an INR of 3.0 to 3.4 for patients with AF, and an INR of 3.5 to 3.9 for patients after MI [27].

Cannegieter and associates investigated the optimal intensity of oral anticoagulation therapy (OAT) in 1608 patients with mechanical heart valves. The optimal intensity of anticoagulation achieved with VKA, defined as the INR level with the lowest incidence of both bleeding and thromboembolism, was in the range of 2.5 to 4.9 . Furthermore, a target range of 3.0 to 3.9 was found better than a target of 2.0 to 2.9 in a subgroup of mitral valve patients. However, the study was underpowered for subgroup analysis [28]. Another study by Pengo $\mathrm{V}$ et al. reports fewer bleeding events at target INR 3 compared to INR 4 achieved with VKA. The thrombotic events were similar in both the groups [29]. Furthermore, American college of chest physicians (ACCP) suggests that addition of antiplatelet agent (APA) to VKAs is associated with a significant reduction in mortality and thromboembolic outcomes with a relatively small increase in the risk of major hemorrhage [30].

\section{Novel mechanical valves with proposed lower INR targets}

A new generation mechanical valve, On-X mechanical valve (Medical Carbon Research Institute, Austin, TX, USA), has been shown to exhibit low thrombogenicity [31]. In the Prospective Randomized On-X Anticoagulation Clinical Trial (PROACT), AVR patients were randomized to receive warfarin at either low dose (INR 1.5-2.0) or a standard dose (INR 2.0-3.0) for 3 months following surgery. Daily aspirin $(81 \mathrm{mg})$ was given to all patients. Mean INR was 1.89 with low dose warfarin and 2.50 with standard treatment $(p<0.0001)$. Major and minor bleeding rates were significantly lower in low-dose group, and there was no significant difference between the two groups in terms of stroke, transient ischemic attack (TIA), or total neurological events and allcause mortality [32]. A recent case report advocate that lower level of anticoagulation may be suitable in patients with On-X valves and proposes that $O n-X$ valve may be helpful when therapeutic levels of anticoagulation cannot be attained due to the increased risk of bleeding [33].

TTK Chitra prosthetic heart valve (CHV) High prevalence of rheumatic valvular disease and the high cost of imports bolstered the need for the development of an Indian valve. As a result, the TTK Chitra prosthetic heart valve (CHV) was developed, which is the first heart valve to be manufactured in India that has been used since 1992 [34]. This tilting disc valve has an integrally machined cobalt alloy cage, an ultrahigh molecular weight polyethylene disc, and a polyester suture ring. Sankarkumar R. et al. evaluated the outcomes of CHV in 285 survivors with isolated MVR or AVR for a total of 1212 patient-years (pt-yr) (AVR, 445 pt-yr; MVR, 767 pt- yr). There was no incidence of a paravalvular leak or structural dysfunction of the valve. The study reported bleeding events (AVR 0.9 per pt-yr, MVR 0.4 per pt-yr) and thromboembolism (AVR $1.6 \%$ per pt-yr, MVR, $2.4 \%$ per pt-yr) with an actuarial survival of $82.4 \pm 4.0 \%$ for AVR and $65.2 \pm 5.0 \%$ for MVR at 7 years [34]. Similarly, Muralidharan S et al. reported 10-year outcomes of patients $(n=65)$ who underwent valve replacement with CHV [MVR, 58.5\%; AVR, 29.3\%; dual valve replacement (DVR), 12.3\%]. All patients maintained with anticoagulation acenocoumarol, warfarin, or phenindione at INR of 2.5-3.0. The study reported the incidence of valve thrombosis $(4.6 \%)$, prosthetic valve endocarditis (PVE) (4.6\%), MI (2.3\%), and the low cardiac output secondary to severe LV dysfunction $(2.3 \%)$ with a long-term mortality rate of $20.9 \%$. CHV has acceptable thromboembolic levels with low cost and has been the valve of choice in a large number of centers dealing with RHD in the lower socioeconomic strata of society [35].

\section{Replacement of VKA therapy by antiplatelet agents}

Current evidence does not support the replacement of VKA therapy with APA for either mechanical aortic or mitral valve prostheses. Earlier studies in the pediatric population have demonstrated an unacceptable risk of thromboembolism when treating with APA alone [36, 37]. In Clopidogrel and aspirin in the prevention of thromboembolic complications after mechanical aortic valve replacement (CAPTA) trial, patients with mechanical AVR were randomized to OAT versus APA. The trial was stopped after valve thrombosis events were reported in one patient [38]. Indirect evidence from this trial in AF provides strong support for the effectiveness of VKA over APA in patients with mechanical valves. ACCP demonstrates an increased risk of major hemorrhage for those targeted for a higher INR (INR 3.0-9.0). Moreover, there exists no evidence which state that high INR for mechanical AVR results in fewer thrombotic events. Furthermore, no evidence demonstrates that higher INR targets have an additional benefit over harm in patients with risk factors [30].

\section{Indian evidence}

In a prospective observational study, Dhanya PS et al. evaluated the pattern of OAT use, achievement of target INR, mean dose of warfarin and acenocoumarol, and the anticoagulationrelated adverse events (AEs). The therapeutic range (TR) of INR was defined as 2.0-3.0 in the AVR patients and 2.5-3.5 in the MVR and DVR patients. The study included $70.9 \%$ of MVR patients. Warfarin was used in $58.2 \%$ patients (mean INR, $2.52 \pm 0.81$; mean dose of $3.68 \pm 1.71 \mathrm{mg}$ ) with time in TR $44.8 \%$. Acenocoumarol was used in $44.8 \%$ patients (mean INR, $2.76 \pm 0.51$; mean dose of $3.13 \pm 1.23 \mathrm{mg}$ ) with time in TR 44.2\%. Thromboembolic complications were reported in 
$3.6 \%$ patients; only when the mean INR $<1.6$. The authors conclude that target therapeutic range (TTR) can be broadened to 1.6-4.0; however, they identified the need of RCTs to fix a lower TR in Indian population [39].

John $\mathrm{S}$ et al. have reported their 25 years of experience with Starr Edward's ball valves in patients with combined MVR and AVR. The target prothrombin time (PT) was maintained at 1.5 times the control value with a low-intensity anticoagulant. A thromboembolic event of 1.05/100 pt-yr and anticoagulantrelated bleeding of 0.12/100 pt-yr was reported [40].

A retrospective study evaluated the complications and outcomes in 88 patients after replacement with Starr-Edwards, St. Jude, and Medtronic-Hall valves in mitral, aortic, or both positions. The study reported that St. Jude valve in mitral position had the highest thromboembolic risk of $12.5 / 100 \mathrm{pt}-\mathrm{yr}$ among the single valve replacement group, and all prostheses had a high thrombotic risk in the DVR group: St. Jude 22.2, Medtronic-Hall 12.5, and Starr-Edwards 8.6 per 100 pt-yr [41]. Panda BR et al. followed up 382 patients with mechanical valves in both positions for 15 years. The authors conclude that protection against thromboembolism and anticoagulationrelated hemorrhage can be boosted with a strict adherence to optimal anticoagulation level, and it also helps to provide the patient with a good quality of life (QoL) [42].

Moreover, an article published in Journal of the Association of Physicians of India (JAPI) concluded that although warfarin is a choice of anticoagulant in the United States (US), acenocoumarol is being widely used in Indian patients with valve replacement. Especially in North India, acenocoumarol is widely used in place of warfarin [43].

\section{Evidence from other Asian countries}

A randomized trial compared the outcomes of moderate (INR, 2.65) versus high (INR, 9) intensity anticoagulation in 258 mechanical prosthetic heart valve patients. Study reported more bleeding episodes in high-intensity group (12.1/100 patient-years) compared to moderate-intensity group (6.2/100 patient-years) $(p<0.002)$. Authors conclude that both groups have equivalent protection, but the moderate anticoagulation group had a significantly lower bleeding risk [44]. Akhtar RP et al. prospectively evaluated 507 prosthetic valve patients on warfarin anticoagulation in Pakistan. A total of $1.13 \%$ per patient year of thromboembolism and $2.04 \%$ per patient year of bleeding events were observed with mean INR $2.6 \pm 0.59$. The study included $52.9 \%, 18.9 \%$, and $15.0 \%$ patients with MVR, DVR, and AVR respectively [45].

A prospective study from China included $45 \%, 27 \%$, and $28 \%$ of patients with MVR, AVR, and DVR. The target INR range was 1.4 to 1.9 for patients with AVR and 1.5-2.0 for those with MVR and DVR. The mean INR reported was 1.68 \pm 0.38 . The study reported a linearized rate of $5.83 \%$ per pt-yr for bleeding and $0.26 \%$ per pt-yr for thromboembolic events after CarboMedics mechanical valve implantation [46]. In a prospective study by Sun X et al., a total of 230, 318, 189, and 5 patients were enrolled with AVR, MVR, DVR, and tricuspid valve replacement (TVR) respectively. The target INR of 2.0 2.5 was achieved with OAT. There were $1.59 \%$ per pt-yr of hemorrhagic events, $0.34 \%$ per pt-yr of thromboembolic, and $0.19 \%$ per pt-yr of thrombosis after prosthesis following St Jude Medical valve implantation for Chinese patients [47]. In a study by Matsuyama K et al., a total of 214 patients were followed retrospectively after mechanical MVR (mean duration of follow-up, 4.8 years; total duration of follow-up, $1027 \mathrm{pt}$-yrs) on OAT with or without aspirin, ticlopidine, or dipyridamole. The target INR was between 1.5 and 2.5. Thromboembolism was observed in $0.8 \%$ per pt-yr and major bleeding in $0.5 \%$ per pt-yr) [48].

A study conducted in Japan concluded that the optimal INR of 2.5-3.5 for patients on OAT recommended by the American Heart Association (AHA) might be too high in Japanese patients, and INR $<2.5$ may be safe to prevent hemorrhagic complications [49].

The target INR ranges recommended by American College of Cardiology (ACC)/AHA and ACCP for mechanical valve replacement are comparable. The current ACCP recommendations relate mostly to bileaflet and other new generation valves. ACC/AHA recommends a target INR of 3.0 for patients with older generation mechanical aortic valves (cage and ball), while ACCP suggests the target INR 2.0-3.0. They also noted high rate of major hemorrhage with an INR that is even somewhat lower, 3.0-4.5. However, the problem is self-limited, because few such valves are being inserted [50]. Both the guidelines [30,51] recommend aspirin in addition to VKA in mechanical valve patients who do not have contraindications to aspirin (i.e., bleeding or aspirin intolerance); however, the dosage slightly varies (ACC/AHA: 75-100 mg/day, ACCP: 50-100 mg/day). Furthermore, ACC/AHA emphasizes the use of aspirin in patients with a history of embolus while on VKA therapy with a therapeutic INR, those with the known vascular disease, and those who are known to be particularly hypercoagulable. For patients with mechanical aortic or mitral valves, ACCP recommends VKA over antiplatelet agents. The target INR for mechanical valve patients according to above guidelines is summarized in Table 2.

\section{Indian recommendations}

- VKA therapy with a target INR range of 2.0 to 3.0 is recommended in patients with mechanical aortic valve replacement without risk factors (grade A, EL 2).

- VKA therapy with a target INR range of 2.5 to 3.5 is recommended in patients with mechanical aortic valve replacement with risk factors- $\mathrm{AF}$, previous thromboembolism, LV dysfunction, or hypercoagulable conditions (grade A, EL 2). 
associated with aspirin plus warfarin, death and embolic events were relatively rare in the first 3 months after bioprosthetic AVR in both the groups [60].

Agarwal S et al. compared outcomes of mechanical versus bioprosthetic MVR in patients between 40 and 60 years of age. Bioprosthetic valve patients received dicoumarol only for 3 months while aspirin was continued indefinitely and the target INR was set as $2.5-3.5$. The rate of valve thrombosis and bleeding was more with mechanical valve than in patients with bioprosthetic valves. The authors concluded implantation of a bioprosthetic valve in patients with this age group [61]. Abraham S et al. evaluated the outcomes of Carpentier Edwards (Porcine) bioprosthesis in 18 MVR, 14 AVR, 1 TVR, and 12 DVR patients. All patients were on OAT and APA for 3 months. The rate of thromboembolism and infective endocarditis (IE) was $2.4 \%$. No incidence of anticoagulantrelated hemorrhage was observed during the follow-up [62]. Talwar S et al. also evaluated the outcomes in Carpentier Edwards (Porcine) bioprosthesis. The target INR was 2.0-3.0. All patients received coumadin for first 6 weeks postoperatively, and indefinite aspirin $150 \mathrm{mg} /$ day. There were seven episodes of thromboembolism ( $0.64 \%$ events/pt-yr), and one episode of hemorrhage [63]. Mandiye SS et al. studied short-term outcomes after MVR, AVR, and DVR with mechanical versus bioprosthetic valves. All patients postoperatively received dicoumarol, and aspirin $150 \mathrm{mg} /$ day. The target INR was 2.0-3.0 in MVR or AVR, and 2.5-3.5 in DVR. The study concluded that mechanical valves have significantly higher complication rate than bioprosthesis valves in Indian patients [64].

Recommendations from the ACCP and ACC/AHA contradict each other about the antithrombotic therapy in the bioprosthetic valve in the postoperative period. The ACCP currently recommends VKA therapy with target INR 2.5 for first 3 months after bioprosthetic MVR. In patients with no other indication for anticoagulation (i.e., atrial dysrhythmias, history of thromboembolism, etc.), ACCP recommends aspirin (50 to $100 \mathrm{mg} /$ day) over VKA therapy for the first 3 months after surgery for AVR with a bioprosthetic device. Moreover, in all patients with bioprosthesis, ACCP recommends continuation of aspirin therapy without VKA therapy beyond the initial 3month postoperative period if the patient remains without a definitive indication for anticoagulation [30]. The ACC/AHA guidelines do not have strong recommendations supporting the use of VKA therapy in patients with bioprosthetic valves [51]. However, they suggest VKA therapy is reasonable for the first 3 months after bioprosthetic MVR and in patients with bioprosthetic AVR VKA therapy might be effective for the first 3 months after valve replacement [51]. Aspirin therapy at a dose of 75 to $100 \mathrm{mg} /$ day is recommended in all bioprosthetic valve patients regardless of whether anticoagulation is employed [51]. Moreover, there are no specific recommendations offered with regard to duration of aspirin therapy in this population. The choice of the antithrombotic regimen in the setting of bioprosthetic valve replacement is largely left to the individual clinicians in ACC/AHA guidelines. The duration and intensity of aspirin treatment are also left to the individual clinician's discretion. Several factors including institutional-specific outcomes, the likelihood of patient adherence to medication regimen, prior personal experience, regional convention, and personal preference may influence a clinician's decision. The target INR for mechanical valve patients according to above guidelines is summarized in Table 2.

\section{Indian recommendations}

- VKA therapy is recommended in the bioprosthetic aortic valve and mitral valve replacement, with a target INR range of 2.0 to 3.0 over no VKA therapy for 3 months (grade B, EL 3).

- In patients with dual bioprosthetic valve replacement (aortic, mitral), VKA therapy is recommended for 3 months with a target INR range of 2.0 to 3.0 (grade B, EL 3).

- After bioprosthetic aortic or mitral valve replacement, long-term aspirin at a dose of 75 to $150 \mathrm{mg} /$ day is recommended after withdrawal of VKA therapy (grade A, EL 2).

\section{Anticoagulants in transcatheter aortic valve implantation}

Transcatheter aortic valve implantation (TAVI) has become established as a treatment option for patients with symptomatic aortic stenosis (AS). In comparison with surgical AVR, TAVI offers superior quality of life with similar mortality rates among patients at very high surgical risk [65]. However, thromboembolic complications from TAVI are significant, and stroke, in particular, is a concern [66]. While the immediate procedural risk relates to valvular debris embolization, $50 \%$ of strokes develop after the first day and may relate to non-procedural events [65-67]. The incidence of cerebrovascular events after TAVI remains high for at least 60 days. This implies that the prothrombotic environment of the bioprosthesis itself may be implicated in distal thromboembolism, and therefore antiplatelet or antithrombotic treatment should play an important role in stroke prevention [68].

Various combinations of antithrombotic regimens (singleAPA, dual-APA, or VKAs) have been used, but evidencebased guidance remains lacking. The benefit of TAVI with the core valve revolving system was evaluated in a prospective trial. All patients received aspirin $100 \mathrm{mg}$ before the procedure, which is continued lifelong. A loading dose of clopidogrel $300 \mathrm{mg}$ was administered the day before the procedure followed by $75 \mathrm{mg}$ daily for 3 to 6 months. The cumulative incidences of mortality were $5.4 \%$ at 30 days, $12.2 \%$ at 6 months, and $15.0 \%$ at 1 year [69]. In a randomized multicenter PARTNER trial, TAVI was compared to surgical AVR 
in high-risk patients. All the patients received heparin during the procedure and dual APAs (aspirin and clopidogrel) for 6 months afterwards. The rates major stroke $(p=0.07)$ and major vascular complications were more frequent in TAVI patients at 1 year $(p<0.001)$ [65]. In a randomized trial, the clinical outcomes of standard therapy (including balloon aortic valvuloplasty) versus TAVI (balloon-expandable bovine pericardial valve) in patients with severe AS, not suitable for surgery, were compared. Adjunctive pharmacologic therapy included heparin during the procedure and dual APAs (aspirin and clopidogrel) for 6 months after the procedure. Despite the higher incidence of major strokes and major vascular events at 1 year with TAVI, it significantly reduced the rates of death from any cause, the composite endpoint of death from any cause or repeat hospitalization, and cardiac symptoms, compared with standard therapy [66].

In a prospective study, cerebral embolization during TAVI was evaluated at 3 months after the surgery. All patients received aspirin $(100 \mathrm{mg} /$ day $)$, clopidogrel $(75 \mathrm{mg} /$ day after a loading dose of $300 \mathrm{mg} /$ day) before the procedure; clopidogrel was discontinued after 6 months, while aspirin continued indefinitely. Procedural micro-embolization signals were detected in all patients. No embolization was found at 3 months follow-up [67]. The risk of cerebrovascular events at discharge, at 1 and 6 months, and at yearly was evaluated in a subgroup of patients enrolled in a randomized PARTNER trial. Clopidogrel loading dose was given $6 \mathrm{~h}$ before the procedure in $134 \mathrm{pa}-$ tients, whereas 34 patients were already on a steady dose of $75 \mathrm{mg}$ daily for $>1$ week. Clopidogrel was not given before TAVI to patients undergoing the transapical procedure and clopidogrel maintenance dose was discontinued for 5 days before TAVI in eight patients. Ninety-three percent of patients were on aspirin before TAVI. At discharge, $89 \%, 59 \%$, and $33 \%$ patients were on aspirin, clopidogrel, and antithrombotic therapy (heparin or warfarin), respectively. Among patients who developed cerebrovascular events, $91 \%$ were on aspirin, $61 \%$ were on clopidogrel, and $35 \%$ were receiving antithrombotic therapy at the time of the event [68]. It is to be noted that none of these trials had measured bleeding or thromboembolic events as the primary objectives.

In a prospective cohort study, Poliacikova $\mathrm{P}$ et al. compared procedural and follow-up complications of TAVI patients based on the type of antithrombotic treatment used (single-APA vs. dual-APA vs. warfarin). A total of $34 \%, 53 \%$, and $13 \%$ patients were on dual-APA, single-APA, and warfarin, respectively. The combined endpoint of all-cause death, acute coronary events, stroke, or bleeding was significantly worse in the dual-APA group. The occurrence of major adverse cardiac and cerebrovascular events was statistically similar in all groups. The results suggest that dual-APA did not protect patients from stroke and may expose them to higher bleeding risk [70].

There are only two case reports on initial Indian experience of TAVI $[71,72]$. The recent American College of Cardiology
Foundation (ACCF)/American Association for Thoracic Surgery (AATS)/Society for Cardiovascular Angiography and Interventions (SCAI)/Society of Thoracic Surgeons (STS) expert consensus document on TAVI did not make much clarity on this difficult area [73]. Rodés-Cabau et al. have summarized the recommendations for antithrombotic therapy in TAVI [74]. The overall comparison of antithrombotic recommendations is presented in Table 3 .

\section{Indian recommendation}

- Antiplatelet agents either alone or in combination with anticoagulants are recommended after TAVI (antiplatelet agents long term) (grade A, EL 2).

\section{Bridging anticoagulants}

The perioperative management of patients receiving VKAs or APAs and requiring a surgical or invasive procedure poses a significant dilemma for practising clinicians. One should take into account of different factors including the type of procedure, risk factors, and type, location, and number of heart valve prosthesis during the management of patients with mechanical heart valves in whom interruption of anticoagulation therapy is needed for diagnostic or surgical procedures.

To minimize the delay in achieving therapeutic anticoagulation, a "bridging" anticoagulant is prescribed. The "bridge" is administered parenterally [short-acting anticoagulant as unfractionated heparin (UFH) or low molecular weight heparin (LMWH)], thereby providing an immediate anticoagulant effect. However, the use of LMWH or UFH as perioperative bridging may be an off-label use as their use is not approved by regulatory authorities or drug manufacturers in this clinical setting as a bridging agent. There is a relative paucity of well-designed clinical trials to enlighten best practices; however, disproportionately large numbers of methodologically weak observational studies are available.

A study by van Geest-Daalderop JH et al. have evaluated days of interruption for acenocoumarol in patients undergoing invasive procedures. They found interruption for 2 days had lower bleeding risks compared to 3 days [76]. In patients undergoing major surgery or procedures, interruption of VKAs, in general, is required to minimize perioperative bleeding [77]. Tinker JH et al. have concluded that patients with cardiac valve prostheses and continuing anticoagulants have minimal risk when they stop the anticoagulant regimen for 13 days preoperatively and 1-7 days postoperatively [78]. A similar method was followed in a study with a small group of patients [79]. Perioperative bleeding and thromboembolic events in patients on anticoagulation with mechanical valves were evaluated in a prospective study. There were 72 complications observed in 603 interventions that resulted in an 
Table 3 Antithrombotic recommendations in patients undergoing TAVI

\begin{tabular}{|c|c|c|c|}
\hline Recommendations & Pre-procedural & Procedural & Post-procedural (first 30 days) \\
\hline $\begin{array}{l}\text { PARTNER } \\
\text { Trial }[65,66]\end{array}$ & $\begin{array}{l}\text { Aspirin } 80 \mathrm{mg}, \\
\quad \text { Clopidogrel } 300 \mathrm{mg}\end{array}$ & $\begin{array}{l}\text { UFH, Goal ACT: } 250 \mathrm{~s} \text {, Reversal with } \\
\text { protamine optional, Bivalirudin—not } \\
\text { allowed? }\end{array}$ & $\begin{array}{l}\text { Aspirin } 81 \mathrm{mg} \text { /day indefinitely }+ \text { Clopidogrel } 75 \mathrm{mg} / \text { day } \times \\
90 \text { days, If warfarin indicated }(\mathrm{AF}) \text {, then no clopidogrel }\end{array}$ \\
\hline $\begin{array}{l}\text { ACC/STS } \\
\quad \text { Recommendations [73] }\end{array}$ & - & $\begin{array}{l}\text { UFH, Goal ACT: } 300 \mathrm{~s} \text {, Reversal } \\
\text { with protamine recommended, } \\
\text { Bivalirudin — not mentioned }\end{array}$ & $\begin{array}{l}\text { Aspirin } 81 \mathrm{mg} / \text { day indefinitely }+ \text { Clopidogrel } 75 \mathrm{mg} / \text { day } \\
\text { 3-6 months, If OAT indicated (AF), avoid triple therapy } \\
\text { unless definite indication exists }\end{array}$ \\
\hline $\begin{array}{l}\text { CCS } \\
\quad \text { Statement [75] }\end{array}$ & - & - & $\begin{array}{l}\text { Indefinite low-dose aspirin generally recommended }+ \\
\text { Thienopyridine } \times 1-3 \text { months, If warfarin indicated } \\
(\mathrm{AF}) \text {, then no clopidogrel }\end{array}$ \\
\hline $\begin{array}{l}\text { ACC VHD } \\
\quad \text { guidelines [51] }\end{array}$ & - & - & $\begin{array}{l}\text { Clopidogrel } 75 \mathrm{mg} \text { daily may be reasonable for the first } 6 \\
\text { months after TAVR in addition to life-long aspirin } 75 \\
\text { to } 100 \mathrm{mg} \text { daily }\end{array}$ \\
\hline $\begin{array}{l}\text { ACCP VHD } \\
\text { guidelines [30] }\end{array}$ & - & - & $\begin{array}{l}\text { Clopidogrel } 75 \mathrm{mg} \text { daily may be reasonable for the first } 3 \\
\text { months after TAVR in addition to life-long aspirin } 75 \\
\text { to } 100 \mathrm{mg} \text { daily }\end{array}$ \\
\hline
\end{tabular}

$A C C$ American College of Cardiology, ACCP American College of Chest Physicians, AF atrial fibrillation, CCS Canadian Cardiovascular Society, OAT oral anticoagulation therapy, STS Society of Thoracic Surgeons, TAVI transcatheter aortic valve implantation, TAVR transcatheter aortic valve replacement, $U F H$ unfractionated heparin, $V H D$ valvular heart disease

overall frequency of $11.9 \%(9.5 \%$, hemorrhage and $2.5 \%$, thromboembolism). Moreover, the level of anticoagulation was not associated with the occurrence of complications [80].

Moderate-intensity anticoagulant therapy (INR of 1.5 to 2.0 ) was reported to be safe and feasible for preventing thromboembolic complications in high-risk surgical patients who are receiving long-term OAT. The study included $18 \%$ patients with a mechanical valve [81]. However, VKA interruption may not be required in minor procedures like dental procedures [82, 83], minor dermatological procedures $[84,85]$, and cataract surgery [86]. A study has shown no significant difference in thromboembolic and major bleeding events between patients bridged with LMWH and those bridged with UFH [87]. The literature demonstrates that most studies assessing the use of LMWH as bridging anticoagulation have used therapeutic dose regimens [88]. Two studies have used low-dose LMWH (including patients with mitral valve prosthesis) [89,90], but it is not clear if this is sufficient as it can be argued that higher doses of LMWH are needed for the prevention of arterial thrombosis. The latter, however, is not established. To aid decision making on bridging interventions, ACC and ACCP divide patients into high and low risk as per thrombotic risk stratification (Table 4).

ACC and ACCP recommend uninterrupted VKA therapy with local hemostasis optimizing agents in procedures with minimal bleeding. These procedures include excision of basal and squamous cell skin cancers, actinic keratosis, and premalignant or cancerous skin nevi; dental cleaning, or simple treatment for dental caries (Table 5); surgery for cataracts or glaucoma. For tooth extractions and endodontic (root canal) procedures, ACCP recommends uninterrupted VKA with co-administration of an oral pro-hemostatic agent or stopping VKAs for 2 to 3 days (partial reversal). The patients should be informed of any minor bleeding (bleeding from gingival mucosa) and advised to continue any pro-hemostatic treatment given.
ACC recommends interrupting VKA for $2-4$ days without bridging in patients with low thrombotic risks, i.e., bileaflet AVR without any risk factors (Table 6). ACC and ACCP recommend interruption of VKA with bridging anticoagulation in patients with any mitral valve prosthesis, any caged-ball or tilting disc aortic valve prosthesis, bileaflet AVR with additional risk factors, patients with recent (within 6 months) stroke or TIA, patients with prior thromboembolism during temporary interruption of VKAs. When interruption of VKA therapy is required, ACC recommends stopping 2-4 days before while ACCP recommends not less than 5 days before (considering 36-42 $\mathrm{h}$ as half-life for a complete reversal of anticoagulant action) the procedure. Both recommend restarting approximately 12 to $24 \mathrm{~h}$ after surgery (evening of or next morning) (Table 6).

\section{Indian recommendation}

- It is not recommended to interrupt VKA therapy during minor dental procedures (cleaning), dermatological procedures, and cataract surgery due to minimal bleeding (grade A, EL 2)

- In patients with low thrombotic risk (bileaflet AVR without atrial fibrillation and no other risk factors for stroke), it is recommended to interrupt VKA therapy without bridging (grade B, EL 3)

- Bridging anticoagulation is recommended in patients with high risk of thromboembolism during temporary interruption of VKAs (grade B, EL 3)

- When interruption of VKA therapy is required, it is recommended to stop for 2-4 days before the procedure. After stopping VKA therapy, INR should be checked after 2 days and maintained $<2$. The VKA therapy should be restarted 12-24 h after surgery (grade A, EL 2) 
Table 4 Thrombotic risk stratification as per ACC, ACCP, CSI and current guideline

\begin{tabular}{|c|c|c|}
\hline Organizations & $\begin{array}{l}\text { Category ( } \% \text { annual risk } \\
\text { of thromboembolism) }\end{array}$ & Patient characteristics \\
\hline \multirow[t]{2}{*}{$\begin{array}{l}\text { ACCP [88] } \\
\text { and CSI [10] }\end{array}$} & High risk $(>10 \%)$ & $\begin{array}{l}\text { - Any mitral valve prosthesis } \\
\text { - Any caged-ball or tilting disc aortic valve prosthesis } \\
\text { - Recent (within } 6 \text { months) stroke/transient ischemic attack } \\
\text { - Prior thromboembolism in temporary VKAs interruption } \\
\text { - Types of surgery associated with an increased risk of stroke or other } \\
\text { thromboembolism (e.g., cardiac valve replacement) }\end{array}$ \\
\hline & Low risk $(<10 \%)$ & - Bileaflet aortic valve prosthesis without $\mathrm{AF}$ and no other risk factors for stroke \\
\hline \multirow[t]{2}{*}{ ACC $[51]$} & High risk $(>10 \%)$ & $\begin{array}{l}\text { - All patients with mechanical MVR or TVR, patients with an AVR and any risk } \\
\text { factors (AF, previous thromboembolism, hypercoagulable condition, } \\
\text { older-generation mechanical valves, } \mathrm{LV} \text { systolic dysfunction }(\mathrm{LVEF}<30 \%) /> \\
1 \text { mechanical valve) for thromboembolism }\end{array}$ \\
\hline & Low risk $(<5 \%)$ & - Bileaflet mechanical aortic valve and no other risk factors \\
\hline \multirow[t]{2}{*}{$\begin{array}{l}\text { Current } \\
\text { guideline }\end{array}$} & High risk $(>10 \%)$ & $\begin{array}{l}\text { - Going for any other major surgery irrespective of valve type and position } \\
\text { - Any mitral valve prosthesis } \\
\text { - Recent (within } 6 \text { months) stroke/transient ischemic attack } \\
\text { - Prior thromboembolism in temporary VKAs interruption } \\
\text { - Bileaflet mechanical aortic valve with risk factors } \\
\text { - AF }\end{array}$ \\
\hline & Low risk $(<10 \%)$ & - Bileaflet mechanical aortic valve and no other risk factors \\
\hline
\end{tabular}

$A C C$ American College of Cardiology, ACCP American College of Chest Physicians, $A F$ atrial fibrillation, $A V R$ aortic valve replacement, $C H F$ congestive heart failure, CSI Cardiological Society of India, $L V E F$ left ventricular ejection fraction, $M V R$ mitral valve replacement, TVR tricuspid valve replacement, $V K A$ vitamin $\mathrm{K}$ antagonist

- The reversal of VKA therapy during emergency surgeries can be achieved by administration of FFP. FFP requirement depends on the PT/INR value, liver function tests, and body weight of the patient (grade A, EL 2)

- Interruption of VKA therapy with bridging anticoagulants is recommended for not more than 2 days in case of elective major surgeries (grade A, EL 3)

\section{Cardiac catheterization in patients with prosthetic valves}

The Bridge or Continue Coumadin for Device Surgery Randomized Controlled Trial (BRUISE CONTROL) randomly

Table 5 Surgeries with high bleeding risks identified by ACCP [88]

- Urologic surgery and procedures consisting of transurethral prostate resection, bladder resection, or tumor ablation; nephrectomy; or kidney biopsy

- Pacemaker or implantable cardioverter-defibrillator device implantation

- Bowel resection, colonic polyp resection, typically of large (i.e., $>1-2 \mathrm{~cm}$ long) sessile polyps

- Surgery and procedures in highly vascular organs, such as the kidney, liver, and spleen

- Major surgeries such as cancer surgery, joint arthroplasty, reconstructive plastic surgery which could cause extensive tissue injury

- Cardiac, intracranial, or spinal surgery

ACCP American College of Chest Physicians assigned patients on warfarin undergoing implantation of a pacemaker or implantable cardioverter-defibrillator (ICD) to the continuation of warfarin or heparin bridging. The strategy of continued warfarin treatment compared to bridging with heparin markedly reduced the incidence of clinically significant device-pocket hematoma [91]. The COMPARE trial randomly assigned patients with $\mathrm{AF}$ undergoing catheter ablation to continued warfarin or discontinuation of warfarin with bridging. In this trial, patients randomized to continue warfarin had a lower risk of stroke and less bleeding [92]. In a randomized trial, patients on OAT referred for pacemaker or ICD were randomized to warfarin continuation versus interruption. There was a trend toward reduced complications in patients randomized to warfarin continuation, though the results were not statistically significant [93]. In another randomized trial, patients were assigned to either uninterrupted OAT or bridging with heparin. The study concluded that maintaining VKA was associated with significant reduction of in-hospital stay compared with bridging to heparin infusion [94].

A recent prospective observational study compared acenocoumarol continuation versus discontinuation in 489 patients undergoing trans-radial diagnostic catheterization. The study concluded that continuation of chronic OAT appears safe during trans-radial diagnostic catheterization [95]. Similarly, in a prospective study, Sanmartín M et al. concluded that the trans-radial approach appears to be a safe option and could be the technique of choice for patients continuing longterm acenocoumarol therapy as it eludes the problems and complications associated with the withdrawal of OAT [96]. 
Table 6 Recommendations on time frame for bridging anticoagulation

\begin{tabular}{|c|c|c|c|}
\hline & $\mathrm{ACCP}[88]$ & $\mathrm{ACC}[51]$ & Current guideline \\
\hline Interruption of VKA & $\begin{array}{l}\text { Stop at least before } 5 \\
\text { days and restart } 12-24 \\
\text { h after surgery }\end{array}$ & $\begin{array}{l}\text { Stop before } 2-4 \text { days } \\
\text { restart } 12-24 \mathrm{~h} \\
\text { after surgery }\end{array}$ & $\begin{array}{l}\text { Stop before } 2-4 \text { days, after stopping VKA therapy, } \\
\text { INR should be checked after } 2 \text { days and should } \\
\text { be maintained }<2 \text {. Restart } 12-24 \text { h after surgery }\end{array}$ \\
\hline \multicolumn{4}{|l|}{ Bridging with UFH or LMWW } \\
\hline Stop VKA & Before at least 5 days & Before $2-4$ days & \multirow{4}{*}{$\begin{array}{l}\text { INR should be checked after } 2 \text { days of stopping } \\
\text { VKA therapy and next decision on therapy } \\
\text { should be taken depending on INR value }\end{array}$} \\
\hline $\begin{array}{l}\text { Starting UFH or LMWH, } \\
\text { when INR }<2\end{array}$ & Not mentioned & $\begin{array}{l}48 \mathrm{~h} \text { before planned } \\
\text { surgery }\end{array}$ & \\
\hline Stopping UFH or LMWH & $\begin{array}{l}\text { 4-6 } \mathrm{h} \text { for UFH, } 24 \mathrm{~h} \\
\text { for LMWH, before } \\
\text { the procedure }\end{array}$ & $\begin{array}{l}\text { 4-6 } \mathrm{h} \text { for UFH, } 12 \mathrm{~h} \\
\text { for LMWH, before } \\
\text { the procedure }\end{array}$ & \\
\hline $\begin{array}{l}\text { Resuming UFH or LMWH, } \\
\text { when adequate hemostasis achieved }\end{array}$ & $48-72 \mathrm{~h}$ & $48-72 \mathrm{~h}$ & \\
\hline
\end{tabular}

ACC American College of Cardiology, ACCP American College of Chest Physicians, INR international normalized ratio, $L M W H$ low molecular weight heparin, $U F H$ unfractionated heparin, $V K A$ vitamin $\mathrm{K}$ antagonist.

The European Heart Rhythm Association (EHRA) position document on antithrombotic management in patients undergoing electrophysiological procedures recommends uninterrupted VKA in patients undergoing ablation procedures like pulmonary vein isolation (PVI) and in patients requiring implantation of cardiac implantable electronic devices; unless they are at very low risk for a thromboembolic event. EHRA recommends interruption of VKA without bridging with heparin in such patients. Furthermore, EHRA recommends not using the formerly commonly practised "bridging therapy" with UFH or LMWH since it significantly increases bleeding complications in this category of patients [97]. ACC recommends only slight modification in VKA dosing for procedures with a low bleeding risk, such as coronary angiography from the radial approach. With interventional procedures at higher risk, stopping VKA anticoagulation and using bridging therapy as is done for other surgical procedures have been recommended [51]. ACC and ACCP recommend considering an acceptable level of anticoagulation in a specific cardiac catheterization procedure.

\section{Indian recommendation}

- Patients with low bleeding risk and undergoing coronary angiography with the radial approach may not require modification in VKA; however, in patients at high risk, bridging therapy is recommended (grade A, EL 1)

- VKA therapy may be reduced or withheld and bridging is considered for patients with the femoral approach in the electrophysiological procedure (grade A, EL 2)

- In patients who are at low risk of thromboembolic events, undergoing PVI, VKA dose should be adjusted to maintain INR $<2$ and regular dose to be commenced after implantation (grade A, EL 2)

- In patients who are at very low risk of thromboembolic events undergoing cardiac implantable electronic devices, change in VKA therapy is not required; however, the dose should be titrated to achieve target INR $<2$ (grade A, EL 2)

\section{Initiation, monitoring, and factors affecting anticoagulation}

\section{INR testing}

Many factors affect the level of VKAs and thereby resultant INR. The subtherapeutic target INR increases the risk of thromboembolic events, on the other side, above the therapeutic INR presents the patient to the risk of bleeding. INR monitoring helps in avoiding over coagulation and also assist in deciding the appropriate dosage regimen, Moreover, dangerous situations can be detected well in time with routine monitoring, which allows dose adjustment, as well as to take actions to prevent recurrence of such situations [98].

The most common test used to monitor anticoagulation therapy is the PT test. The PT is expressed as INR. The TTR is a good overall measure of the quality of antithrombotic treatment with VKAs in patients with VHD $[99,100]$. It is recommended that the INR measurement should be performed in the National Accreditation Board for Testing and Calibration Laboratories (NABL) accredited laboratory. The laboratory should follow the clinical and laboratory standards institute guidelines for coagulation testing [101]. As per the guideline, the sample should be transported in a shortest possible time at an ambient temperature $\left(15-22{ }^{\circ} \mathrm{C}\right)$ and the sample testing should be accomplished within $4 \mathrm{~h}$ of collection. As heparin has the potential to neutralize platelet releasates, testing for UFH monitoring should preferably be processed within $1 \mathrm{~h}$. Extremes of temperature (i.e., both refrigerated and high) should be avoided. Transport delay might affect labile clotting factors such as FV and FVIII and lead to prolonged clotting times and in vitro loss 
of factor activity. In such cases, plasma should be separated and frozen and then transported [102]. With consideration of $4 \mathrm{~h}$ of sample travel time, a reliable INR facility should be available to the patient within $4 \mathrm{~h}$ travel time.

\section{Point-of-care INR testing}

The gold standard for monitoring INR is the lab testing of blood obtained by venipuncture, in hospital. The point-ofcare (POC) INR systems (coagulometer) can be an alternative to older laboratory testing of INR. POC monitors measure a thromboplastin-mediated clotting time, by an electrochemical mechanism, which is converted to plasma PT equivalent by a microprocessor and expressed as either the PT or the INR. POC testing involves putting a single drop of blood from a finger stick, onto a test strip. It is aimed at convenience for the patient, faster test results to a healthcare provider, faster decision making, improved clinical outcome, and reduced healthcare resources. Lucas F et al. validated a novel wholeblood capillary technique for measuring the PT for the first time, and subsequently, this technique became available for professional use in doctor's offices and hospitals [103]. A number of instruments for home anticoagulant monitoring have been developed later. Usage of the initial meters was largely unreliable due to considerable variations and limited quality checks and they had relatively poor precision and did not use whole blood calibrators. However, the POC devices differ in the method of endpoint detection and use microfluidic technology. McBane RD et al. compared two commercially available POC devices, Coaguchek and ProTime 3 in determining the INR and found that correlation with plasma was greater for the Coaguchek $\left(r^{2}=0.90\right)$ compared with the ProTime 3 device [104]. Furthermore, the INR differed from the laboratory values with an over-estimation on the lower end of INR values. With the advent of newer technology for measurement and quality control procedures, the reliability of PT/INR meters have vastly improved. The cost of POC meters ranges from 5000 to 10,000 rupees with the cost of the strip ranging from 50 to 100 rupees. This is higher than the 30-40 rupees that the laboratory testing costs [105]. However, these devices are economic as they reduce the cost of visiting the healthcare facility. This is of great importance in India, as most of INR facilities are available far in the urban or semi-urban area. These POC devices have shown to be costeffective for patients on long-term anticoagulants [106, 107]. Studies have found a statistically significant advantage of selfmanagement methods in achieving the good INR control in patients with mechanical valves $[108,109]$. By comparing the outcomes of self-monitoring or self-management of OAT with standard monitoring in 8950 patients, a recent Cochrane database systematic review (28 RCTs) reports that participants who self-monitor or self-manage can improve the quality of their OAT with reduction of thromboembolic events [110].
Sharma P et al. in their systematic review (26 RCTs, 8763 patients) detected the clinical and cost-effectiveness of POC tests (CoaguChek system, INRatio2 PT/INR monitor and ProTime Microcoagulation system) for the self-monitoring of the coagulation status of people receiving long-term VKA therapy. The study report that self-monitoring, and in particular self-management with POC device, of anticoagulation status appeared cost-effective when pooled estimates of clinical effectiveness were applied [111]. A study by Lakshmy R et al. has shown the reliability and accuracy of Coaguchek XS INR kits in Indian patients [105].

ACCP and ACC/AHA recommend the practice of selfmanagement of patients over outdoor INR monitoring for VKA anticoagulation, in patients who are motivated and can demonstrate competency in self-management strategies [112, 113].

\section{Indian recommendation}

- The practice of patient self-management (PSM) of anticoagulation with patient self-monitoring is recommended (grade B, EL 1)

- Use of POC devices can be alternated with the conventional laboratory testing to reduce hospital visits and the cost of the treatment (grade B, EL 1)

\section{Loading dose, dose adjustments, and frequency of INR monitoring}

There is wide variation in patient response to VKA dose. In view of this and narrow therapeutic index, VKA dose should be optimized for initiation of therapy. Still, there is a considerable uncertainty about loading dose of VKAs. Moreover, there are no randomized data that address the optimal time to start anticoagulation therapy; however, all major guidelines recommend that VKA therapy should be started in the first 24-48 $\mathrm{h}$ after the surgical procedure.

The $2 \mathrm{mg}$ initial dosing of acenocoumarol has been investigated by Amian A et al. and found that it is as effective as the $4 \mathrm{mg}$ dose in reducing thromboembolic events and number of hemorrhage episodes [114]. Harrison L et al. report less excess anticoagulation with a $5 \mathrm{mg}$ loading dose of warfarin than $10 \mathrm{mg}$ loading dose; the smaller dose also avoided the development of a potential hypercoagulable state caused by precipitous decreases in levels of protein $\mathrm{C}$ during the first $36 \mathrm{~h}$ of warfarin therapy [115]. Crowther MA et al. have also demonstrated that $10 \mathrm{mg}$ loading dose of warfarin is not more effective than a $5 \mathrm{mg}$ loading dose in achieving an INR of 2.0 to 3.0 by day 4 or 5 of therapy [116]. Garcia D et al. found a decrease in warfarin dose requirements with age. The authors suggested to lower the empiric starting dose of $5 \mathrm{mg}$ daily and maintenance doses in the geriatric age group to avoid over-anticoagulation [117]. In a study by Van Geet-Daalderop JH et al., a model of standardized 
individualized dose regimen was evaluated. The model proposed an initial dose of 6-4-2 mg acenocoumarol, exceeding this mean daily dose to a small extent, was appropriate for patients younger than 70-75 years. An initial dose regimen of 4 2-1 mg was suggested in the elderly patients [118]. A metaanalysis by Mahtani KR et al. found considerable uncertainty between the use of a $5 \mathrm{mg}$ and a $10 \mathrm{mg}$ loading dose for the initiation of warfarin. There was some evidence of lower initiation doses or age-adjusted doses in elderly patients leading to fewer high INRs. However, there was insufficient evidence to warrant genotype-guided initiation [119]. Similar findings were also observed in another meta-analysis by Heneghan et al. [120]. Lastoria $\mathrm{S}$ et al. compared $5 \mathrm{mg}$ versus $10 \mathrm{mg}$ loading dose. The $10 \mathrm{mg}$ dosage regimen took less time to attain the TR and was associated with lower warfarin doses at discharge and better INR at first out-patients follow-up visit [121]. A two-step dosing nomogram has been prospectively evaluated by Kim YK et al. [99]. Moreover, Dhanya PS et al. have found no difference in TTR achieved by warfarin versus acenocoumarol [39].

When VKA therapy is initiated, the INR may begin to respond after 2 to 3 days because of the depletion of factor VII. Bridging anticoagulation by UFH or LMWH is recommended by ACC, ACCP, and Cardiological Society of India (CSI) during this initial period, and continued until the INR has been in the TTR for a minimum of $24 \mathrm{~h}[10,51,88]$. ACC and CSI recommend an initial dose of warfarin as $5 \mathrm{mg}$. However, individualization of warfarin dose depending on various factors (e.g., age, bleeding risk, medication compliance history) and anticipated drug interactions is also recommended. Lower initiation dosages might be required in older patients and persons with liver disease, poor nutritional status, or heart failure (HF). The ACCP guidelines suggest an alternative warfarin initiation dosage of $10 \mathrm{mg}$ daily for the first 2 days of therapy, in addition to a $5 \mathrm{mg}$ initial dose of warfarin, in healthy persons who can be treated as outpatients [122]. These recommendations were based on a meta-analysis of clinical trials which included venous thromboembolism (VTE) patients. They also compared early start (day 1 or 2 of heparin) versus late start (days 3-10 of heparin) for the VKA therapy together with UFH or LMWH therapy and recommended to start on day 1 or 2 of heparin.

As per the current ACCP recommendations, the first INR after baseline INR can be obtained after the patient has received two or three doses. Then, the frequency could be decreased to twice weekly until the INR is within the TR. Later the monitoring could be carried out every weekly, followed by every other week, and finally monthly. Moreover, the guidelines allow considering INR monitoring up to every 12 weeks in patients who are stable (defined as having at least 3 months of consistent results with no need to adjust VKA dosing). However, the frequency of monitoring should be increased if a patient's INR becomes subtherapeutic or supratherapeutic, and reduce when INR is stabilized [122]. For patients taking
VKAs with previously stable therapeutic INRs who present with a single out-of-range INR of $\leq 0.5$ below or above therapeutic INR, ACCP suggests continuing the current dose and testing the INR within 1 to 2 weeks without routinely administering bridging heparin.

\section{Indian recommendations}

- The initial recommended dosage of VKAs is warfarin $5 \mathrm{mg}$ and acenocoumarol $2 \mathrm{mg}$. However, individualization of VKA dose depending on age, bleeding risk, medication compliance history, and anticipated drug interactions is also recommended (grade A, EL 2).

- After baseline INR is determined, the next INR can be obtained after the patient has received two or three doses. Then after, the frequency of INR monitoring should be decided according to the value of INR (grade C, EL 4).

- INR checking should be as follows: first, at discharge; second, $48 \mathrm{~h}$; third, after 1 week of discharge; then after the frequency should be decided depending on INR value at first week (grade C, EL 4) (PT/INR reports $48 \mathrm{~h}$ after discharge as patient will be in the loading phase at the time of discharge. The fluctuation of INR for a week before the revisit after discharge not desirable).

- In patients with stable INR for 3 months with no dose adjustment, it is recommended to consider INR monitoring in every 12 weeks (grade A, EL 1). However, in the case of subtherapeutic or supratherapeutic INR, the frequency of monitoring should be increased until it stabilizes again. It should be monitored 1-2 monthly in high thrombotic risk patients (grade C, EL 4).

- In most asymptomatic fluctuations, the dose adjustment should be done by calculating the weekly or monthly dose of VKAs (grade C, EL 4).

- For patients taking VKAs with previously stable therapeutic INRs who present with a single out-of-range INR of $\leq$ 0.5 below or above therapeutic INR, it is recommended continuing the current dose and testing the INR within 1 to 2 weeks with no routinely administering bridging with heparin (grade A, EL 2).

- If INR falls below the target in high-risk patients, an increase in VKA dose or UFH may be considered (grade C, EL 4).

\section{Proposed algorithm/guide}

A stepwise guide for initiation and maintenance of VKA therapy is as follows:

1. Patient consent

2. Anticoagulation with heparin

3. Start VKAs 


\section{Initiation of VKAs}

- Establishment of baseline INR should be done in every case, which will guide further therapy.

- Initial dose: initial dose of warfarin is typically $5 \mathrm{mg} /$ day (acenocoumarol $2 \mathrm{mg}$ /day) in most patients. A reduced dose may be considered for patients $>70$ years of age, elevated baseline INR ( $>1.1$ ), hypo-albuminemia patients (e.g., malnourished, liver disorders, postoperative), impaired nutrition (weight $<45 \mathrm{~kg}$ ), $\mathrm{HF}$, taking medications that increase the sensitivity of VKAs, or previously documented increased sensitivity to VKAs.

- Whenever feasible, a single strength VKA tablet should be prescribed such that doses are multiples of one tablet strength. Patients should take their VKA once a day at the same time in the evening, and have their INR test performed in the morning. This limits diurnal variations and provides the physician with the same day window for dosage adjustment in the event of an unanticipated INR change.

2. Check INR on morning of day 2 and adjust the doseproposed nomogram

3. Stop heparin when INR is therapeutic

4. Regular INR checks

5. INR target and frequency of monitoring

- It is recommended that during the initiation phase, INR should be monitored every 2-4 days, until INR is in the TTR for two consecutive values. Once stabilized, INR should be monitored weekly. The interval can be gradually increased up to every 4 weeks if the INR remains stable and within TR. However, ACCP recommends monitoring of INR every 12 weeks in the stable patients. The monitoring frequency should be increased with any substitution, deletion, or addition of any drug as a concomitant therapy during OAT. The INR testing interval is presented in the flowchart as below (Fig. 1).

6. Maintenance therapy

- Dosage adjustment is not required for minor fluctuations of INR as long as the results remain within the patient's target range. Fluctuations of INR beyond the patient's target range should always prompt a direct communication with the patient to determine the cause. Consider causes such as a change in dosage of VKAs, patient compliance, medications including over the counter (OTC) drugs, dietary changes, unusual alcohol consumption, or intercurrent illness.

- The recent trend is to change the total VKA dose for example if the patient is taking $5 \mathrm{mg}$ /day, the weekly dose is $35 \mathrm{mg}$. If the dose must be decreased by $10 \%$, then the weekly dose should be $35 \mathrm{mg}-3.5 \mathrm{mg}=31.5 \mathrm{mg}$ and the daily dose becomes $31.5 \mathrm{mg} \div 7=4.5 \mathrm{mg}$.
Once a patient makes the transition from the initial dosing phase to the maintenance phase, more consideration to the multiple factors that may affect the INR should be given when interpreting low or high INR values. The ideal regimen should provide the same dose every day, but this is not always possible. VKAs come in many tablet strengths: 1, 2, 2.5, 3, 4, 5, 6, 7.5 , and $10 \mathrm{mg}$. Still, for some patients, a given tablet strength might not be enough while the next higher tablet strength may be too much. In this situation, one needs to give different doses on different days of the week. It is better if the doses are similar rather than greatly different. In most cases, alternating doses (e.g., $2.5 \mathrm{mg}$ alternating with $5 \mathrm{mg}$ ) or repeating doses (e.g., $2.5 \mathrm{mg}$, then $2.5 \mathrm{mg}$, then $5 \mathrm{mg}$ ) should be avoided, as they provide different total weekly doses of VKAs. The algorithm can be prepared as shown in Fig. 1 (and associated tables, Table 7 [123]: [warfarin nomogram] and Table 8 [124] [acenocoumarol nomogram for dosage adjustments]; adapted from that of the anticoagulation service at the University of Michigan and is consistent with recommendations from the ACCP guideline). The proposed algorithm for initiation and maintenance of VKA is described in Fig. 1. To help the physician in selecting the number of tablets of given strength of coumadin based on the availability of that tablet strength, a computer-based programme can be used (Fig. 2) [125, 126].

\section{Factors affecting VKA therapy}

\section{Pharmacogenetics}

Growing evidence indicates that up to $60 \%$ of the individual pharmacological response to warfarin might be due to genetic variables and affected by polymorphisms in the genes mainly vitamin $\mathrm{K}$ epoxide reductase complex subunit 1 (VKORC1), the target enzyme of warfarin, and cytochrome P450 2C9 (CYP2C9), the main enzyme involved in warfarin metabolism [127]. Although the genotypes of VKORC1 and CYP2C9 are clearly the most important genetic factors for warfarin response, genetic variations in other genes, for instance, CYP4F2 and $G G C X$ also show significant association with warfarin response [127]. Compared to CYP2C9 polymorphisms, VKORC1 polymorphisms have been reported to be more potent modifiers of warfarin response. Individuals with VKORC1 A haplotype ( $\mathrm{H} 1$ and H2) have been shown to require low warfarin dose compared to individuals with $V K O R C 1 B$ haplotype (H7, $\mathrm{H} 8$ and H9) due to decreased expression of messenger ribonucleic acid [128]. VKORC1-1639G > A (rs9923231) SNP is a good predictor to distinguish high and low dose requirement group over the VKORC1 haplotype [129-131].

Warfarin dose titration algorithms have been established which can provide a base for genetic testing in India [132, 133]. Many of the studies have earlier shown that around 75- 
Fig. 1 Proposed initiation and maintenance of VKA therapy

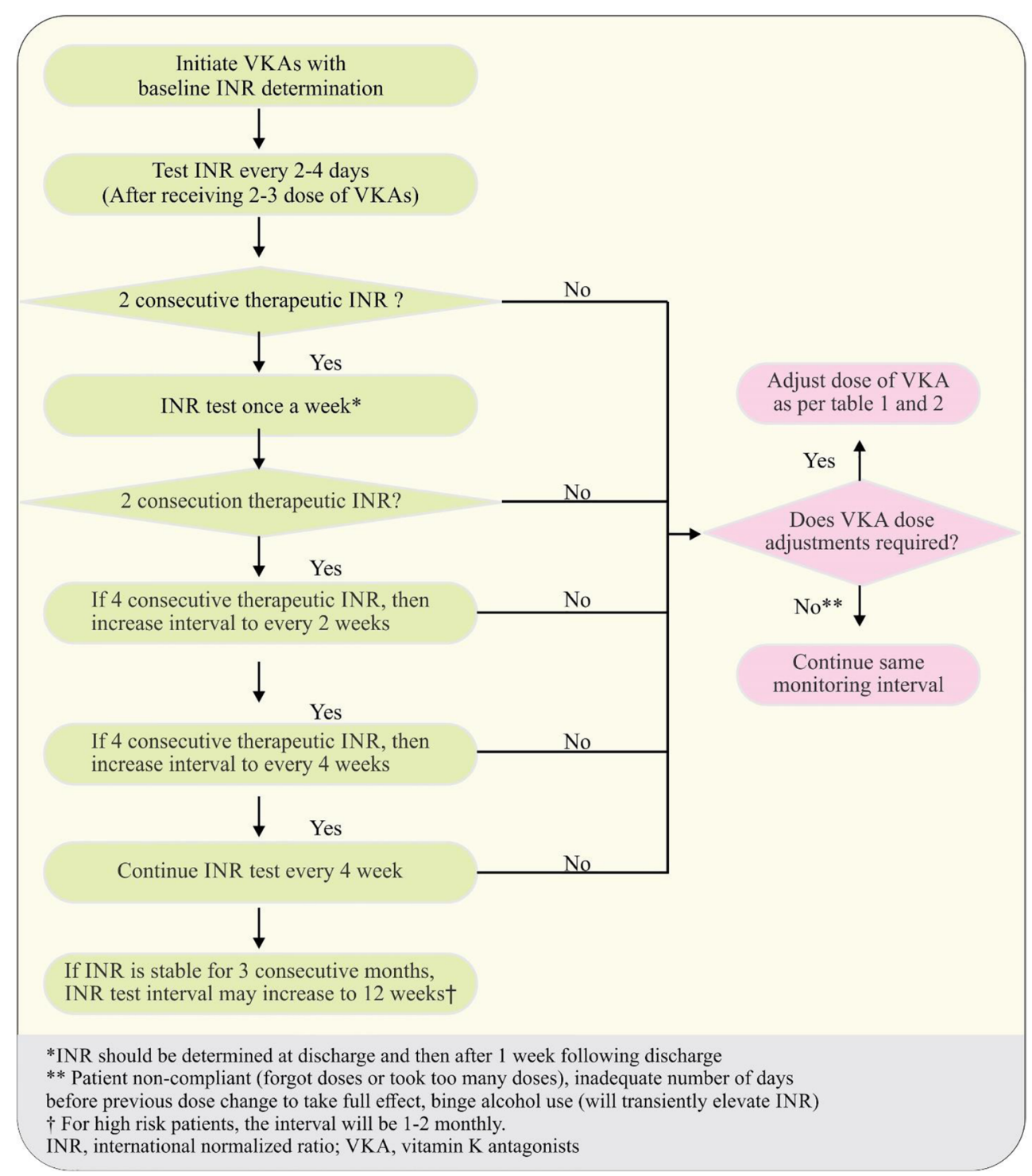

Table 7 Proposed nomogram for dose adjustment for patients on warfarin maintenance therapy; target INR 2.0-3.0 or 2.5-3.5, no significant bleeding [123]

INR Intervention (refer to flowchart in Fig. 1 for timing of next INR)

$\leq 1.5$

$1.5<\mathrm{INR}<$ therapeutic range

INR in therapeutic range

INR $>$ therapeutic range but $<5.0$

INR $5.0-9.0$

$>9.0$; no bleeding
- Give one-time top-up equal to $20 \%$ of weekly dose and increase weekly dose by $10-20 \%$

- No change in dose

- If two consecutive INRs are low, increase weekly dose by $10-20 \%$

- No change

- Lower weekly dose (10-20\%) or consider omitting one single dose

- Increase the frequency of INR monitoring and resume therapy at 10-20\% lower weekly dose when INR therapeutic

Note: If the INR is only minimally elevated (0.1-0.4 above upper limit of the therapeutic range), dose reduction may not be necessary

- Omit 1 to 2 doses then recheck INR

- Increase the frequency of INR monitoring and resume therapy at 10-20\% lower weekly dose when INR therapeutic

- If the patient is at high risk of serious bleeding, consider administering vitamin $\mathrm{K} 1$ to $2 \mathrm{mg}$ orally

- Discontinue warfarin temporarily, consider administering vitamin K 2-5 mg orally then recheck INR

- Increase the frequency of INR monitoring and resume therapy at $20 \%$ lower weekly dose when INR therapeutic

- Give additional vitamin $\mathrm{K}$ if INR is not substantially reduced by $24 \mathrm{~h}$. 
Table 8 Proposed nomogram for dosage adjustments for patients on acenocoumarol maintenance therapy; target INR $2.0-3.0$ or 2.5-3.5, no significant bleeding [124]

\begin{tabular}{ll}
\hline INR & Intervention (refer to flowchart in Fig. 1 for timing of next INR) \\
\hline$<1.3$ & Add $1 \mathrm{mg} /$ day to the current dose and repeat INR after 1 week \\
$1.4-2.0$ & Add $0.5 \mathrm{mg} /$ day to the current dose and repeat INR after 1 week \\
$2.1-3.5$ & Maintain current dose \\
$3.6-4.0$ & Decrease current dose by $0.5 \mathrm{mg} /$ day and repeat after 1 week \\
$>4.0$ & Stop the drug for 3 days and repeat INR till INR falls. If INR $<4.0$ on repeated \\
& measurement, then to follow as above.
\end{tabular}

INR international normalized ratio
$80 \%$ of the Indian population carries VKORC1-1639GG (rs9923231) genotype, which is associated with high dose requirement [129, 134-136]. A study by Rathore $\mathrm{S}$ et al. has shown that the VKORC1-1639 $G>A$ status can be indicative of establishing the therapeutic dose of OATs in Indian prosthetic valve patients [136]. When inter-individual dose variability of acenocoumarol in the Indian patients with $C Y P 2 C 9$ and VKORC1 gene polymorphisms were evaluated, lower dose requirements for carriers of the studied polymorphisms had been identified and there was considerable variability in the dose requirements of carriers and non-carriers of the variant alleles [137]. Similarly, Krishna Kumar D et al., by studying South Indian patients with heart valve replacement, report decreased requirement of the daily maintenance dose of acenocoumarol in patients with CYP2C9 and VKORCl(-1639 G>A) genetic polymorphisms [138]. Although, translation of warfarin pharmacogenetics into clinical practice is slowly emerging in India.

Recently, FDA has recommended pharmacogenetics testing before initiating warfarin. However, ACCP recommends against the routine use of pharmacogenetic testing for guiding doses of VKA in patients initiating VKA therapy. CSI has mentioned about the availability of tests but has not recommended routine test for initiation of warfarin $[9,113]$.

\section{Indian recommendation}

- If the patient did not achieve target INR in spite of high dose of warfarin, pharmacogenetics testing may be considered, provided that it is easily available and costeffective (grade C, EL 4).

\section{Anticoagulant interactions}

Drug-drug interaction As VKAs are metabolized mainly by CYP2C9, the inhibition of CYP2C9 results in a decreased catabolism of VKAs and a stronger anticoagulant effect,
Fig. 2 A representation of outpatient anticoagulation flow sheet

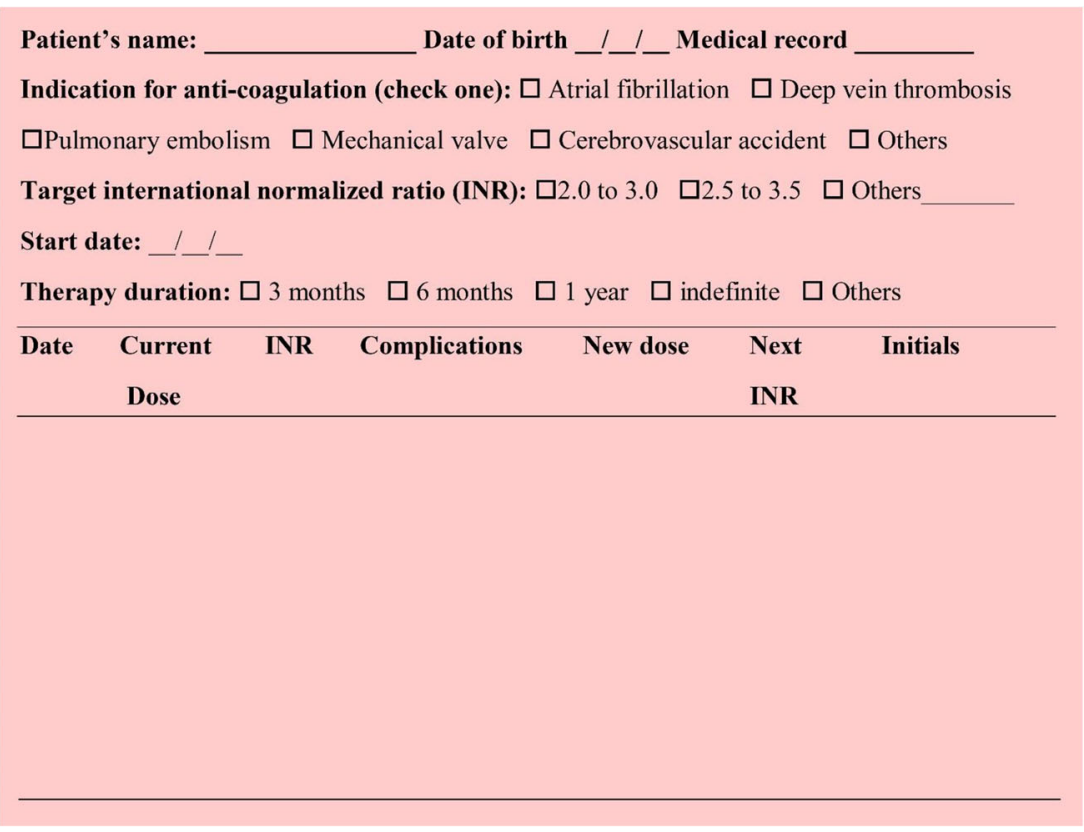


whereas its induction enhances their catabolism and leads to a lower anticoagulant effect.

Amiodarone, fluconazole, fluvastatin, fluvoxamine, isoniazid, lovastatin, miconazole, metronidazole, trimethoprimsulfamethoxazole, and phenylbutazone are known inhibitors of CYP2C9, thus potentiating VKAs effect [139]. Antibiotics, which cause decreased production of vitamin $\mathrm{K}$ by intestinal microbiota result in an increased sensitivity to VKAs. Barbiturates, namely carbamazepine and rifampicin, are inducers of CYP2C9 [139]. Other drugs interact with other cytochromes also involved in the metabolism of VKAs, such as quinolones which inhibit CYP1A2, and macrolide antibiotics which inhibit CYP3A4 [139].

In the Apixaban for Reduction in Stroke and Other Thromboembolic Events in Atrial Fibrillation (ARISTOTLE) trial, patients receiving both warfarin and amiodarone had time in the TR lower than patients not on amiodarone (56.5\% vs. $63.0 \% ; p<0.0001)$ [140]. OTC medications, i.e., paracetamol and other nonsteroidal anti-inflammatory drugs (NSAIDs) were shown to enhance the anticoagulant effect of warfarin, thus patients receiving warfarin must monitor their INR more frequently when taking these medications, especially paracetamol at doses exceeding $2 \mathrm{~g} /$ day. This interaction has been demonstrated in placebo-controlled RCTs. Patients on stable OAT with warfarin were randomized to receive placebo or paracetamol $2 \mathrm{~g}$ daily or $3 \mathrm{~g}$ daily for 10 days. Paracetamol ( $2 \mathrm{~g} / 3 \mathrm{~g}$ daily) was found to potentiate the anticoagulant response produced by warfarin [141]. A large number of drugs interfere with VKA. In a study by Wittkowsky AK et al., it was shown that $81.6 \%$ of the 134,833 patients receiving long-term warfarin therapy were prescribed a concurrent prescription for at least 1 potentially interacting drug, with interactions known to increase the INR [142]. Warfarin drug interactions were one of the common drug interaction found in a cardiology ward in one prospective study conducted in India [143].

ACCP suggest avoiding concomitant treatment with NSAIDs, including COX-2-selective NSAIDs, and certain antibiotics for patients taking VKAs [113].

Although not a direct interaction but dehydration due to aggressive diuresis postoperatively and fluid restriction increases INR and dosage of warfarin has to be adjusted or stopped. If vomiting or diarrhea precipitates dehydration, it can derange INR and monitoring of INR and alteration of Warfarin dosage is warranted.

\section{Indian recommendation}

- It is recommended to avoid drugs that inhibit or enhance the activity of cytochrome P450 during the VKA therapy (grade A, EL 1).

- It is recommended to educate patients on drug interaction with over the counter drugs and antibiotics, and need for frequent monitoring INR when they are used (grade B, EL 3).
- Amiodarone, if needed, should be used with caution along with VKA therapy (grade A, EL 1).

- NSAIDs should not be used with VKAs, if at all NSAIDs are needed, paracetamol may be considered with close supervision (grade A, EL 1).

\section{Drug-herbs interaction}

The interaction between VKAs and herbs is well reported in the literature. These include the interaction with Panax ginseng, Hypericum perforatum, Salvia milthiorizza, Gingko biloba, Sereno arepens, Angelica sinensis, Vaccinium species, Allium sativum, Zingiber officinale, Tanacetum parthenium, Lucium barbarum, Matricaria chamomilla, Boswellia serrata, and Camellia sinensis [144, 145].

Drug-food interaction Indians with their different dietary habits compared to their western counterparts are more prone to VKAfood interactions. Indian takes more of dietary green leafy vegetables which would prevent the achievement of target INR on patients with VKAs and cause variability in INR values.

The interaction between the dietary vitamin $\mathrm{K}$ and VKAs is well known. Evidence has demonstrated that anti-coagulated patients should maintain a steady intake of vitamin $\mathrm{K}$ once INR stability has been achieved. Foods such as mango, grapefruit juice, cranberry, caffeine, and alcohol potentiate the effect of VKAs, whereas vitamin K-rich foods like dark green and cruciferous vegetables, animal products and seafood, soybean oils, fenugreek, soy milk, and green tea inhibit the effect of VKAs. Patients should be educated not to avoid vitamin K-rich foods; however, they should be advised to maintain the vitamin $\mathrm{K}$ content in the diet constantly. The best way to achieve this is by avoiding changes to normal eating patterns [146, 147].

In special situations, such as during fasting, the VKA therapy should be closely monitored in patients who are on longterm anticoagulant therapy. Lai YF et al. in their prospective study evaluated the effects of fasting in patients taking warfarin. The study reported that the mean INR of medically stable patients taking warfarin increases significantly with fasting. Moreover, closer monitoring or a dosage adjustment may be necessary during fasting in patients with higher end of INR target ranges or at increased risk of bleeding [148]. Similarly, a recent prospective study also suggested for closer follow-up of fasting patients who are on warfarin therapy [149]. Moreover, a pilot study also demonstrated that fasting deeply affects the stability of INR and increases the risk of bleeding in patients treated long-term with acenocoumarol [150].

ACCP suggests against routine use of vitamin K supplementation (food) for patients with VKA. CSI suggests avoiding vitamin K-rich food $[9,113]$. 


\section{Indian recommendation}

- Patients are advised to maintain constant vitamin K composition in their diet to avoid fluctuation of VKA therapy (grade C, EL 4).

- Patient in special situations such as fasting, VKA therapy should be carefully monitored (grade B, EL 2).

\section{Anticoagulation in special patient populations}

\section{Pregnancy}

Increase in fibrinogen factors VII, VIII, and X; von Willebrand factor; and a relative decrease in protein $\mathrm{S}$ activity, stasis, and venous hypertension during pregnancy results in the hypercoagulable state [151]. This hypercoagulable state extends into the postpartum period too and requires a persistently higher maintenance dose of VKAs [152]. The increase in total blood volume affects the distribution of anticoagulants in pregnancy contributing to unpredictable changes in the amount of medication required $[152,153]$.

Optimal anticoagulation therapy is essential for pregnant patients; however, the appropriate choice of agent among the existing options (VKA, UFH, or LMWH) is highly debatable [151]. The warfarin enables it to cross placental barriers and cause embryopathy. The risk is high in organogenesis phase of first 6-9 weeks of gestation. The overall risk of embryopathy is $<10 \%$ in the first trimester and it reaches up to the level of the non-treated population after second trimester. The embryopathic actions are dose-dependent; reduced adverse events are seen with dose $<5$ mg [154-156]. Warfarin can be replaced with LMWH since they do not cross the placenta. However, use of heparin is associated with the reported incidence of $12-24 \%$ of the increased risk of maternal thromboembolic events [157].

According to a published review, it is very common in India that pregnancy is diagnosed late in the first trimester. Furthermore, uneducated patients and who have no idea about the teratogenic effects, the risk of embryopathy increases with continuous use of VKAs in the first trimester. Women of childbearing age should be warned about the teratogenic and harmful effects of VKAs, especially in early pregnancy. They should be advised to use secure methods of contraception while on VKAs. In case of suspected pregnancy, early tests 5 weeks from the last menstrual period must be offered. In India, enforcing the practice of conversion to therapeutic once-daily LMWH prior to conception is difficult. Furthermore, all newer anticoagulants are contraindicated in pregnancy and lactation [158].

In a prospective study, women with mechanical heart valves were assigned to receive warfarin throughout pregnancy or subcutaneous heparin in the first trimester and warfarin for the other trimesters. Both groups received heparin at the time of delivery. There were no warfarin-induced fetal malformations. There were eight minor thromboembolic episodes and one prosthetic valve thrombosis (PVT) and one maternal death, not different between the groups. The incidence of spontaneous abortion was similar between the groups. The authors recommend the use of warfarin in the first trimester of pregnancy [159]. Likewise, a 10-year patient experience study suggests that continued oral intake of anticoagulants is safe and successful in pregnant patients with mechanical heart valve prosthesis [160]. A retrospective study to analyze the maternal and perinatal outcome in women with prosthetic heart valves on different anticoagulant regimens (heparin, warfarin, and acenocoumarol) reveal that no anticoagulant regimen is entirely safe during pregnancy as there is a certain degree of risk with each regimen [161]. Similarly, another study based on 25 years of anticoagulation experience in pregnancy also showed no anticoagulant regimen is entirely safe in pregnant women; heparin did not offer a clear advantage over OAT [162]. A simplified guidelines, developed by Panduranga $P$ et al., for anticoagulation management in developing countries where factor Xa measurement facility is not available in hospital suggest that the anticoagulant treatment suitable for pregnant women with mechanical valve prosthesis is dependent on the availability of anti-factor Xa level monitoring facilities, the patient's pre-pregnancy dose of warfarin, and the type of anticoagulant preferred by the patient in relation to the maternal and fetal risks [163]. Moreover, the guidelines also recommend close monitoring of the patient by a team of healthcare practitioners, including cardiology, hematology, and obstetric specialists. The current ACC, ACCP, CSI guidelines recommend warfarin in first trimester if dose required for target INR is < $5 \mathrm{mg}$. The warfarin should be replaced by heparin at 36 weeks of gestation before delivery (Table 9).

\section{Indian recommendation}

- Women with valve replacement should be advised to plan their pregnancy and inform the surgeon if the period is missed (grade C, EL 4).

- Women of childbearing age should be warned about the teratogenic and harmful effects of VKAs, especially in early pregnancy (grade C, EL 4).

\section{Before 36 weeks of gestation}

- Oral VKA therapy is recommended throughout pregnancy in patients with daily warfarin dose requirement of $\leq 5 \mathrm{mg}$ (or equivalent acenocoumarol dose) with target INR of 3 (grade B, EL 3)

- Subcutaneous UFH with activated partial thromboplastin time (aPTT) monitoring should be considered if warfarin dose is $>5 \mathrm{mg}$ (or for equivalent acenocoumarol dose) (grade B, EL 3). 
Table 9 Recommendations on management of anticoagulation in pregnancy

Before 36 gestational weeks

Oral VKAs ACC/AHA - Can be used throughout pregnancy (class IIa) with substitution by UFH/LMWH during weeks 6-12 of gestation if

[51] 1) Preferred by the patient

2) The dose of warfarin required to achieve target INR $>5 \mathrm{mg}$ (class IIa)

- Just before planned delivery has to be replaced by UFH or LMWH (class I)

- Strongly recommended in MPV in second and third trimesters

ACCP [164] Can be used throughout pregnancy in high risk ${ }^{\mathrm{a}}$ patients with UFH or LMWH before delivery (grade 1A)

ESC [165] If warfarin daily dose is $<5 \mathrm{mg}$, oral anticoagulation is the safest regimen throughout the pregnancy

CSI [10] Patients requiring smaller doses ( $<3 \mathrm{mg}$ acenocoumarol, $<5 \mathrm{mg}$ warfarin) should be maintained on oral VKA

Heparin ACC/AHA - 1) SC use of LMWH and UFH throughout pregnancy, 2) SC UFH in the first trimester completely removed in current derivatives $\quad$ [51] 2014 guidelines

- The patients who prefer: ${ }^{b} \mathrm{LMWH}$ administered twice daily and the dose should be adjusted to attain peak anti-factor Xa levels: $0.8-1.2 \mathrm{U} / \mathrm{mL}$ approx. 4-6 $\mathrm{h}$ after the injection. Alternatively, continuous IV UFH (with aPTT at least twice that of the control) during the 1st trimester is permissible if warfarin dose $>5 \mathrm{mg} /$ day

- IV UFH in the first trimester is difficult from a practical standpoint, as 3-month hospital admission required

ACCP [164] • Monitored UFH/LMWH can be option throughout gestation or during 6-12 weeks of gestation (grade 1A)

- In low-risk patients, LMWH should be given twice daily with anti-factor Xa levels of $0.35-0.70 \mathrm{U} / \mathrm{mL} 4 \mathrm{~h}$ after SC injection

- The starting dose should be $100 \mathrm{U} / \mathrm{kg}$ of dalteparin and $1 \mathrm{mg} / \mathrm{kg}$ of enoxaparin.

ESC [165] - LMWH and UFH considered if warfarin dose $>5 \mathrm{mg}$

- LMWH adjusted to achieve anti-factor Xa activity of 0.8-1.2 U/mL 4-6 h after administration, monitored on a weekly basis

CSI [10] - Patients with VKA (>3 mg acenocoumarol, $>5 \mathrm{mg}$ warfarin) should be considered for heparin therapy

- Switch over to heparin from before conception/from 6th week is widely used, but not always needed

- LMWH therapy requires monitoring of factor X assays

All of the above guidelines agree that LMWH should be given twice daily and that it is harmful to administer LMWH without regularly monitoring the patient's anti-factor Xa levels

Aspirin ACC/AHA Low dose (75-100 mg/day) given in second and third trimesters (class I)

[51]

ACCP [164] Low dose is given in addition to anticoagulation in high-risk patients (grade 2C)

ESC [165] Not recommended

CSI [10] Stable patients requiring high doses of VKA, the target INR may be lowered by 0.5 and aspirin added for the first trimester to avoid heparin

Target INR ACC/AHA 3 for all prosthetic valve patients

ACCP [164] 2-3 for patients with bileaflet aortic valves w/o high-risk factors ${ }^{\mathrm{a}}$

ESC [165] No target recommendation

CSI [10] Not mentioned

After 36 gestational weeks

ACC/AHA - Stopping warfarin at 36 weeks and starting continuous IV UFH with aPTT monitoring, which should be continued until

[51] approximately 2-3 weeks before the planned delivery

- Additionally, UFH can be discontinued 4-6 h before the planned delivery and restarted 4-6 h after delivery

- In the absence of significant bleeding, oral warfarin should then be initiated $24 \mathrm{~h}$ after the birth

ACCP [164] - Stopping warfarin at 36 weeks and starting dose-adjusted IV UFH or LMWH

- This treatment should continue until $36 \mathrm{~h}$ before delivery when LMWH should be replaced by IV UFH

ESC [165] - Continuing VKA until the patient is close to term ${ }^{\mathrm{c}}$ (At this point, warfarin should be replaced by UFH/LMWH

- If spontaneous labour occurs on oral anticoagulation, cesarean section is indicated due to obstetric-related causes

CSI [10] - If cesarean section is planned, VKA discontinued 3 days before

- If vaginal delivery is expected VKA discontinued at 34 weeks and LMWH with monitoring of factor X assays. Labor should be initiated at 36-37 weeks

- If labor starts unexpectedly, 2-4 mg IV vitamin K and FFP administered to reduce the risk of fetal injury.

VKA restarted on day 1-2 with usual maintenance dose when hemostasis is adequate

ACC/AHA American college of cardiology/American heart institute, ACCP American college of chest physician, aPTT activated partial thromboplastin time, ESC European society of cardiology, INR international normalized ratio, $I V$ intravenous, $L M W H$ low molecular weight heparin, $M P V$ mechanical prosthetic valves, $S C$ subcutaneous, UFH unfractionated heparin, VKA vitamin $\mathrm{K}$ antagonists

${ }^{a}$ First generation prosthesis, mitral valve prosthesis, history of thromboembolism, atrial fibrillation, left ventricular dysfunction

${ }^{\mathrm{b}} \mathrm{ACC} / \mathrm{AHA}$ recommends discussing the preferred option of anticoagulation in pregnant patients

${ }^{\mathrm{c}}$ Although the word term is not specified, it is generally accepted to signify $48 \mathrm{~h}$ before delivery 
- Low-dose (75-150 mg) aspirin is recommended in second and third trimester (only in high-risk patients or all patients or in stable patients to reduce INR by 0.5 ) (grade C, EL 4).

\section{At 36 weeks of gestation}

- If the patient is hospitalized, VKA may be substituted with UFH. If not, VKA therapy should be discontinued prior to admission for delivery. (grade C, EL 4).

- When hemostasis is adequate, VKA therapy should be restarted on day 1 at maintenance dose along with heparin. (grade C, EL 4).

\section{Elderly population}

Anticoagulation management in elderly patients is a challenging issue. Indeed, elderly patients are at high risk of thromboembolic and hemorrhagic events. The benefit-risk balance of anticoagulation therapy should be carefully assessed when decisions are made about introducing and/or continuing the treatment in an individual elderly patient. Specific considerations, discussed below, need to be taken into account to maximize the safety of anticoagulation in the elderly [166, 167].

Comorbidities and co-medication Elderly patients are more likely to have comorbidities and therefore multiple prescriptions, this is a key point to consider when introducing anticoagulation in this population of patients. This is particularly true for VKAs because these drugs have a narrow therapeutic index and multiple pharmacokinetic and pharmacodynamics potential alterations [166]. In a cross-sectional study by Rouaud A et al., the impact of comorbidities on quality of INR control in geriatric population was analyzed [168].

Pharmacokinetics in the elderly An age-related decrease in body weight seems to affect VKAs' pharmacokinetics. The change in the plasma proteins and other cellular components may modify the unbound heparin levels leading to unpredictable pharmacokinetics [169].

Pharmacodynamics in the elderly Poor dietary vitamin $\mathrm{K}$ intake among elderly is one of the major factors contributing to variability of response and greater sensitivity to VKAs which leads to a reduced competitive antagonism to the effect of VKAs [166]. On the contrary, vitamin K containing OTC multivitamin tablets can significantly reduce response to VKAs [170]. Other mechanisms involved in increased sensitivity to VKAs are decreased production of vitamin $\mathrm{K}$ by intestinal flora in the presence of broad-spectrum antibiotics or increased catabolism of vitamin K-dependent clotting factors in hypermetabolic states such as fever [171, 172]. The concomitant intake of medications interfering with platelet aggregation, such as aspirin or NSAIDs, frequently prescribed in elderly patients, increase the bleeding risk [173].

Hemorrhagic risk Bleeding and especially intracranial hemorrhage is the most dreaded complication of anticoagulant therapy. Regardless of the category of anticoagulant, increasing age represents an independent risk factor for bleeding with anticoagulation in the TR [174]. Insufficient education has been shown to be a major risk factor for anticoagulationrelated bleeding complications in the elderly [175].

Renal function The most significant change in organ function affecting drug pharmacokinetics is the decline in renal function, with an average loss in glomerular filtration rate (GFR) of $0.75 \mathrm{~mL} / \mathrm{min} /$ year. Hence, to avoid adverse effects related to the excessive accumulation of drugs excreted by the kidney, a routine estimation of renal function is recommended in all geriatric patients [176]. VKAs are metabolized in the liver while other anticoagulants depend on renal excretion. Thus, VKAs do not require dosage adjustments in renal impairment patients and offer convenience in the elderly population.

The European Society of Cardiology (ESC) working group on thrombosis recommends considering all of the above factors for antithrombotic therapy in elderly $[10,177]$.

\section{Indian recommendation}

- Frequent renal tests and observation for adverse effects with concomitant medications are recommended in elderly patients considering them as high-risk patients for developing hemorrhagic complications (grade B, EL 3).

\section{Cancer}

Several studies have suggested that there is a role of blood coagulation proteins in tumor progression. Hypercoagulable state is commonly seen in cancer patients is an important risk factor for thrombosis, and may also play a role in tumor progression and metastasis [178, 179]. The risk of thrombosis among cancer patients is about four times higher than in the general population and the risk increases to about 6.7-fold in patients receiving chemotherapy [180]. A number of anticancer agents, as well as of drugs used in supportive cancer therapy have been associated with an increased risk of VTEs. The combination of hormonal and chemotherapy seems to play a synergistic role in the development of thrombosis in patients with cancer [181]. Cancer patients with VTE are more likely to develop recurrent thromboembolic complications and major bleeding during anticoagulant treatment than those without malignancy. These risks correlate with the extent of the cancer $[182,183]$. Several studies have shown the better feasibility of 
LMWH compared to warfarin in cancer patients in order to circumvent the problem of coumadin and chemotherapy interaction $[184,185]$. Similar results were observed in a case report, wherein warfarin was replaced by LMWH [186]. Cancer patients who are on active anti-cancer therapy are at increased risk of bleeding due to chemotherapy-induced thrombocytopenia. Such interactions have been demonstrated in few reports [187-189].

\section{Indian recommendation}

- In patients with chemotherapy, VKA therapy should be closely monitored (grade A, EL 2)

\section{Renal impairment}

As VKAs are metabolized in the liver, no dosage adjustments are required in patients with chronic renal impairment. However, a careful monitoring of therapy is recommended.

In patients with renal insufficiency, dosing and monitoring of anticoagulants should be considered carefully. Anti-Xa activity is also affected during renal impairment; it is prolonged in severe renal impairment (creatinine clearance $<30 \mathrm{~mL} / \mathrm{min}$ ) and, to a lesser extent, in moderate renal dysfunction (30$50 \mathrm{~mL} / \mathrm{min}$ ) [190]. Moreover, the risk of thrombotic and bleeding complications and prevalence of AF is high in patients with renal failure $[191,192]$. Use of VKAs is shown to reduce ischemic complications without significant bleeding risk in patients with mild-to-moderate chronic kidney disease (CKD) and AF (195). Heparin derivatives depend largely on renal excretion; therefore, in patients with renal disorders, heparin dosage adjustment is necessary in order to avoid accumulation and hence over-anticoagulation [191].

Dosage adjustment for factor Xa inhibitors in patients with renal insufficiency is recommended by ACCP [122].

Indian recommendations

- Renal impairment patients should be closely monitored (grade B, EL 3).

\section{Management of prosthetic valve complications}

\section{Thromboembolic events}

Even with appropriate antithrombotic therapy, the reported annual risk of thromboembolic events in patients with a mechanical heart valve is $1-2 \%$ and with the bioprosthetic valve is $0.7 \%$ [193].
Transthoracic echocardiography (TTE) and transesophageal echocardiography (TEE) are important tests in the diagnosis of suspected prosthetic valve thromboembolism [194]. TTE is the first line examination to evaluate severe obstructive thrombosis, whereas TEE is the method of choice for the diagnosis of small prosthetic thrombosis [194]. The prosthetic valve should be considered the source of thromboembolism even if echocardiographic findings are unchanged in suspected cases [194]. Annual follow-up in patients with prosthetic heart valves should include a review of the adequacy of anticoagulation and any issues related to compliance with medical therapy. Screening questions for symptoms that may be related to embolic events are especially important if anticoagulation has been suboptimal [195]. Studies show that patients on VKA anticoagulation who are managed by a dedicated pharmacist-led anticoagulation clinic have lower rates of bleeding and thromboembolism compared with conventional monitoring by a clinician's office $[196,197]$.

A cohort of patients $(N=25,656)$ with aortic valve bioprostheses were evaluated for the risks and benefits of short-term anticoagulation (aspirin-only, 49\%; warfarin-only, 12\%; warfarin plus aspirin, 23\%) by the Society of Thoracic Surgeons-Adult Cardiac Surgery Database (STS-ACSD). Patients treated with warfarin plus aspirin had a lower adjusted risk of death (relative risk (RR) $0.80,95 \%$ confidence interval (CI), 0.66 to 0.96 ) and embolic event (RR $0.52,95 \%$ CI, 0.35 to 0.76 ) but a higher risk of bleeding (RR $2.80,95 \%$ CI, 2.18 to 3.60) relative to aspirin-only. Further, given the clear tradeoff between thromboembolic and bleeding events, the study recommended the use of warfarin plus aspirin for bioprosthetic AVR patients [60]. Similarly, Mistiaen W et al. in their retrospective study also advocated aspirin in bioprosthetic AVR patients with larger valve size for prevention of thromboembolism. The long-term use of warfarin after bioprosthetic AVR could be cautiously considered in elderly patients with AF and previous thromboembolic events [198].

Measures to improve patient compliance, including patient education and more frequent monitoring, should be instituted. Patients should be educated about symptoms related to embolic events and instructed to promptly report to a healthcare provider as soon as the symptoms occur [175, 199-201].

European Association of Echocardiography (EAE) and ACC recommend TTE for diagnosis of thromboembolic events $[10,51,202]$. Thromboembolic events are managed by increasing the target INR range and adding additional antithrombotic drug. It also includes increasing patient compliance to anticoagulation therapy and thereby maintaining the adequate anticoagulation.

\section{Indian recommendations}

- TTE is recommended for the diagnosis of thromboembolic events (grade A, EL 2). 
- Treatment with tissue plasminogen activator (tPA) and heparin is recommended in patients with stroke; other vascular occlusions should be managed by surgery (grade C, EL 4).

- In anticoagulant patients with thromboembolic events, daily aspirin $(75-81 \mathrm{mg})$ is recommended with an increase in the target INR range (mechanical AVR: 2.5-3, mechanical MVR: 3-4) (grade C, EL 4).

- In patients with bioprosthetic valve, who are only on aspirin, the addition of VKAs can be considered (grade B, EL 3).

- Measures to increase patient compliance (patient education) are recommended in all patients with thromboembolic events (grade C, EL 4).

\section{Thrombosis of prosthetic valves}

The prevalence of mechanical valve thrombosis is $0.3-1.3 \%$ per pt-yr in developed countries and 6.1\% per pt-yr in developing countries [203-205]. Bioprosthetic valve thrombosis is less common. The adsorption of plasma proteins, including fibrinogen, onto the surface of the valve prosthesis, leads to platelet adhesion and induction of the coagulation cascade [206]. Another etiological factor is a turbulent trans-prosthetic blood flow, an un-physiological flow that increases the blood-borne shear stress, which causes metabolic and structural damage to the endocardium making it susceptible to further thrombosis [206]. Similarly, blood stasis in re-circulation areas downstream of the prosthesis also favors thrombosis. Other device-free causes are clot-promoting factors including inadequate coagulation, $\mathrm{AF}$, incomplete endothelialization of the valve sewing ring, and inflammation often with a raised fibrinogen level. Type of valve and location also affect the risk of thrombosis [206]. Thrombosis is 20 times more likely in the tricuspid position; mitral prosthetic valve thrombosis is $2-3$ times more common than aortic prosthetic thrombosis. However, the introduction of the bileaflet mechanical valve and use of pyrolytic carbon as a valve material have reduced the risk of thrombosis as pyrolytic carbon is more biocompatible and thromboresistant and wear resistant [207].

Differentiation of valve dysfunction due to thrombus versus fibrous tissue growth (pannus) is challenging because of similar clinical presentations. TTE allows evaluation of valve hemodynamic and detection of valve stenosis or regurgitation. Leaflet motion and thrombus may be visualized in some patients. TTE also allows measurement of LV size and systolic function, left atrial (LA) size, right heart function, and an estimation of pulmonary pressures $[205,208]$. A study by Habib G et al. comparing the efficacy of TTE and TEE in 23 prosthetic heart valve patients concluded that TTE was the procedure of choice in patients with severe obstructive prosthetic thrombosis, while the TEE approach appeared promising in partial thrombosis with mild or absent obstruction [209]. Thrombi on the LA side of the mitral valve can be imaged directly with TEE, which is obscured by shadowing in TTE imaging. Thrombi tend to be larger, less dense, and more mobile on ultrasound imaging than chronic fibrous ingrowth or pannus. Thrombus size measured with TEE is an independent predictor of outcome after thrombolysis of prosthetic heart valve obstruction [205, 210]. Irrespective of New York Heart Association (NYHA) class, patients with thrombus area $<0.8 \mathrm{~cm}^{2}$ are at lower risk for complications from thrombolysis. TEE should be used to identify lower-risk patients for thrombolysis [210]. ACC recommends TTE in patients with suspected prosthetic valve thrombosis to assess hemodynamic severity and resolution of valve dysfunction, and if the thrombus is detected, TEE can be used to assess thrombus size and valve motion.

The left-sided prosthetic heart valve thrombosis can be treated either by fibrinolytics or surgical intervention [205]. When treating left-sided PVT, the risks associated with reoperative surgery must be weighed against the risks of embolic complications and bleeding associated with the use of fibrinolytic therapy. In patients with recent hemorrhagic stroke, surgery is a better choice because of the bleeding risks associated with fibrinolysis. In patients with large, mobile clots that extend beyond the prosthesis, surgical intervention is better suitable than fibrinolysis, which is associated with significant risk of systemic embolism. Although RCTs have not been performed, the weight of the evidence favors surgical intervention for leftsided prosthetic valve thrombosis unless the patient is asymptomatic and the thrombus burden is small. Nevertheless, several studies also suggested heparin could be an initial option of treatment for the non-obstructive PVT [211, 212].

The fibrinolytic therapy of a left-sided obstructed prosthetic heart valve is associated with an overall rate $15-17 \%$ of bleeding risk [210, 213, 214]. Factors including active internal bleeding, history of hemorrhagic stroke, recent cranial trauma or neoplasm, diabetic hemorrhagic retinopathy, large thrombi, mobile thrombi, systemic hypertension $(>200 \mathrm{mmHg}$ / $120 \mathrm{mmHg}$ ), hypotension or shock, and NYHA class III to IV symptoms identify patients at risk for adverse outcomes of fibrinolytic therapy. The degree of risk is directly related to thrombus size. Thrombus area (2D TEE) $>0.8 \mathrm{~cm}^{2}$ and thrombus diameter $1.0 \mathrm{~cm}$ is associated with increased embolic risk and the rate of complications increases 2.4 fold per $1.0 \mathrm{~cm}^{2}$ increase in size, which makes surgery better option [210]. The mortality rate in thrombosed prosthetic heart valve patients is reduced with prompt surgical treatment. Deviri $\mathrm{E}$ et al. in a retrospective study reported that perioperative mortality increased directly with NYHA class; $17.5 \%$ in NYHA IV and $4.7 \%$ in NYHA I to III. Mortality was similar for removing the thrombus or replacing the entire prosthetic valve [215]. In 2009, Roudaut A et al. presented one of the first studies that directly compared fibrinolysis to surgery in a large singlecenter retrospective study. These data suggest no difference between the approaches with respect to mortality, a much higher rate of embolic episodes in the fibrinolysis group, and 
less hemodynamic success. Furthermore, long-term freedom from recurrence was better in the surgical group [214]. Likewise, fibrinolysis was as successful as surgical intervention in normalizing hemodynamics in a non-randomized, retrospective cohorts of thrombosed mechanical, or biological tricuspid valve prostheses. Small pulmonary emboli appear to be well tolerated with fibrinolysis of right-sided valve thrombosis, and systemic emboli are uncommon [216, 217].

Clinical symptoms can be effectively ameliorated and normal hemodynamics can be restored with the prompt surgical treatment of a thrombosed prosthetic heart valve in patients who do not have a contraindication to surgical intervention. A meta-analysis of 7 studies with 690 cumulative episodes of left-sided prosthetic valve thrombosis showed that fibrinolytic therapy was able to restore normal valve function of only about $70 \%$ in 244 cases, whereas with surgery restoration rate was $86.5 \%$ in 446 cases. Statistically significant differences in the mortality rates were not observed between surgical and fibrinolytic therapy, but surgery was associated with lower rates of thromboembolism (1.6\% vs. 16\%), major bleeding events $(1.4 \%$ vs. $5 \%)$, and recurrent prosthetic valve thrombosis $(7.1 \%$ vs. $25.4 \%)$ [218].

In a retrospective study by Singh AK et al., thrombolytic therapy for the thrombosed prosthetic bileaflet mechanical valve at the mitral and the aortic position was compared [219]. Overall, $53 \%$ and $27 \%$ patients had complete and partial resolution with thrombolytic therapy and in $20 \%$ patients, no change was observed. The proportion of patients to full response to the fibrinolytic therapy was similar at both mitral and aortic position. Whereas, partial response was high in mitral position (31\%) compared to aortic valve (17\%). Thrombolysis avoided surgery in NYHA III/IV patients with almost 50\% complete response. Management of PVT with thrombolytic therapy has also been demonstrated in various case reports and case series. Srinivas B et al. demonstrated successful management of acute prosthetic valve thrombosis post mitral valve replacement in the first trimester of pregnancy with IV streptokinase [220]. Likewise, Sharma V et al. reports the management of left-side PVT and Kuchulakanti PK et al. reports successful treatment of aortic prosthetic valve thrombosis, with tenecteplase [221, 222].

ACC and ACCP recommend fibrinolytics or surgical intervention for the management of PVT; the clinical judgment should be based on the position of the valve (left or right) and thrombus burden as assessed by echocardiography [38, 51]. The strategies for addressing PVT and recommended dose of fibrinolytics are represented in Table 10 [30, 51]. However, ACCP does not elaborate upon the doses of fibrinolytic therapy used. If fibrinolytic therapy is successful, ACC suggests following IV UFH until VKA therapy achieves an INR of 3.0 to 4.0 for aortic prosthetic valves and 3.5 to 4.5 for mitral prosthetic valves; with a structured institutional protocol with indications, contraindications, and a specific timeline for medication administration and patient monitoring. ACC suggest to change anticoagulation regimen as outlined in the management of thromboembolic events after assessment of the adequacy of anticoagulation and follow up of the same. CSI recommend a change from mechanical to bioprosthesis in patients having protein $\mathrm{C}$ or S deficiency as they are unsuited for Coumadin therapy. CSI also suggest a trial of direct oral thrombin inhibitor before resorting to surgery [10].

\section{Indian recommendation}

- TTE is recommended in patients with suspected prosthetic valve thrombosis to assess hemodynamic severity and resolution of valve dysfunction (grade B, EL 3). Cinefluoroscopy can be considered as an additional tool for diagnosis of prosthetic valve thrombosis (grade C, EL 4).

- TEE is recommended to assess thrombus size and valve motion (grade B, EL 3).

- UFH is recommended in a very small and non-obstructive thrombus burden of left-sided PVT if not treated fibrinolytics are recommended (grade B, EL 3).

- In patients with left-sided PVT, with thrombus burden $\leq$ $0.8 \mathrm{~cm}^{2}$ fibrinolytics are recommended over surgery (grade B, EL 3).

- Emergency surgery is recommended in case of left-sided PVT with a mobile or large thrombus $>0.8 \mathrm{~cm}^{2}$. Fibrinolytics can be considered in patients with contraindications to surgery (grade B, EL 3).

- The right-sided thrombosis can be treated with fibrinolytics if no contraindications to fibrinolytics are present. If fibrinolytic therapy is successful, IV UFH is recommended until the patient achieves an INR of 3.0 to 4.0 for aortic prosthetic and 3.5 to 4.5 for mitral prosthetic valves (grade B, EL 3).

\section{Bleeding complications}

The incidence of major bleeding complications in patients with a mechanical valve and taking OAT varies from 0.34 to $1.32 \%$ per pt-yr [223]. The prominent features associated with anticoagulant overdose include bleeding (which may be manifested as nasal bleeds), hematemesis, hemoptysis, gastrointestinal bleeding, vaginal bleeding, hematuria, cutaneous hemorrhages, gingival bleeding, hematomata, and bleeding into joints or menorrhagia.

Numerous risk scores have been developed to help predict bleeding events considering other comorbidities such as previous gastrointestinal bleeding, CKD, previous stroke or MI, and anemia (Table 11). The majority of these risk scores have been developed to assess bleeding risk in patients with AF. The outpatient bleeding risk index has been prospectively validated (majority of the patients were prosthetic valve patients in 
Table 10 The management strategies for prosthetic valve thrombosis (ACCP, ACC)

\begin{tabular}{|c|c|c|}
\hline PVT & $\mathrm{ACC}[51]$ & ACCP $[30]$ \\
\hline Diagnosis & - Based on TTE and TEE for assessment of thrombus burden & - Not mentioned \\
\hline Clinical judgment & - Based on thrombus burden and position of valve (left/right) & - Based on thrombus burden and position of valve (left/right) \\
\hline Emergency surgery & $\begin{array}{l}\text { Left-sided PVT } \\
\text { - with a mobile or large thrombus }\left(>0.8 \mathrm{~cm}^{2}\right) \\
\text { - with NYHA class III to IV symptoms }\end{array}$ & $\begin{array}{l}\text { Left-sided PVT } \\
\cdot \text { with a mobile or large thrombus }\left(>0.8 \mathrm{~cm}^{2}\right)\end{array}$ \\
\hline Fibrinolytics & $\begin{array}{l}\text { Left-sided PVT } \\
\text { - Very small thrombus- UFH, if persists give fibrinolytics } \\
\text { - Thrombus }\left(\leq 0.8 \mathrm{~cm}^{2}\right) \text { : fibrinolytics in patients with recent } \\
\text { onset }(<14 \text { days) of NYHA class I to II symptoms } \\
\text { (class II, level B) }\end{array}$ & $\begin{array}{l}\text { Left-sided PVT } \\
\text { - Very small- UFH, accompanied by serial Doppler } \\
\text { echocardiography to document thrombus resolution } \\
\text { or improvement over other alternatives if persists } \\
\text { give fibrinolytics } \\
\text { - Thrombus }\left(\leq 0.8 \mathrm{~cm}^{2}\right) \text { : fibrinolytics over surgery } \\
\text { - In left-sided PVT with }>0.8 \mathrm{~cm}^{2} \text {, in whom surgery } \\
\text { is contraindicated } \\
\text { - In absence of contraindications to fibrinolytics, given } \\
\text { in right-sided PVT }\end{array}$ \\
\hline Fibrinolytic dosage & $\begin{array}{l}\text { - tPA: } 10 \mathrm{mg} / 20 \mathrm{mg} \text { IV bolus followed by } 90 / 10 \\
\text { mg infused IV over } 2 / 3 \mathrm{~h} \\
\text { - Heparin and glycoprotein IIb/IIIa inhibitors are held, } \\
\text { aspirin can be continued } \\
\text { - Alternatively, streptokinase } 500,000 \mathrm{IU} \text { in } 20 \mathrm{~min} \\
\text { followed by } 1,500,000 \mathrm{IU} \text { over } 10 \mathrm{~h} \\
\text { - Urokinase is less effective than tissue plasminogen } \\
\text { activator or streptokinase }\end{array}$ & Not mentioned \\
\hline
\end{tabular}

$A C C$ American College of Cardiology, ACCP American College of Chest Physicians, $I U$ international units, $I V$ intravenous, $N Y H A$ New York Heart Association, $P V T$ prosthetic valve thrombosis, $t P A$ tissue plasminogen activator, TEE transesophageal echocardiography, TTE transthoracic echocardiogram, $U F H$ unfractionated heparin

validation study) and is often a useful tool for helping to guide clinician decision-making. Age is by far the strongest predictor of hemorrhage. The risk of bleeding appears to steadily increase once a patient is $>75$ years old [228]. Pharmacogenetics also seems to influence the risk of bleeding events.

Excessive anticoagulation (INR $\geq 5$ ) greatly increases the risk of hemorrhage. In patients with acute or prior intracerebral hemorrhage, antithrombotic therapies present a clinical dilemma with competing risks and benefits. In a retrospective study, Phan and associates found that discontinuation of anticoagulation therapy for 1-2 weeks had a low probability of thromboembolic events in patients with high embolic risk [229]. Similarly, another report suggests interruption of anticoagulation therapy as safe in patients with intracerebral hemorrhage and mechanical heart valves but without previous evidence of systemic embolization [230]. In major bleeding

Table 11 Bleeding risk prediction scores

\begin{tabular}{|c|c|c|c|}
\hline Risk score [source] & Bleeding risk factors & $\begin{array}{l}\text { Risk classification } \\
\text { points }\end{array}$ & $\begin{array}{l}\text { Annual rate of } \\
\text { major bleeding }\end{array}$ \\
\hline $\begin{array}{l}\text { Outpatient bleeding } \\
\text { risk index } \\
{[224]}\end{array}$ & $\begin{array}{l}\text { Age } \geq 65 \text { years, history of stroke, history of gastrointestinal bleeding, } \\
\text { recent } \mathrm{MI} \text {, or } \mathrm{Hct}<30 \% \text { or } \mathrm{SCr}>1.5 \mathrm{mg} / \mathrm{dl} \text { or diabetes } \\
1 \text { point each }\end{array}$ & $\begin{array}{l}\text { Low: } 0 \\
\text { Intermediate: } 1-2 \\
\text { High: } \geq 3\end{array}$ & $\begin{array}{l}\text { Low: } 3 \\
\text { Intermediate: } 12 \\
\text { High: } 30\end{array}$ \\
\hline $\begin{array}{l}\text { Contemporary bleeding } \\
\text { risk model } \\
{[225]}\end{array}$ & $\begin{array}{l}(0.49 \times \text { age } \geq 70 \text { years })+(0.32 \times \text { female sex })+(0.58 \times \text { remote bleed }) \\
\quad+(0.62 \times \text { recent bleed })+(0.71 \times \text { alcohol } / \text { drug abuse })+(0.27 \\
\quad \times \text { diabetes })+(0.82 \times \text { anemia })+(0.32 \times \text { antiplatelet therapy }) *\end{array}$ & $\begin{array}{l}\text { Low: } \leq 1.07 \\
\text { Intermediate: } 1.07-2.18 \\
\text { High: }>2.19\end{array}$ & $\begin{array}{l}\text { Low: } 0.9 \\
\text { Intermediate: } 2.0 \\
\text { High: } 5.4\end{array}$ \\
\hline $\begin{array}{l}\text { Has-bled } \\
{[226]}\end{array}$ & $\begin{array}{l}\text { Hypertension }(\mathrm{SBP}>160 \mathrm{mmHg}) \text {, abnormal renal/liver function, } \\
\text { stroke, history of bleeding, labile INR, elderly age ( }>65 \text { years), } \\
\text { drugs (antiplatelet/NSAIDS/alcohol) } \\
1 \text { point each }\end{array}$ & $\begin{array}{l}\text { Low: } 0-1 \\
\text { Intermediate: } 2 \\
\text { High: } \geq 3\end{array}$ & $\begin{array}{l}\text { Low: } 1.1 \\
\text { Intermediate: } 1.9 \\
\text { High: } 4.9\end{array}$ \\
\hline $\begin{array}{l}\text { Hemorrhages } \\
{[227]}\end{array}$ & $\begin{array}{l}\text { Hepatic or renal disease, ethanol abuse, malignancy, older age (>75 years) } \\
\text { reduced platelet count/function, re-bleeding, uncontrolled hypertension, } \\
\text { anemia, genetic factors (CYP2C9 SNP), excessive fall risk, stroke } \\
1 \text { point each }\end{array}$ & $\begin{array}{l}\text { Low: } 0-1 \\
\text { Intermediate: } 2-3 \\
\text { High: } \geq 4\end{array}$ & $\begin{array}{l}\text { Low: } 2.1 \\
\text { Intermediate: } 5 \\
\text { High: } 8.8\end{array}$ \\
\hline
\end{tabular}

NSAID non-steroidal anti-inflammatory drugs, $M I$ myocardial infarction, SBP systolic blood pressure 
cases, the risk of bleeding and valve thrombosis must be weighed and the period of discontinuing anticoagulation should be adjusted based on individual case [231].

In a study on Indian patients with MVR, the incidences of bleeding complication are common in patients with a mechanical valve $(6 \%)$ than those with a bioprosthetic valve $(0.9 \%)$ [61]. Evidence suggests that fresh frozen plasma (FFP) and packed red cell transfusion are used as antithrombotic therapies for the management of bleeding incidences in prosthetic valves patients in India [41, 61, 64].

Several RCTs report the efficacy of vitamin K for the management of bleeding complications in patients with excessive anticoagulation therapy $[232,233]$. Yiu KH et al. demonstrate low dose intravenous vitamin $\mathrm{K}$ as a safe alternative to FFP infusion for warfarin overdose in patients with mechanical heart valves [232]. Lubetsky A et al. show that oral administration of vitamin $\mathrm{K} 1$ is as effective and safe as intravenous administration in patients with excessive anticoagulation [233]. Moreover, the addition of oral vitamin $\mathrm{K} 1$ along with omitting warfarin significantly reduces the time to achieve INR of 4.0 in patients with excessive anticoagulation [234]. Overall, high dose vitamin $\mathrm{K}$ therapy (5-10 $\mathrm{mg}$ ) and large volume typespecific FFP therapy are the effective treatment options for controlling the INR in mechanical heart valve patients with warfarin-induced major bleeding complications [223].

Management of bleeding events as recommended by ACC and ACCP are presented in Fig. 3. For patients initiating VKA therapy, ACCP suggests against the routine use of clinical prediction rules for bleeding as the sole criterion to withhold VKA therapy. For patients with VKA associated major bleeding, ACCP suggests rapid reversal of anticoagulation with four-factor prothrombin complex concentrates (PCC) rather than with plasma [51, 88].

\section{Indian recommendation}

- In absence of active bleeding and INR in the range of 4.510.0 , it is recommended withholding VKA with serial INR determination, and resuming when INR is therapeutic (grade B, EL 3).

- In absence of active bleeding, and INR $>10$, it is recommended withholding VKA and administering FFP and should be hospitalized (grade C, EL 4).

- For patients with VKA-associated active bleeding, withhold VKA, and administer FFP. It is also recommended to administer vitamin $\mathrm{K} 1$ as slow IV infusion if uncontrolled (grade A, EL 2).

\section{Prosthetic valve endocarditis}

Prosthetic valve endocarditis (PVE) is a serious complication of cardiac valve replacement and is an important cause of morbidity and mortality. After excluding other common causes of fever, echocardiography should be performed in all cases where there is a medium or high clinical suspicion or when the patient is severely ill [235]. Durack and colleagues proposed a diagnostic criterion which combines echocardiographic findings with clinical and microbiological data [236]. Echocardiographic findings that were considered to be major criteria for the diagnosis of IE includes (1) presence of vegetations which are defined as irregularly shaped, independently mobile structures with relatively low echogenicity that are implanted in a valve or mural endocardium in the trajectory of a regurgitant jet or implanted in a prosthetic material with no alternative anatomical explanation; (2) presence of abscesses; or (3) presence of a new dehiscence of a valvar prosthesis [236]. Vegetations formed in the valve ring area may
Fig. 3 Management of bleeding events in prosthetic valve patients (ACC, ACCP)

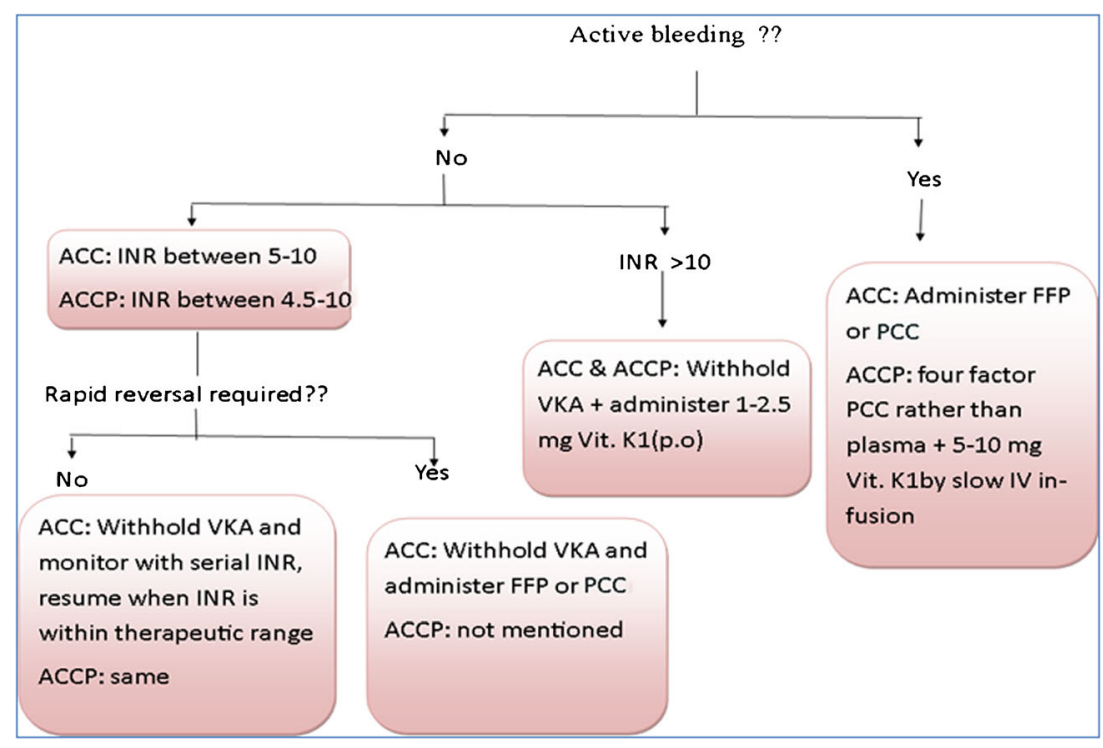


spread to the leaflet of the prosthetic valve, stent, or occluder, could impair the opening and closing of the valve. Without considering the echocardiographic findings in the context of the clinical presentation, differentiation of vegetations from other masses, such as thrombus, sutures, or pledgets, might be difficult [237]. Echo-lucent or an echo-dense mass produce abnormal cavities, which can be seen in the valve ring area. Abscesses may occasionally infiltrate the septum and impair the conduction system and are sometimes observed even in cases in which vegetations are absent. Edema and hematoma might occur early after surgery, particularly in stentless valves, and simulate a walled-off abscess. Progression of an abscess may result in a fistula between the heart chambers. Shunt detection in such cases can be facilitated by color Doppler [237]. Suture dehiscence and paravalvular regurgitation in all prosthetic valves and valve destruction in bioprosthetic valves can be caused due to IE [235].

TEE was demonstrated superior to TTE in assessing PVE and its complications. TEE has been shown to have high sensitivity (86-94\%) and specificity (88-100\%) for the detection of vegetations [238-241]. Secondary destruction of leaflet tissue may lead to infection of bioprosthetic valve leaflets [235]. It is often difficult to distinguish between wear-and-tear degeneration of tissue valves and IE. TEE helps in improving the diagnostic accuracy of IE on bioprosthetic valves [242]. TEE is also superior to TTE in detecting associated perivalvular abscesses in the posterior but not in the anterior aortic root (because of shadowing, depending on valve location) [243-245]. The reported sensitivity and specificity for the diagnosis of perivalvular abscesses with TTE are $28 \%$ and $98 \%$ respectively, and with TEE are $87 \%$ and $95 \%$, respectively [243]. TEE is, therefore, necessary in cases in which IE is strongly suspected, even when no significant findings are seen on TTE [246]. Multiple TEE planes combined with TTE views must be exploited to minimize the risk of missing a significant finding when images are technically difficult to obtain. When both TEE and TTE studies are negative, there is a $95 \%$ negative predictive value $[247,248]$. The thromboembolic risk was reported higher with PVE than that of native valve IE, i.e., rates between 50 and $88 \%$ [38, 249, 250]. Antimicrobial therapy remains the mainstay of therapy; however, most patients require surgical removal and replacement of infected prosthesis. Furthermore, the postponement in the prevention of embolization is allied with stroke within 3 days of diagnosis [250]. The risk of embolism is related to the size, and mobility of vegetation, especially patients with very mobile and large $(>15 \mathrm{~mm})$ vegetations are at higher risk. Moreover, the risk of new embolism is highest during the first days of antibiotic therapy and decreases after 2 weeks [194]. Roudaut A et al. have demonstrated performing diagnostic blood cultures in the presence of fever to rule out IE [205]. In a case-control study, Agarwal S et al. identified the risk factors for PVE in Indian population. These risk factors were functional NYHA class III or IV, history of smoking, prior history of IE, fever in the intensive care unit (ICU), wound infection, and gastrointestinal bleeding [251]. There are no randomized studies assessing the impact of antithrombotic therapy on PVE. However, the results of observational studies suggest that the risk of continuing anticoagulation outweigh the benefits [250, 252-255]. Carpenter JL et al. compared the outcomes of anticoagulation in native valve IE $(N=82)$ with PVE patients $(N=18)$. The study reported that $36 \%$ of patients with PVE had symptomatic cerebral hemorrhage during anticoagulation continuation and $80 \%$ of them died. Furthermore, central nervous system (CNS) hemorrhage was the principal cause of death in patients with PVE [256].

Two different recommendation statements from ESC [194, 257] and one AHA statement [258] suggest performing TTE in suspected IE. In the case of negative TTE in suspected PVE, TEE is recommended. A repeated TTE/TEE within 7-10 days is recommended in patients with high suspicion of IE if initial examinations are negative. ACC and ESC recommend using Modified Duke criteria in evaluating a patient with suspected IE $[51,194]$. ACCP recommended that "In patients on VKA for a prosthetic valve who develop IE, VKA can be discontinued at the time of initial presentation until it is clear that invasive procedures will not be required and the patient has stabilized without signs of CNS involvement. When the patient is deemed stable without contraindications or neurologic complications, reinstitution of VKA therapy is suggested" [38]. Prosthetic cardiac valve implantation has been indicated as one of the conditions associated with the highest probability of adverse outcomes from IE $[259,260]$. According to the guideline, IE prophylaxis is not required in routine anesthetic injections through non-infected tissue, dental radiographs, prosthodontic or orthodontic appliances, adjustment of orthodontic appliances replacement or removable, orthodontic brackets placement, deciduous teeth shedding, and bleeding from trauma to the lips or oral mucosa [259]. Moreover, prophylaxis is also not recommended for bronchoscopy unless the respiratory tract mucosa is incised [259].

- Procedures requiring antibiotic prophylaxis [259, 260]:

1. Dental procedures: all dental procedures that involve dental-gingival manipulation, and management of a periapical region of teeth or oral mucosa perforation.

2. Respiratory tract procedures: incision or biopsy during tonsillectomy and adenoidectomy.

3. Procedures for infected skin, skin structure, or musculoskeletal tissue

\section{Indian recommendations}

\section{Diagnosis}

- TTE is recommended in suspected IE, in the case of negative TTE in suspected PVE, TEE is recommended. If initial examinations are negative, repetition of TTE/TEE 
is recommended within 7-10 days in patients with high suspicion of IE. Modified Duke criteria should be used in evaluating a patient with suspected IE (grade B, EL 3).

\section{Prophylaxis}

- Antibiotic prophylaxis is recommended for certain dental procedures like gingival or periapical (root) procedures with perforation of the mucosa, and also for infected GI and urogenital tract procedures (grade C, EL 4).

\section{Antithrombotic}

- It is recommended to discontinue VKA, in patients on VKA for a prosthetic valve who develop IE, until it is clear that invasive procedures will not be required and the patient has stabilized without signs of CNS involvement. When the patient is deemed stable without contraindications or neurologic complications, reinstitution of VKA therapy is recommended (grade B, EL 3).

\section{Follow-up evaluations and management of concomitant cardiac disease}

Congestive heart failure (CHF), coronary arterial disease (CAD), and $\mathrm{AF}$ are the frequent complications encountered in patients with valve replacement. CAD and arrhythmias are the more commonly combated hitches in AS and mitral valve disease patients respectively [10]. Data regarding the optimal follow-up management after valve surgery is limited. Therefore, physician preference and experience are inevitable for the clinical practice [261]. Therefore, a consensus regarding special management of concomitant heart diseases with follow-up and evaluation of progressive diseases is highly desirable in the patients with VHD.

\section{Heart failure}

Patients with heart valve prostheses have substantial cardiac compromise and are expected to be at noticeable risk for CHF [10]. Following valve surgery, CHF may be responsible for further complications like prosthetic-related complications, deterioration of repair, LV dysfunction, or progression of another valve disease. Therefore, it is likely to be very crucial to manage CHF during follow-up for VHD.

The ACC/AHA categorized CHF into four stages incorporating both risk factors and abnormalities of cardiac structure [51]. Stage A patients are at high risk for HF without any structural heart disease; however, stage $\mathrm{B}$ and $\mathrm{C}$ are the patients with any structural heart disease. Valve patients should be treated as stage $\mathrm{C}$ or $\mathrm{D}$ preoperatively and stage $\mathrm{B}$ or $\mathrm{C}$ following surgery. Similarly, the NYHA classifies CHF according to the severity of $\mathrm{HF}$ and provides the guidance for patient management. Stage B and C patients are generally managed with moderate doses of angiotensin-converting enzyme (ACE) inhibitors and $\beta$ blockers along with antithrombotics [10]. However, in uncontrolled CHF cases, the addition of spironolactone and digoxin may be considered. Furthermore, in patients with severely decompensated AS with NYHA class IV HF symptoms, vasodilator therapy may be recommended [51].

\section{Indian recommendations}

- Antithrombotics are recommended in valve replacement patients with stage A heart failure (grade A, EL 1). ACE inhibitors and $\beta$ blockers could be beneficial if added in older patients (grade B, EL 3)

- ACE inhibitors and $\beta$ blockers along with antithrombotics are recommended in patients with stage $\mathrm{B}, \mathrm{C}$ heart failure (grade A, EL 1). Moreover, spironolactone and digoxin can be added if congestive failure supervenes despite regular medications (grade A, EL 2).

- In patients with stage D heart failure, other interventions including cardiac transplant are recommended (grade D, EL 4).

\section{CAD}

Concomitant VHD and CAD are usually problematic in elder populations. The prevalence of mitral regurgitation (MR) and AS in patients aged $\geq 70$ years is reported as $10 \%$ and $4 \%$ respectively. Furthermore, in AS patients, the prevalence of concurrent $\mathrm{CAD}$ has been $>50 \%$ and $>65 \%$ in patients with age $>70$ and $>80$ years respectively. In addition, elderly patients often have more comorbidity with previous cardiac operations; and the CABG during valve surgery could reciprocate and doubles the operative risk of the procedure [262].

In an era of drug-eluting stent (DES) usage, the concurrent use of dual APAs with VKAs has been a major issue in patients with percutaneous coronary intervention (PCI). The existing guidelines do not address these issues. Approximately $5 \%$ of patients requiring PCI also present with an indication for OAT. In such cases, the type of stent selected, the use of oral anticoagulants, APA, or their combinations, the target INR, and the duration of treatment are essential considerations in relation to the risk of thrombosis/thromboembolic events and bleeding risk. Whenever possible, triple therapies with shorter durations are preferred over longer durations [263]. Moreover, pertaining to shorter duration of triple antithrombotic therapy, a bare-metal stent (BMS) may offer the advantages of lower bleeding risk over DES in patients with non ST segment elevation acute 
coronary syndrome (NSTE-ACS) and necessitate OAT for AF, mechanical heart valve, deep venous thrombosis (DVT), or other conditions [264, 265]. However, these recommendations do not specify the optimal treatment according to the various indications for anticoagulation or the duration of treatment, nor do they take into account the estimated thrombosis and bleeding risks. On the other hand, a meta-analysis including patients with DES versus BMS with indications for OAT reveals that there were no significant differences between DES and BMS for a pooled estimate of hazard ratio (HR) for the major adverse cardiac event (MACE), all-cause mortality, MI, and bleeding complications [266].

The WOEST (What is the Optimal Antiplatelet and Anticoagulant Therapy in Patients with Oral Anticoagulation and Coronary Stenting) trial is the first published study to demonstrate the optimal APA therapy in patients taking OAT. Patients $(N=563$, from this $25 \%$ are NSTE-ACS) randomized to single APA (clopidogrel) were associated with significantly less bleeding complications and no increase in thrombotic events than those randomized to dual APAs (aspirin and clopidogrel) [267]. The target INR should be lowered to 2.5 to 3.0 for mechanical heart valves and to 2.0 to 2.5 for other indications during triple therapy treatment for PCI [268]. Schematic algorithms have also been suggested for selection of an appropriate approach to decide on interventions in patients who are on anticoagulation and undergoing stenting [263, 267, 269].

\section{Indian recommendations}

- Bare metal stents are recommended over drug-eluting stents in patients with valve replacement to lower bleeding risk (grade D, EL 4).

\section{Atrial fibrillation}

The estimated prevalence of postoperative atrial fibrillation (POAF) is approximately $30 \%$ after CABG surgery, $40 \%$ after valve replacements or repair, and up to $50 \%$ after combined CABG and valvular procedures [270, 271]. In a large prospective trial, the Prophylactic Oral Amiodarone for the Prevention of Arrhythmias that Begin Early After Revascularization, Valve Replacement, or Repair (PAPABEAR), amiodarone (10 mg/kg daily) was compared with placebo. The study concluded that prophylaxis with oral amiodarone was effective and safe in all patients for prevention of AF [272]. Similarly, a meta-analysis of 19 trials comparing prophylactic amiodarone versus placebo for prevention of AF after cardiac surgery has demonstrated a significant reduction in AF (reduced by $50 \%$ in the amiodarone group), ventricular tachyarrhythmia, strokes, and hospital stay. The authors concluded that in the absence of a contraindication, prophylactic amiodarone should be implemented as a routine therapy for high-risk patients undergoing cardiac surgery. A total dose of 5 to $10 \mathrm{~g}$ was sufficient irrespective of the timing of initiation (preoperative, intraoperative, or postoperative) or route of administration (oral, IV, or both). Likewise, the scheduled duration of therapy was short in the postoperative period ( $<2$ weeks) [273]. Furthermore, the addition of $\beta$ blockers may help in the postoperative period by reducing sympathetic triggers of $\mathrm{AF}$ [274]. Kar SK et al. evaluated the effect of prophylactic amiodarone in patients with RHD undergoing valve replacement surgery. The study reported that a single dose $(3 \mathrm{mg} / \mathrm{kg})$ of intraoperative amiodarone may be used to decrease postoperative arrhythmia in patients with valve replacement surgery [275]. Furthermore, a single intraoperative dose $(3 \mathrm{mg} / \mathrm{kg})$ of IV amiodarone has improved the rate of conversion from AF to normal sinus rhythm, decreased both the need and energy requirement for cardioversion/defibrillation, and decreased the AF recurrence within 1 day [276].

The European Association for Cardio-thoracic Surgery (EACTS) recommends the perioperative use of $\beta$ blockers as the first choice in all patients undergoing cardiac surgery, unless otherwise contraindicated and amiodarone in whom $\beta$ blocker therapy is not possible [277].

\section{Indian recommendations}

- Prophylactic amiodarone is recommended as a routine therapy for high-risk patients undergoing cardiac surgery in absence of a contraindication (grade A, EL 1).

- Amiodarone at a dose of 100-200 mg daily for 3 months with dosage monitoring along with $\beta$ blockers is recommended for transient perioperative AF (grade A, EL 2).

\section{Follow-up cardiac evaluation}

Doppler echocardiography at baseline (before discharge) serves as a reference for subsequent examinations in patients with valve replacement. The measurements should include regional and global left and right ventricular systolic function and size, diastolic LV function (not assessable with mitral valve prosthesis), atrial size, function of the native valves, pulmonary artery pressure estimates, pressure gradient across the newly implanted prosthesis, effective valvar orifice area, and presence of paravalvular leaks [278]. The first postoperative workup should include patient's medical history, physical examination, electrocardiography (ECG), echocardiography, chest $\mathrm{x}$-ray, complete blood count $(\mathrm{CBC})$, creatinine, electrolytes, lactate dehydrogenase, and INR [278, 279]. The followup schedule generally depends upon the patient's progress and accessibility to local facilities. However, all patients should continue to be followed-up at a cardiac center to identify prosthetic function deterioration, regurgitation recurrence, or disease progression at another valve site, any of which can occur 
with or without any change in symptoms [279]. Following patients require echocardiography at clinic visit [279]:

a. Previously recognized abnormality that necessitates monitoring for progression/response to treatment, e.g., MR, sewing ring thrombus, previous IE, etc.

b. New symptoms that advocate prosthetic dysfunction, progression of another valve lesion, or worsening LV function. Along with TTE, TEE and cinefluoroscopy may also be used in suspicion of prosthetic dysfunction. In bileaflet and tilting disc valves, cinefluoroscopy is used to identify the early limitation of leaflet movement.

c. Bioprostheses, homografts, or autografts, to identify structural deterioration.

d. In case of the Ross procedure, to identify aortic root dilatation, progressive aortic regurgitation (AR), or structural deterioration in the pulmonary homograft.

e. In case of Marfan's syndrome, to identify progressive dilatation of the aorta or progressive MR.

ESC recommends "first postoperative visit to the hospital or a cardiac specialist within 6 weeks of discharge if there has been no period of inpatient rehabilitation or within 12 weeks if a rehabilitation programme has been completed" [279]. The ACC recommends annual follow-up for cardiac history and physical examination in an asymptomatic uncomplicated patient [51]. Furthermore, an echocardiographic examination should be performed within 6 weeks to 3 months after valve implantation [51], while American Society of Echocardiography (AS-Echo) guideline recommends a baseline TTE at discharge or 2-4 weeks after hospital discharge, as an essential component of the first postoperative visit. Both guidelines recommend further follow-up by TTE and/or TEE if clinical symptoms or signs suggestive of prosthetic valve dysfunction or other cardiac pathology persist; with preference to TTE for initial examination [51, 202]. ACC advocates that there should not be any echocardiographic testing after the initial postoperative evaluation in stable mechanical valve patients, who do not have any symptoms or clinical evidence of prosthetic valve or ventricular dysfunction or dysfunction of other heart valves [51]. However, the frequency of echocardiographic testing has not been indicated by ACC; however, AS-Echo recommends annual follow-up in mechanical valve patients in the presence of a change in clinical status [202]. ACC recommends annual TTE after the first 10 years, while AS-Echo recommends annual echocardiography after the first 5 years in bioprosthetic valve patients, even in the absence of a change in clinical status [51, 202].

\section{Indian recommendations}

- A first postoperative visit to a cardiac specialist should be within 1 month of discharge (grade A, evidence level 4).
- The timings of echocardiographic examination: first, at predischarge; second, at 1 month; then yearly; and should be done at any time when symptoms occur (grade C, EL 4).

- The patient should be followed up by TTE and/or TEE in case of clinical symptoms or signs of prosthetic valve dysfunction (grade C, EL 4).

- Echocardiographic testing is recommended for (a) unexplained cardiac symptoms, and (b) annually in all patients with CHF. Moreover, echocardiography is indicated whenever there is an episode of thromboembolism (grade C, EL 4).

- Mechanical heart valve patients should undergo annual follow up in presence of a change in clinical status (grade C, EL 4).

\section{CT and MRI scan-post valve implantation}

Metals, polymers, and carbons are used in the preparation of prosthetic heart valves. Numerous studies have evaluated the safety of magnetic resonance imaging (MRI) examinations with a scanner that operates at $\leq 1.5$ Tesla in heart valve prostheses [280-282]. They found relatively minor magnetic field interactions in relation to the static magnetic fields of the MRI systems. The forces put forth by a magnetic field on these valves have been found to be less than the forces exerted by gravity. These forces were substantially lower than those exerted by the beating heart and resultant pulsatile blood flow [283]. Consequently, these patients are unlikely to be at risk for valve dehiscence. There is a hypothetical probability of electromagnetic interaction with metal in valves that may cause interruption of opening and closing of valves (referred to as the Lenz effect). However, no such cases have been reported in clinical practice with the low magnetic field [284]. Moreover, heating due to MR system was reported to be minor [280-282, 285]. Furthermore, image interpretation is rarely influenced by the artifacts provoked by mechanical valves [283]. In a cohort study, the safety of MR imaging was evaluated in patients who had undergone prior cardiac surgery. Out of 25 mechanical valve patients included, none of them developed adverse cardiac events, such as arrhythmia or worsening cardiac function, related to MRI [249]. Consequently, prosthetic heart valves, as well as metal sternal sutures and mediastinal clips, should not be considered as contraindications for an MRI $\leq 3$ T any time after implantation [286, 287].

According to AHA scientific statement, the presence of a prosthetic heart valve or annuloplasty ring that has been formerly evaluated for MRI safety should not be considered as a contraindication to an MRI $\leq 3 \mathrm{~T}$ (and possibly even $4.7 \mathrm{~T}$ in some cases) any time after implantation [287]. MRI examination of patients with sternal wires is generally considered to be safe. Patients with IE and risk of valve dehiscence cannot undergo MRI [10]. 


\section{Indian recommendations}

- MRI examination (3 T or less) is safe in patients with a prosthetic heart valve or annuloplasty ring or sternal wire (grade C, EL 3).

- MR examination for patients with risk of endocarditis and valve dehiscence should be decided in consultation with a radiologist (grade D, EL 4).

Acknowledgments The VHD India consensus committee constitutes the following members along with the listed authors: Bipin Bihari Mohanty (Chief Consultant Cardiothoracic Surgeon, Aditya CARE Hospitals, Bhubaneshwar), Jagdish Mange (Chief Cardiothoracic Surgeon, Shree Mahavir Health and Medical Relief Society, Surat), Manish Puranik (Consultant Minimally Invasive Cardiac Surgeon, Seth Nandlal Dhoot Hospital, Aurangabad), Manoj P Nair (Senior Consultant, Cardio Vascular Thoracic Surgery, Aster Medcity, Kochi), Pankaj Goel (Director, Cardiothoracic \& Vascular Surgery, Ivy Healthcare, Amritsar), RM Krishnan (Chief Cardiothoracic Surgeon, Meenakshi Mission Hospital, Madurai), Sathyaki Nambala (Chief Heart Surgeon, Apollo Hospitals, Bangalore). Their valuable contributions toward the development of this consensus document are duly acknowledged.

The authors acknowledge the following expert panel members for contributing their valuable inputs toward the development of this guideline: Abraham Oman, Adil Rizvi, Akhilesh Pandey, Anil Aggarwal, Anil Jose, Athouba Singh Arambam, Avinash Dal, A. K. Chaudhary, A. R. Krishna Prasad, Ashwani Suri, Bikash Rai Das, B. R. Ravindra Setty, Chaitanya Shete, Devang Naik, Deepak Naphade, Dhaval Naik, Dhiman Kahali, Dilip Ratnani, Ganesh Shivnani, Gaurav Goel, G. R. Kane, Jacob Jamesraj, Jayant Karbhase, Jitendra Patnaik, J. Mahesh Babu, Kanaknarayan Bhattacharya, Karunakara Padhy, Krishna Kumar P. N., Krishna Prasad, Krishnanand Pai, Kiran Vargesh, K. G. Jayaprasanna, K. V. Krishna Kumar, K. V. Rajashekar Rao, K. Venkat Reddy, Lalit Kapoor, Manish Aggrawal, Manish Porwal, Manmohan, Manoj Durairaj, Mubeen Mohammad, Narendra G. Nishanimath, N. Salgunan, Pranav Modi, P. Babu, Raghunath Mohapatra, Rajeev Godbole, Rajiv Gupta, Rakesh Chugh, Rakesh Goel, Ritwik Raj, R. Ragavendran, Sameer Sharma, Sanjay Jain, Santosh Kumar Pandey, Saptarshi Roy, Shaji Palangadan, Shailesh Jain, Shantesh Kaushik, Siva Muthukumar, Shripal Doshi, Sudhakar Rao M., Sukumar Mehta, Sumit Narang, Sunil Agarwal, Surender Bajaj, Sushan Mukhopadhyay, Sushant Srivastava, Susmit Bhattachary, S. K. Nair, S. Thiyagarajamurthy, Usha Rani, Vidyut Kumar Sinha, Vineet Pandey, Vishal Aggarwal, V. Chitralekha, V. Sridhar, and Yogesh Belapurkar. The authors thank Leena Patel, Rabi Narayan Panigrahy, and Syam K. Yelamanchi from Jeevan Scientific Technology Limited (Hyderabad, India) for providing writing and editorial support in the development of this guideline.

Open Access This article is distributed under the terms of the Creative Commons Attribution 4.0 International License (http:// creativecommons.org/licenses/by/4.0/), which permits unrestricted use, distribution, and reproduction in any medium, provided you give appropriate credit to the original author(s) and the source, provide a link to the Creative Commons license, and indicate if changes were made.

Publisher's note Springer Nature remains neutral with regard to jurisdictional claims in published maps and institutional affiliations.

\section{References}

1. Baskett RJ, Exner DV, Hirsch GM, Ghali WA. Mitral insufficiency and morbidity and mortality in left ventricular dysfunction. Can J Cardiol. 2007;23(10):797-800.

2. Iung B, Vahanian A. Epidemiology of acquired valvular heart disease. Can J Cardiol. 2014;30(9):962-70.

3. Howell EJ, Butcher JT. Valvular heart diseases in the developing world: developmental biology takes center stage. J Heart Valve Dis. 2012;21(2):234-40.

4. Kumar RK, Tandon R. Rheumatic fever \& rheumatic heart disease: the last 50 years. Indian J Med Res. 2013;137(4):643-58.

5. Manjunath C, Srinivas P, Ravindranath K, Dhanalakshmi C. Incidence and patterns of valvular heart disease in a tertiary care high-volume cardiac center: a single center experience. Indian Heart J. 2014;66(3):320-6.

6. Iung B, Baron $\mathrm{G}$, Tornos P, Gohlke-Bärwolf C, Butchart EG, Vahanian A. Valvular heart disease in the community: a European experience. Curr Probl Cardiol. 2007;32(11):609-61.

7. Singh JP, Evans JC, Levy D, et al. Prevalence and clinical determinants of mitral, tricuspid, and aortic regurgitation (the Framingham heart study). Am J Cardiol. 1999;83(6):897-902.

8. Manji RA, Menkis AH, Ekser B, Cooper DK. The future of bioprosthetic heart valves. Indian J Med Res. 2012;135(2):150-1.

9. Manji RA, Ekser B, Menkis AH, Cooper DK. Bioprosthetic heart valves of the future. Xenotransplantation. 2014;21(1):1-10.

10. Bajaj R, Karthikeyan G, Sinha N, et al. CSI consensus statement on prosthetic valve follow up. Indian Heart J. 2012;64(Suppl 2):S3-S11.

11. Butany J, Ahluwalia MS, Munroe C, et al. Mechanical heart valve prostheses: identification and evaluation (erratum). Cardiovasc Pathol. 2003;12(6):322-44.

12. Isaacs AJ, Shuhaiber J, Salemi A, Isom OW, Sedrakyan A. National trends in utilization and in-hospital outcomes of mechanical versus bioprosthetic aortic valve replacements. J Thorac Cardiovasc Surg. 2015;149(5):1262-9.

13. Russell EA, Tran L, Baker RA, et al. A review of valve surgery for rheumatic heart disease in Australia. BMC Cardiovasc Disord. 2014;14(1):134.

14. Hammermeister K, Sethi GK, Henderson WG, Grover FL, Oprian $\mathrm{C}$, Rahimtoola SH. Outcomes 15 years after valve replacement with a mechanical versus a bioprosthetic valve: final report of the veterans affairs randomized trial. J Am Coll Cardiol. 2000;36(4):1152-8.

15. Gammie JS, Sheng S, Griffith BP, et al. Trends in mitral valve surgery in the United States: results from the Society of Thoracic Surgeons adult cardiac database. Ann Thorac Surg. 2009;87(5):1431-9.

16. Vassileva CM, Boley T, Markwell S, Hazelrigg S. Impact of hospital annual mitral procedural volume on mitral valve repair rates and mortality. J Heart Valve Dis. 2012;21(1):41-7.

17. Chatterjee S, Rankin JS, Gammie JS, et al. Isolated mitral valve surgery risk in 77,836 patients from the Society of Thoracic Surgeons database. Ann Thorac Surg. 2013;96(5):1587-95.

18. McNeely CA, Vassileva CM. Long-term outcomes of mitral valve repair versus replacement for degenerative disease: a systematic review. Curr Cardiol Rev. 2015;11(2):157-62.

19. Doshi JV, Agrawal S, Garg J, et al. Percutaneous mitral heart valve repair-MitraClip. Cardiol Rev. 2014;22(6):289-96.

20. Vassileva CM, Mishkel G, McNeely C, et al. Long-term survival of patients undergoing mitral valve repair and replacement a longitudinal analysis of medicare fee-for-service beneficiaries. Circulation. 2013;127(18):1870-6.

21. Brtko M, Dusek J. Antithrombotic therapy in patients after valve surgery with special attention to the combination of anticoagulant and antiplatelet therapy. Cor et Vasa. 2013;55(2):e164-9. 
22. Paparella D, Di Mauro M, Worms KB, Bolotin G, Russo C, Trunfio S. Antiplatelet versus oral anticoagulant therapy as antithrombotic prophylaxis after mitral valve repair. J Thorac Cardiovasc Surg. 2016;151(5):1302-8.

23. Handelsman Y, Bloomgarden ZT, Grunberger G, et al. American Association of Clinical Endocrinologists and American College of Endocrinology-clinical practice guidelines for developing a diabetes mellitus comprehensive care plan-2015. Endocr Pract. 2015;21(s1):1-87.

24. Acar J, Iung B, Boissel JP, et al. AREVA: multicenter randomized comparison of low-dose versus standard-dose anticoagulation in patients with mechanical prosthetic heart valves. Circulation. 1996;94(9):2107-12.

25. Torella M, Torella D, Chiodini P, et al. LOWERing the INtensity of oral anticoaGulant Therapy in patients with bileaflet mechanical aortic valve replacement: results from the "LOWERING-IT" trial. Am Heart J. 2010;160(1):171-8.

26. Hering D, Piper C, Bergemann R, et al. Thromboembolic and bleeding complications following St. Jude Medical valve replacement: results of the German experience with low-intensity anticoagulation study. Chest J. 2005;127(1):53-9.

27. Torn M, Cannegieter SC, Bollen WL, van der Meer FJ, van der Wall EE, Rosendaal FR. Optimal level of oral anticoagulant therapy for the prevention of arterial thrombosis in patients with mechanical heart valve prostheses, atrial fibrillation, or myocardial infarction: a prospective study of 4202 patients. Arch Intern Med. 2009;169(13):1203-9.

28. Cannegieter SC, Rosendaal F, Wintzen A, Van der Meer F, Vandenbroucke J, Briet E. Optimal oral anticoagulant therapy in patients with mechanical heart valves. N Engl J Med. 1995;333(1):11-7.

29. Pengo V, Barbero F, Banzato A, et al. A comparison of a moderate with moderate-high intensity oral anticoagulant treatment in patients with mechanical heart valve prostheses. Thromb Haemost. 1997;77(5):839-44.

30. Whitlock RP, Sun JC, Fremes SE, Rubens FD, Teoh KH. Antithrombotic and thrombolytic therapy for valvular disease: antithrombotic therapy and prevention of thrombosis: American College of Chest Physicians Evidence-Based Clinical Practice Guidelines. Chest J. 2012;141(2 suppl):e576S-600S.

31. Williams MA, van Riet $\mathrm{S}$. The On-X heart valve: mid-term results in a poorly anticoagulated population. J Heart Valve Dis. 2006;15(1):80-6.

32. Puskas J, Gerdisch M, Nichols D, et al. Reduced anticoagulation after mechanical aortic valve replacement: interim results from the prospective randomized on- $\mathrm{X}$ valve anticoagulation clinical trial randomized Food and Drug Administration investigational device exemption trial. J Thorac Cardiovasc Surg. 2014;147(4):1202-10.

33. Karkar AM, Castresana MR, Odo N, Agarwal S. Anticoagulation dilemma in a high-risk patient with $\mathrm{On}-\mathrm{X}$ valves. Ann Card Anaesth. 2015;18(2):257-60.

34. Sankarkumar R, Bhuvaneshwar GS, Magotra R, et al. Chitra heart valve: results of a multicenter clinical study. J Heart Valve Dis. 2001;10(5):619-27.

35. Muralidharan S, Muthubaskeran V, Chandrasekar P. Ten years outcome of Chitra heart valves. Indian J Thorac Cardiovasc Surg. 2011;27(1):24-7.

36. McGrath LB, Gonzalez-Lavin L, Eldredge WJ, Colombi M, Restrepo D. Thromboembolic and other events following valve replacement in a pediatric population treated with antiplatelet agents. Ann Thorac Surg. 1987;43(3):285-7.

37. Serra A, McNicholas K, Olivier H Jr, Boe S, Lemole G. The choice of anticoagulation in pediatric patients with the St. Jude Medical valve prostheses. J Cardiothorac Surg. 1986;28(5):588-91.

38. Schlitt A, von Bardeleben RS, Ehrlich A, et al. Clopidogrel and aspirin in the prevention of thromboembolic complications after mechanical aortic valve replacement (CAPTA). Thromb Res. 2003;109(2):131-5.

39. Dhanya PS, Nidheesh C, Kuriakose KM, Puthiyaveetil N. Pattern of oral anticoagulant use following prosthetic heart valve replacement: a prospective observational study. Indian J Thorac Cardiovasc Surg. 2011;27(3):119-24.

40. John S, Ravikumar E, John CN, Bashi VV. 25-year experience with 456 combined mitral and aortic valve replacement for rheumatic heart disease. Ann Thorac Surg. 2000;69(4):1167-72.

41. Bharat V. Mechanical heart valves: an insight into thrombotic complications. Indian Heart J. 1999;51(1):59-63.

42. Panda BR, Shankar R, Kuruvilla KT, et al. Combined mitral and aortic valve replacement for rheumatic heart disease: fifteen-year follow up and long-term results. J Heart Valve Dis. 2009;18(2):170-9.

43. Order JA. Current Indian scenario on the use of oral anticoagulants. J Assoc Physicians India. 2014;62(6 Suppl):28-9.

44. Saour JN, Sieck JO, Mamo LA, Gallus AS. Trial of different intensities of anticoagulation in patients with prosthetic heart valves. N Engl J Med. 1990;322(7):428-32.

45. Akhtar RP, Abid AR, Zafar H, Khan JS. Aniticoagulation in patients following prosthetic heart valve replacement. Ann Thorac Cardiovasc Surg. 2009;15(1):10-7.

46. Zhou XM, Zhuang W, Hu JG, Li JM, Yu JF, Jiang L. Low-dose anticoagulation in Chinese patients with mechanical heart valves. Asian Cardiovasc Thorac Ann. 2005;13(4):341-4.

47. Sun X, Hu S, Qi G, Zhou Y. Low standard oral anticoagulation therapy for Chinese patients with St. Jude mechanical heart valves. Chin Med Sci J. 2003;116(8):1175-8.

48. Matsuyama K, Matsumoto M, Sugita T, et al. Anticoagulant therapy in Japanese patients with mechanical mitral valves. Circ J. 2002;66(7):668-70.

49. Mori T, Asano M, Ohtake H, et al. Anticoagulant therapy after prosthetic valve replacement-optimal PT-INR in Japanese patients. Ann Thorac Cardiovasc Surg. 2002;8(2):83-7.

50. Stein PD, Alpert JS, Bussey HI, Dalen JE, Turpie AG. Antithrombotic therapy in patients with mechanical and biological prosthetic heart valves. Chest J. 2001;119(1_suppl):220S-7S.

51. Nishimura RA, Otto CM, Bonow RO, et al. 2014 AHA/ACC guideline for the management of patients with valvular heart disease: a report of the American College of Cardiology/American Heart Association task force on practice guidelines. J Am Coll Cardiol. 2014;63(22):e57-185.

52. Cohn LH, Mudge GH, Pratter F, Collins JJ Jr. Five to eight-year follow-up of patients undergoing porcine heart-valve replacement. N Engl J Med. 1981;304(5):258-62.

53. Heras M, Chesebro JH, Fuster V, et al. High risk of thromboemboli early after bioprosthetic cardiac valve replacement. J Am Coll Cardiol. 1995;25(5):1111-9.

54. Durães AR, Durães MA, Correia LC, Aras R. Antithrombotic strategy in the three first months following bioprosthetic heart valve implantation. Arq Bras Cardiol. 2013;101(5):466-72.

55. El-Husseiny M, Salhiyyah K, Raja SG, Dunning J. Should warfarin be routinely prescribed for the first three months after a bioprosthetic valve replacement? Interact Cardiovasc Thorac Surg. 2006;5(5):616-23.

56. Colli A, Verhoye JP, Heijmen R, Antunes M. Action investigators. Low-dose acetyl salicylic acid versus oral anticoagulation after bioprosthetic aortic valve replacement. Final report of the ACTION registry. Int J Cardiol. 2013;168(2):1229-36.

57. Sundt T, Zehr K, Dearani J, et al. Is early anticoagulation with warfarin necessary after bioprosthetic aortic valve replacement? J Thorac Cardiovasc Surg. 2005;129(5):1024-31.

58. Mérie C, Køber L, Olsen PS, et al. Association of warfarin therapy duration after bioprosthetic aortic valve replacement with risk of mortality, thromboembolic complications, and bleeding. JAMA. 2012;308(20):2118-25. 
59. Al-Atassi T, Lam K, Forgie M, et al. Cerebral microembolization after bioprosthetic aortic valve replacement comparison of warfarin plus aspirin versus aspirin only. Circulation. 2012;126(11 suppl 1):S239-44.

60. Brennan JM, Edwards FH, Zhao Y, et al. Early anticoagulation of bioprosthetic aortic valves in older patients: results from the Society of Thoracic Surgeons Adult Cardiac Surgery National Database. J Am Coll Cardiol. 2012;60(11):971-7.

61. Agarwal S, Gupta S, Minhas HS, Geelani MA, Mandiye SS, Banerjee A. Comparison of outcomes after mitral valve replacement with a mechanical versus a bioprosthetic valve in patients between forty and sixty years of age. Indian J Thorac Cardiovasc Surg. 2009;25(1):12-7.

62. Abraham S, Kumar AS. Bioprosthetic valves - an initial experience. Indian J Thorac Cardiovasc Surg. 2002;18(3):115-7.

63. Talwar S, Sharma AK, Kumar AS. Tissue heart valve implantation in India; indications, results and impact on quality of life. Indian J Thorac Cardiovasc Surg. 2008;24(1):10-4.

64. Mandiye SS, Agarwal S, Pratap H, Singh AK, Satsangi DK. Comparison over short term of mortality and morbidity of mechanical and bioprosthetic heart valves in the Indian population. Indian J Thorac Cardiovasc Surg. 2010;26(2):139-43.

65. Smith CR, Leon MB, Mack MJ, et al. Transcatheter versus surgical aortic-valve replacement in high-risk patients. N Engl J Med. 2011;364(23):2187-98.

66. Leon MB, Smith CR, Mack M, et al. Transcatheter aortic-valve implantation for aortic stenosis in patients who cannot undergo surgery. N Engl J Med. 2010;363(17):1597-607.

67. Kahlert P, Al-Rashid F, Döttger P, et al. Cerebral embolization during transcatheter aortic valve implantation: a transcranial Doppler study. Circulation. 2012;126(10):1245-55.

68. Tay EL, Gurvitch R, Wijesinghe N, et al. A high-risk period for cerebrovascular events exists after transcatheter aortic valve implantation. JACC Cardiovasc Interv. 2011;4(12):1290-7.

69. Tamburino C, Capodanno D, Ramondo A, et al. Incidence and predictors of early and late mortality after transcatheter aortic valve implantation in 663 patients with severe aortic stenosis. Circulation. 2011;123(3):299-308.

70. Poliacikova P, Cockburn J, de Belder A, Trivedi U, Hildick-Smith D. Antiplatelet and antithrombotic treatment after transcatheter aortic valve implantation-comparison of regimes. J Invasive Cardiol. 2013;25(10):544-8.

71. Seth A, Rastogi V, Kumar V, Maqbool S, Mustaqueem A, Sekar VR. Transcatheter aortic valve implantation with Core valve: first Indian experience of three high surgical risk patients with severe aortic stenosis. Indian Heart J. 2013;65(4):395-9.

72. Maqbool S, Kumar V, Rastogi V, Seth A. Transcatheter aortic valve implantation under conscious sedation-the first Indian experience. Indian Heart J. 2014;66(2):208-10.

73. Holmes DR, Mack MJ, Kaul S, et al. 2012 ACCF/AATS/SCAI/ STS expert consensus document on transcatheter aortic valve replacement. J Am Coll Cardiol. 2012;59(13):1200-54.

74. Rodés-Cabau J, Dauerman HL, Cohen MG, et al. Antithrombotic treatment in transcatheter aortic valve implantation: insights for cerebrovascular and bleeding events. J Am Coll Cardiol. 2013;62(25):2349-59.

75. Webb J, Rodés-Cabau J, Fremes S, et al. Transcatheter aortic valve implantation: a Canadian cardiovascular society position statement. Can J Cardiol. 2012;28(5):520-8.

76. van Geest-Daalderop JH, Hutten BA, Péquériaux NC, de VriesGoldschmeding HJ, Rakers E, Levi M. Invasive procedures in the outpatient setting: managing the short-acting acenocoumarol and the long-acting phenprocoumon. Thromb Haemost. 2007;98(4):747-55.

77. McKenna R. Abnormal coagulation in the postoperative period contributing to excessive bleeding. Med Clin North Am. 2001;85(5):1277-310.
78. Tinker JH, Tarhan S. Discontinuing anticoagulant therapy in surgical patients with cardiac valve prostheses: observations in 180 operations. JAMA. 1978;239(8):738-9.

79. Katholi RE, Nolan SP, McGuire LB. The management of anticoagulation during noncardiac operations in patients with prosthetic heart valves. Am Heart J. 1978;96(2):163-5.

80. Torn M, Rosendaal FR. Oral anticoagulation in surgical procedures: risks and recommendations. Br J Haematol. 2003;123(4):676-82.

81. Larson BJ, Zumberg MS, Kitchens CS. A feasibility study of continuing dose-reduced warfarin for invasive procedures in patients with high thromboembolic risk. Chest J. 2005;127(3):922-7.

82. Bajkin BV, Popovic SL, Selakovic SD. Randomized, prospective trial comparing bridging therapy using low-molecular-weight heparin with maintenance of oral anticoagulation during extraction of teeth. J Oral Maxillofac Surg. 2009;67(5):990-5.

83. Evans IL, Sayers MS, Gibbons AJ, Price G, Snooks H, Sugar AW. Can warfarin be continued during dental extraction? Results of a randomized controlled trial. Br J Oral Maxillofac Surg. 2002;40(3):248-52.

84. Alcalay J. Cutaneous surgery in patients receiving warfarin therapy. Dermatol Surg. 2001;27(8):756-8.

85. Syed S, Adams BB, Liao W, Pipitone M, Gloster H. A prospective assessment of bleeding and international normalized ratio in warfarin-anticoagulated patients having cutaneous surgery. J Am Acad Dermatol. 2004;51(6):955-7.

86. Jamula E, Anderson J, Douketis JD. Safety of continuing warfarin therapy during cataract surgery: a systematic review and metaanalysis. Thromb Res. 2009;124(3):292-9.

87. Spyropoulos AC, Turpie AG, Dunn AS, Kaatz S, Douketis J, Jacobson A. \& REGIMEN investigators. Perioperative bridging therapy with unfractionated heparin or low-molecular-weight heparin in patients with mechanical prosthetic heart valves on longterm oral anticoagulants (from the REGIMEN registry). Am J Cardiol. 2008;102(7):883-9.

88. Douketis JD, Spyropoulos AC, Spencer FA, et al. Perioperative management of antithrombotic therapy: antithrombotic therapy and prevention of thrombosis: American College of Chest Physicians evidence-based clinical practice guidelines. Chest J. 2012;141(2 suppl):e326S-50S

89. Pengo V, Cucchini U, Denas G, et al. Standardized low-molecular-weight heparin bridging regimen in outpatients on oral anticoagulants undergoing invasive procedure or surgery. Circulation. 2009;119(22):2920-7.

90. Malato A, Saccullo G, Lo Coco L, et al. Patients requiring interruption of long-term oral anticoagulant therapy: the use of fixed sub-therapeutic doses of low-molecular-weight heparin. J Thromb Haemost. 2010;8(1):107-13.

91. Birnie DH, Healey JS, Wells GA, et al. Pacemaker or defibrillator surgery without interruption of anticoagulation. N Engl J Med. 2013;368(22):2084-93.

92. Di Biase L, Burkhardt JD, Santangeli P, et al. Periprocedural stroke and bleeding complications in patients undergoing catheter ablation of atrial fibrillation with different anticoagulation management: results from the role of coumadin in preventing thromboembolism in atrial fibrillation (AF) patients undergoing catheter ablation (COMPARE) randomized trial. Circulation. 2014;129(25):2638-44.

93. Cheng A, Nazarian S, Brinker JA, et al. Continuation of warfarin during pacemaker or implantable cardioverter-defibrillator implantation: a randomized clinical trial. Heart Rhythm. 2011;8(4):536-40.

94. Tolosana JM, Berne P, Mont L, et al. Preparation for pacemaker or implantable cardiac defibrillator implants in patients with high risk of thrombo-embolic events: oral anticoagulation or bridging with intravenous heparin? A prospective randomized trial. Eur Heart J. 2009;30(15):1880-4. 
95. Gallego-Sánchez G, Gallardo-López A, Córdoba-Soriano JG, et al. Safety of transradial diagnostic cardiac catheterization in patients under oral anticoagulant therapy. J Cardiol. 2017;69(3):561-4.

96. Sanmartín M, Pereira B, Rúa R, et al. Safety of diagnostic transradial catheterization in patients undergoing long-term anticoagulation with coumarin derivatives. Rev Esp Cardiol. 2007;60(09):988-91.

97. Sticherling C, Marin F, Birnie D, et al. Antithrombotic management in patients undergoing electrophysiological procedures: a European heart rhythm association (EHRA) position document endorsed by the ESC working group thrombosis, heart rhythm society (HRS), and Asia Pacific heart rhythm society (APHRS). EP Europace. 2015;17(8):1197-214.

98. Monitoring Oral Anticoagulation Therapy. Availabe at: http:// www.japi.org/june_2014_special_issue/06_monitoring_oral_ anticoagulation.pdf. Last accessed on 31 Dec 2018.

99. Kim YK, Nieuwlaat R, Connolly S, et al. Effect of a simple twostep warfarin dosing algorithm on anticoagulant control as measured by time in therapeutic range: a pilot study. J Thromb Haemost. 2010;8(1):101-6.

100. Phillips KW, Ansell J. Outpatient management of oral vitamin K antagonist therapy: defining and measuring high-quality management. Expert Rev Cardiovase Ther. 2008;6(1):57-70.

101. Collection, transport, and processing of blood specimens for testing plasma based coagulation assays and molecular hemostasis assay: approved guideline-Fifth Edition. CLSI Document. H21A5. Wayne PA: Clinical and Laboratory Standards Institute:2008. Available at https://clsi.org/media/1399/h21a5_sample.pdf. Last accessed on 31 Dec 2018.

102. Favaloro EJ, Funk DMA, Lippi G. Pre-analytical variables in coagulation testing associated with diagnostic errors in hemostasis. Lab Med. 2012;43(2):1-10.

103. Lucas F, Duncan A, Jay R, et al. A novel whole blood capillary technic for measuring the prothrombin time. Am J Clin Pathol. 1987;88(4):442-6.

104. McBane RD, Felty CL, Hartgers ML, Chaudhry R, Beyer LK, Santrach PJ. Importance of device evaluation for point-of-care prothrombin time international normalized ratio testing programs. Mayo Clin Proc. 2005;80(2):181-6.

105. Lakshmy R, Kumar AS. Comparative evaluation of point of care coagulation monitoring by coaguchek XS-comparison with standard laboratory method. Indian J Thorac Cardiovasc Surg. 2010;26(2):125-8

106. Connock M, Stevens C, Fry-Smith A, Jowett S, Fitzmaurice D, Moore D. Clinical effectiveness and cost-effectiveness of different models of managing long-term oral anticoagulation therapy: a systematic review and economic modelling. Health Technol Assess. 2007;11(38):iii-v ix-66.

107. Kong MC, Lim TG, Ng HJ, Chan YH, Lee LH. Feasibility, costeffectiveness and patients acceptance of point-of-care INR testing in a hospital-based anticoagulation clinic. Ann Hematol. 2008;87(11):905-10.

108. Xu Z, Wang Z, Ou J, Xu Y, Yang S, Zhang X. Two monitoring methods of oral anticoagulant therapy in patients with mechanical heart valve prothesis: a meta-analysis. J Thromb Thrombolysis. 2012;33(1):38-47.

109. Nagler M, Bachmann LM, Schmid P, et al. Patient selfmanagement of oral anticoagulation with vitamin $\mathrm{K}$ antagonists in everyday practice: efficacy and safety in a nationwide longterm prospective cohort study. PLoS One. 2014;9(4):e95761.

110. Heneghan CJ, Garcia-Alamino JM, Spencer EA, et al. Selfmonitoring and self-management of oral anticoagulation. Cochrane Database Syst Rev. 2016;5(7):CD003839.

111. Sharma P, Scotland G, Cruickshank M, et al. The clinical effectiveness and cost-effectiveness of point-of-care tests (CoaguChek system, INRatio2 PT/INR monitor and ProTime microcoagulation system) for the self-monitoring of the coagulation status of people receiving long-term vitamin $\mathrm{K}$ antagonist therapy, compared with standard UK practice: systematic review and economic evaluation. Health Technol Assess. 2015;19(48):1-172.

112. Hirsh J, Fuster V, Ansell J, Halperin JL. American Heart Association/American College of Cardiology Foundation guide to warfarin therapy1. J Am Coll Cardiol. 2003;41(9):1633-52.

113. Holbrook A, Schulman S, Witt DM, et al. Evidence-based management of anticoagulant therapy: antithrombotic therapy and prevention of thrombosis: American College of Chest Physicians evidence-based clinical practice guidelines. Chest J. 2012;141(2_suppl):e152S-84S.

114. Amian A, Rodríguez J, Muñiz R, et al. Treatment with oral anticoagulants (acenocoumarol): influence of the initial doses in the incidence of hemorrhagic and thromboembolic episodes. Sangre. 1994;39(6):413-6.

115. Harrison L, Johnston M, Massicotte MP, Crowther M, Moffat K, Hirsh J. Comparison of 5-mg and 10-mg loading doses in initiation of warfarin therapy. Ann Intern Med. 1997;126(2):133-6.

116. Crowther MA, Ginsberg JB, Kearon C, et al. A randomized trial comparing 5-mg and 10-mg warfarin loading doses. Arch Intern Med. 1999;159(1):46-8.

117. Garcia D, Regan S, Crowther M, Hughes RA, Hylek EM. Warfarin maintenance dosing patterns in clinical practice: implications for safer anticoagulation in the elderly population. Chest $\mathrm{J}$. 2005;127(6):2049-56.

118. Van Geest-Daalderop JH, Hutten BA, Péquériaux NC, Levi M, Sturk A. Improvement in the regulation of the vitamin K antagonist acenocoumarol after a standard initial dose regimen: prospective validation of a prescription model. J Thromb Thrombolysis. 2009;27(2):207-14.

119. Mahtani KR, Heneghan CJ, Nunan D, et al. Optimal loading dose of warfarin for the initiation of oral anticoagulation. Cochrane Database Syst Rev. 2012;12:CD008685.

120. Heneghan C, Tyndel S, Bankhead C, et al. Optimal loading dose for the initiation of warfarin: a systematic review. BMC Cardiovasc Disord. 2010;10(1):18.

121. Lastória S, Fortes AT Jr, Maffei FHA, et al. Comparison of initial loading doses of $5 \mathrm{mg}$ and $10 \mathrm{mg}$ for warfarin therapy. J Vasc Br. 2014;13(1):12-7.

122. Wigle P, Hein B, Bloomfield HE, Tubb M, Doherty M. Updated guidelines on outpatient anticoagulation. Am Fam Physician. 2013;87(8):556-66.

123. British Columbia Medical Services Commission Medical Services Commission. Warfarin therapy management. Victoria (BC): British Columbia Medical Services Commission. Available at https://www2.gov.bc.ca/assets/gov/health/practitioner-pro/bcguidelines/warfarinmgmt_2015_full.pdf. Last Accessed on 31 Dec 2018.

124. Azim A, Baronia AK, Rao B, Singh RK, Gurjar M, Singh N. Safety and cost-effectiveness of acitrom for DVT prophylaxis in critically ill patients requiring prolonged mechanical ventilationa preliminary experience. J Anaesthesiol Clin Pharmacol. 2010;26(3):360-2.

125. Ebell MH. A systematic approach to managing warfarin doses. Fam Pract Manag. 2005;12(5):77 79-80, 83.

126. Jaffer A, Bragg L. Practical tips for warfarin dosing and monitoring. Cleve Clin J Med. 2003;70(4):361-71.

127. Gaikwad T, Shetty S, Ghosh K. Warfarin pharmacogenetics: how close are we to clinical practice? Indian J Hum Genet. 2013;19(3):277-8.

128. Rieder MJ, Reiner AP, Gage BF, et al. Effect of VKORC1 haplotypes on transcriptional regulation and warfarin dose. $\mathrm{N}$ Engl $\mathrm{J}$ Med. 2005;352(22):2285-93.

129. Kumar DK, Shewade DG, Manjunath S, Ushakiran P, Reneega G, Adithan C. Inter and intra ethnic variation of vitamin $\mathrm{K}$ epoxide 
reductase complex and cytochrome P450 4F2 genetic polymorphisms and their prevalence in south Indian population. Indian J Hum Genet. 2013;19(3):301-10.

130. Perini J, Struchiner C, Silva-Assuncao E, et al. Pharmacogenetics of warfarin: development of a dosing algorithm for Brazilian patients. Clin Pharmacol Ther. 2008;84(6):722-8.

131. Gage B, Eby C, Johnson J, et al. Use of pharmacogenetic and clinical factors to predict the therapeutic dose of warfarin. Clin Pharmacol Ther. 2008;84(3):326-31.

132. Rathore SS, Agarwal SK, Pande S, Singh SK, Mittal T, Mittal B. Therapeutic dosing of acenocoumarol: proposal of a population specific pharmacogenetic dosing algorithm and its validation in north Indians. PLoS One. 2012;7(5):e37844.

133. Pavani A, Naushad SM, Rupasree Y, et al. Optimization of warfarin dose by population-specific pharmacogenomic algorithm. Pharmacogenomics J. 2012;12(4):306-11.

134. Shalia KK, Doshi SM, Parikh S, et al. Prevalence of VKORC1 and CYP2C9 gene polymorphisms in Indian population and its effect on warfarin response. J Assoc Physicians India. 2012;60:34-8.

135. Gaikwad T, Ghosh K, Kulkarni B, Kulkarni V, Ross C, Shetty S. Influence of CYP2C9 and VKORC1 gene polymorphisms on warfarin dosage, over anticoagulation and other adverse outcomes in Indian population. Eur J Pharmacol. 2013;710(1):80-4.

136. Rathore S, Agarwal S, Pande S, Mittal T, Mittal B. The impact of VKORC1-1639 G> A polymorphism on the maintenance dose of oral anticoagulants for thromboembolic prophylaxis in North India: a pilot study. Indian J Hum Genet. 2011;17(Suppl 1):S54-7.

137. Kaur A, Khan F, Agrawal SS, Kapoor A, Agarwal SK, Phadke SR. Cytochrome P450 (CYP2C9* 2,* 3) \& vitamin-K epoxide reductase complex (VKORC1-1639G< A) gene polymorphisms $\&$ their effect on acenocoumarol dose in patients with mechanical heart valve replacement. Indian J Med Res. 2013;137(1):203-9.

138. Kumar DK, Madhan S, Balachander J, Chandran BS, Thamijarassy B, Adithan C. Effect of CYP2C9 and VKORC1 genetic polymorphisms on mean daily maintenance dose of acenocoumarol in south Indian patients. Thromb Res. 2013;131(4):363-7.

139. Bungard TJ, Yakiwchuk E, Foisy M, Brocklebank C. Drug interactions involving warfarin: practice tool and practical management tips. Can Pharm J. 2011;144(1):21-5.

140. Flaker G, Lopes RD, Hylek E, et al. Amiodarone, anticoagulation, and clinical events in patients with atrial fibrillation: insights from the ARISTOTLE trial. J Am Coll Cardiol. 2014;64(15):1541-50.

141. Zhang Q, Bal-dit-Sollier C, Drouet L, et al. Interaction between acetaminophen and warfarin in adults receiving long-term oral anticoagulants: a randomized controlled trial. Eur J Clin Pharmacol. 2011;67(3):309-14.

142. Wittkowsky AK, Boccuzzi SJ, Wogen J, Wygant G, Patel P, Hauch O. Frequency of concurrent use of warfarin with potentially interacting drugs. Pharmacotherapy. 2004;24(12):1668-74.

143. Patel VK, Acharya LD, Rajakannan T, Surulivelrajan M, Guddattu V, Padmakumar R. Potential drug interactions in patients admitted to cardiology wards of a south Indian teaching hospital. Australas Med J. 2011;4(1):9-14.

144. Milić N, Milosević N, Golocorbin KS, Bozić T, Abenavoli L, Borrelli F. Warfarin interactions with medicinal herbs. Nat Prod Commun. 2014;9(8):1211-6.

145. Ge B, Zhang Z, Zuo Z. Updates on the clinical evidenced herbwarfarin interactions Evid Based Complement Alternat Med. 2014;2014:957362.

146. de Assis MC, Rabelo ER, Ávila CW, Polanczyk CA, Rohde LE. Improved Oral anticoagulation after a dietary vitamin $\mathrm{K}$-guided strategy a randomized controlled trial. Circulation. 2009;120(12):1115-22.

147. Franco V, Polanczyk CA, Clausell N, Rohde LE. Role of dietary vitamin $\mathrm{K}$ intake in chronic oral anticoagulation: prospective evidence from observational and randomized protocols. Am J Med. 2004;116(10):651-6.
148. Lai YF, Cheen MHH, Lim SH, et al. The effects of fasting in Muslim patients taking warfarin. J Thromb Haemost. 2014;12(3):349-54.

149. Awiwi MO, Yagli ZA, Elbir F, Aglar AA, Guler E, Vural U. The effects of Ramadan fasting on patients with prosthetic heart valve taking warfarin for anticoagulation. J Saudi Heart Assoc. 2017;29(1):1-6.

150. Addad F, Amami M, Ibn Elhadj Z, Chakroun T, Marrakchi S, Kachboura S. Does Ramadan fasting affect the intensity of acenocoumarol-induced anticoagulant effect? Br J Haematol. 2014;166(5):792-4.

151. Srivastava AR, Modi P, Sahi S, Niwariya Y, Singh H, Banerjee A. Anticoagulation for pregnant patients with mechanical heart valves. Ann Card Anaesth. 2007;10(2):95-107.

152. Brooks C, Rutherford JM, Gould J, Ramsay MM, James DK. Warfarin dosage in postpartum women: a case-control study. BJOG Int J Obstet Gynaecol. 2002;109(2):187-90.

153. Lebaudy C, Hulot JS, Amoura Z, et al. Changes in enoxaparin pharmacokinetics during pregnancy and implications for antithrombotic therapeutic strategy. Clin Pharmacol Ther. 2008;84(3):370-7.

154. Cotrufo M, De Feo M, De Santo LS, et al. Risk of warfarin during pregnancy with mechanical valve prostheses. Obstet Gynecol. 2002;99(1):35-40.

155. Hassouna A, Allam H. Limited dose warfarin throughout pregnancy in patients with mechanical heart valve prosthesis: a meta-analysis. Interact Cardiovasc Thorac Surg. 2014;18(6):797-806.

156. Vitale N, De Feo M, De Santo LS, Pollice A, Tedesco N, Cotrufo M. Dose-dependent fetal complications of warfarin in pregnant women with mechanical heart valves. J Am Coll Cardiol. 1999;33(6):1637-41.

157. Chan WS, Anand S, Ginsberg JS. Anticoagulation of pregnant women with mechanical heart valves: a systematic review of the literature. Arch Intern Med. 2000;160(2):191-6.

158. Gopalakrishnan S, Narayanan S. Oral anticoagulants: current Indian scenario. Medicine update. Assoc Phys India. 2013;90:410-3.

159. Geelani MA, Singh S, Verma A, Nagesh A, Betigeri V, Nigam M. Anticoagulation in patients with mechanical valves during pregnancy. Asian Cardiovasc Thorac Ann. 2005;13(1):30-3.

160. Pavankumar P, Venugopal P, Kaul U, et al. Pregnancy in patients with prosthetic cardiac valve: a 10 -year experience. Scand Cardiovasc J. 1988;22(1):19-22.

161. Suri V, Keepanasseril A, Aggarwal N, et al. Mechanical valve prosthesis and anticoagulation regimens in pregnancy: a tertiary centre experience. Eur J Obstet Gynecol Reprod Biol. 2011;159(2):320-3.

162. Tounsi A, Abid D, Louati D, et al. Anticoagulation in pregnant women with mechanical heart valve prostheses: 25 -year experience at a tertiary care hospital in a developing country. World J Cardiovasc Dis. 2014;4(06):287-93.

163. Panduranga P, El-Deeb M, Jha C. Mechanical prosthetic valves and pregnancy: a therapeutic dilemma of anticoagulation. Sultan Qaboos Univ Med J. 2014;14(4):e448-54.

164. Bates SM, Greer IA, Middeldorp S, Veenstra DL, Prabulos A-M, Vandvik PO. VTE, thrombophilia, antithrombotic therapy, and pregnancy: antithrombotic therapy and prevention of thrombosis: American College of Chest Physicians evidence-based clinical practice guidelines. Chest J. 2012;141(2 suppl):e691S-736S.

165. Vahanian A, Alfieri O, Andreotti F, et al. Guidelines on the management of valvular heart disease. Eur Heart J. 2012;33(19):2451-96.

166. Robert-Ebadi H, Le Gal G, Righini M. Use of anticoagulants in elderly patients: practical recommendations. Clin Interv Aging. 2009;4:165-77.

167. Dhond AJ, Michelena HI, Ezekowitz MD. Anticoagulation in the elderly. Am J Geriatr Cardiol. 2003;12(4):243-50.

168. Rouaud A, Hanon O, Boureau AS, Chapelet GG, de Decker L. Comorbidities against quality control of VKA therapy in non- 
valvular atrial fibrillation: a French national cross-sectional study. PLoS One. 2015;10(3):e0119043.

169. Ignjatovic V, Straka E, Summerhayes R, Monagle P. Age-specific differences in binding of heparin to plasma proteins. J Thromb Haemost. 2010;8(6):1290-4.

170. Rohde LE, de Assis MCS, Rabelo ER. Dietary vitamin K intake and anticoagulation in elderly patients. Curr Opin Clin Nutr Metab Care. 2007;10(1):1-5.

171. Jawarkar AK, Lokare PO, Kizhatil A, Jawarkar JA. Prevalence of anemia and effectiveness of iron supplementation in anemic adolescent school girls at Amravati City (Maharashtra). J Health Res Rev. 2015;2(1):7-10.

172. Self TH, Oliphant CS, Reaves AB, Richardson AM, Sands CW. Fever as a risk factor for increased response to vitamin $\mathrm{k}$ antagonists: a review of the evidence and potential mechanisms. Thromb Res. 2015;135(1):5-8.

173. Davidson BL, Verheijen S, Lensing AW, Gebel M, Brighton TA, Lyons RM. Bleeding risk of patients with acute venous thromboembolism taking nonsteroidal anti-inflammatory drugs or aspirin. JAMA Intern Med. 2014;174(6):947-53.

174. Hughes M, Lip GYH. Risk factors for anticoagulation-related bleeding complications in patients with atrial fibrillation: a systematic review. QJM. 2007;100(10):599-607.

175. Kagansky N, Knobler H, Rimon E, Ozer Z, Levy S. Safety of anticoagulation therapy in well-informed older patients. Arch Intern Med. 2004;164(18):2044-50.

176. Samama MM. Use of low-molecular-weight heparins and new anticoagulants in elderly patients with renal impairment. Drugs Aging. 2011;28(3):177-93.

177. Andreotti F, Rocca B, Husted S, et al. Antithrombotic therapy in the elderly: expert position paper of the European Society of Cardiology Working Group on thrombosis. Eur Heart J. 2015;36(46):3238-49.

178. Mandalà M, Ferretti G, Cremonesi M, Cazzaniga M, Curigliano G, Barni S. Venous thromboembolism and cancer: new issues for an old topic. Crit Rev Oncol Hematol. 2003;48(1):65-80.

179. Hiller E. Cancer and thrombosis: managing the risks and approaches to thromboprophylaxis. Onkologie. 2006;29(10):474-8.

180. Heit JA, Silverstein MD, Mohr DN, Petterson TM, O'Fallon WM, Melton LJ. Risk factors for deep vein thrombosis and pulmonary embolism: a population-based case-control study. Arch Intern Med. 2000;160(6):809-15.

181. Rivkin SE, Green S, Metch B, et al. Adjuvant CMFVP versus tamoxifen versus concurrent CMFVP and tamoxifen for postmenopausal, node-positive, and estrogen receptor-positive breast cancer patients: a southwest oncology group study. J Clin Oncol. 1994;12(10):2078-85.

182. Joung S, Robinson B. Venous thromboembolism in cancer patients in Christchurch, 1995-1999. N Z Med J. 2002;115(1155):257-60.

183. Hutten BA, Prins MH, Gent M, Ginsberg J, Tijssen JG, Büller HR. Incidence of recurrent thromboembolic and bleeding complications among patients with venous thromboembolism in relation to both malignancy and achieved international normalized ratio: a retrospective analysis. J Clin Oncol. 2000;18(17):3078-83.

184. Sezer A, Sumbul AT, Abali G, Sumbul Z, Muallaoglu S, Abali H. Can low molecular weight heparins circumvent the problem of coumadine and chemotherapy interaction in cancer patients with prosthetic heart valves? Asian Pac J Cancer Prev. 2014;15(4):1889-90.

185. Saccullo G, Malato A, Raso S, et al. Cancer patients requiring interruption of long-term warfarin because of surgery or chemotherapy induced thrombocytopenia: the use of fixed subtherapeutic doses of low-molecular weight heparin. Am J Hematol. 2012;87(4):388-91.

186. Alvi S, Shereck E, Heran MK, Sandor GG, Rassekh SR. Successful treatment of acute lymphoblastic leukemia in a child with trisomy 21 and complex congenital heart disease with mechanical prosthetic valve. Case Rep Pediatr. 2012.

187. Lee MTM, Chen C-H, Chuang H-P, et al. VKORC1 haplotypes in five East-Asian populations and Indians. Pharmacogenomics. 2009;10(10):1609-16.

188. Sellam J, Costedoat-Chalumeau N, Amoura Z, et al. Potentiation of fluindione or warfarin by dexamethasone in multiple myeloma and AL amyloidosis. Joint Bone Spine. 2007;74(5):446-52.

189. Prandoni P, Trujillo-Santos J, Surico T, Dalla Valle F, Piccioli A, Monreal M. Recurrent thromboembolism and major bleeding during oral anticoagulant therapy in patients with solid cancer: findings from the RIETE registry. Haematologica. 2008;93(9):1432-4.

190. Mahe I, Gouin-Thibault I, Drouet L, et al. Elderly medical patients treated with prophylactic dosages of enoxaparin. Drugs Aging. 2007;24(1):63-71.

191. Grand'Maison A, Charest AF, Geerts WH. Anticoagulant use in patients with chronic renal impairment. Am J Cardiovasc Drugs. 2005;5(5):291-305.

192. Kulkarni N, Gukathasan N, Sartori S, Baber U. Chronic kidney disease and atrial fibrillation: a contemporary overview. J Atr Fibrillation. 2012;2(11):62-70.

193. Di Biase L. Use of direct oral anticoagulants in patients with atrial fibrillation and valvular heart lesions. J Am Heart Assoc. 2016;5(2).

194. Pepi M, Evangelista A, Nihoyannopoulos P, et al. Recommendations for echocardiography use in the diagnosis and management of cardiac sources of embolism. Eur Heart J Cardiovasc Imaging. 2010;11(6):461-76.

195. Huber KC, Gersh BJ, Bailey KR, et al. Variability in anticoagulation control predicts thromboembolism after mechanical cardiac valve replacement: a 23 -year population-based study. Mayo Clin Proc. 1997;72(12):1103-10.

196. Lalonde L, Martineau J, Blais N, et al. Is long-term pharmacistmanaged anticoagulation service efficient? A pragmatic randomized controlled trial. Am Heart J. 2008;156(1):148-54.

197. Locke C, Ravnan SL, Patel R, Uchizono JA. Reduction in warfarin adverse events requiring patient hospitalization after implementation of a pharmacist-managed anticoagulation service. Pharmacotherapy. 2005;25(5):685-9.

198. Mistiaen W, Van Cauwelaert P, Muylaert P, Sys SU, Harrisson F, Bortier H. Thromboembolic events after aortic valve replacement in elderly patients with a Carpentier-Edwards Perimount pericardial bioprosthesis. J Thorac Cardiovasc Surg. 2004;127(4):1166-70.

199. Tang EO, Lai CS, Lee KK, Wong RS, Cheng G, Chan TY. Relationship between patients warfarin knowledge and anticoagulation control. Ann Pharmacother. 2003;37(1):34-9.

200. Zeolla MM, Brodeur MR, Dominelli A, Haines ST, Allie ND. Development and validation of an instrument to determine patient knowledge: the oral anticoagulation knowledge test. Ann Pharmacother. 2006;40(4):633-8.

201. Kneeland PP, Fang MC. Current issues in patient adherence and persistence: focus on anticoagulants for the treatment and prevention of thromboembolism. Patient Prefer Adherence. 2010;4:51-60.

202. Zoghbi WA, Chambers JB, Dumesnil JG, et al. Recommendations for evaluation of prosthetic valves with echocardiography and doppler ultrasound: a report From the American Society of Echocardiography's Guidelines and Standards Committee and the Task Force on Prosthetic Valves, developed in conjunction with the American College of Cardiology Cardiovascular Imaging Committee, Cardiac Imaging Committee of the American Heart Association, the European Association of Echocardiography, a registered branch of the European Society of Cardiology, the Japanese Society of Echocardiography and the Canadian Society of Echocardiography, endorsed by the American College of Cardiology Foundation, American Heart Association, European Association of Echocardiography, a registered branch of the European Society of Cardiology, the Japanese Society of 
Echocardiography, and Canadian Society of Echocardiography. J Am Soc Echocardiogr. 2009;22(9):975-1014.

203. Karthikeyan G, Math RS, Mathew N, et al. Accelerated infusion of streptokinase for the treatment of left-sided prosthetic valve thrombosis: a randomized controlled trial. Circulation. 2009;120(12):1108-14.

204. Talwar S, Kapoor CK, Velayoudam D, Kumar AS. Anticoagulation protocol and early prosthetic valve thrombosis. Indian Heart J. 2003;56(3):225-8.

205. Roudaut R, Serri K, Lafitte S. Thrombosis of prosthetic heart valves: diagnosis and therapeutic considerations. Heart. 2007;93(1):137-42.

206. Piper C, Hering D, Horstkotte D. Prosthetic valve thrombosis: predisposition and diagnosis. Eur Heart J Suppl. 2001;3(suppl_Q):Q16-21.

207. Dasi LP, Simon HA, Sucosky P, Yoganathan AP. Fluid mechanics of artificial heart valves. Clin Exp Pharmacol Physiol. 2009;36(2):225-37.

208. Barbetseas J, Nagueh SF, Pitsavos C, Toutouzas PK, Quiñones MA, Zoghbi WA. Differentiating thrombus from pannus formation in obstructed mechanical prosthetic valves: an evaluation of clinical, transthoracic and transesophageal echocardiographic parameters. J AmColl Cardiol. 1998;32(5):1410-7.

209. Habib G, Cornen A, Mesana T, Monties JR, Djiane P. Diagnosis of prosthetic heart valve thrombosis. The respective values of transthoracic and transoesophageal Doppler echocardiography. Eur Heart J. 1993;14(4):447-55.

210. Tong AT, Roudaut R, Özkan M, et al. Transesophageal echocardiography improves risk assessment of thrombolysis of prosthetic valve thrombosis: results of the international PRO-TEE registry. $\mathrm{J}$ AmColl Cardiol. 2004;43(1):77-84.

211. Lengyel M. Diagnosis and treatment of left-sided prosthetic valve thrombosis. Expert Rev Cardiovasc Ther. 2008;6(1):85-93.

212. Mutuberría-Urdaniz M, Rodríguez-Palomares JF, et al. Nonobstructive prosthetic heart valve thrombosis (NOPVT): really a benign entity? Int J Cardiol. 2015;197:16-22.

213. Roudaut R, Lafitte ST, Roudaut MF, et al. Fibrinolysis of mechanical prosthetic valve thrombosis: a single-center study of 127 cases. J AmColl Cardiol. 2003;41(4):653-8.

214. Roudaut R, Lafitte S, Roudaut MF, et al. Management of prosthetic heart valve obstruction: fibrinolysis versus surgery. Early results and long-term follow-up in a single-centre study of 263 cases. Arch Cardiovasc Dis. 2009;102(4):269-77.

215. Deviri E, Sareli P, Wisenbaugh T, Cronje SL. Obstruction of mechanical heart valve prostheses: clinical aspects and surgical management. J Am Coll Cardiol. 1991;17(3):646-50.

216. Keuleers S, Herijgers P, Herregods MC, et al. Comparison of thrombolysis versus surgery as a first line therapy for prosthetic heart valve thrombosis. J Am Coll Cardiol. 2011;107(2):275-9.

217. Cáceres-Lóriga FM, Pérez-López H, Morlans-Hernández K, et al. Thrombolysis as first choice therapy in prosthetic heart valve thrombosis. A study of 68 patients. J Thromb Thrombolysis. 2006;21(2):185-90.

218. Karthikeyan G, Senguttuvan NB, Joseph J, Devasenapathy N, Bahl VK, Airan B. Urgent surgery compared with fibrinolytic therapy for the treatment of left-sided prosthetic heart valve thrombosis: a systematic review and meta-analysis of observational studies. Eur Heart J. 2013;34(21):1557-66.

219. Singh AK, Agarwal S, Satyarthi S, Satsangi DK. Comparison of thrombolytic therapy for prosthetic valve thrombosis at the mitral and aortic position. Indian J Thorac Cardiovasc Surg. 2011;27(3):114-8.

220. Srinivas B, Moorthy N, Kuldeep A, Jeevan H, Chandrasekaran D, Manjunath C. Thrombolytic therapy in prosthetic valve thrombosis during early pregnancy. Indian Heart J. 2012;64(1):74-6.

221. Sharma V, Singh R, Mishra R, Arora A, Gupta L, Yadava O. Use of tenecteplase for left-sided prosthetic valve thrombosis. JAPI. 2012;60(5):55-8.
222. Kuchulakanti PK, Chirde S, Akkala R. Successful treatment of aortic prosthetic valve thrombosis with bolus dose tenecteplase. Indian Heart J. 2014;66(2):251-2.

223. Panduranga P, Al-Mukhaini M, Al-Muslahi M, Haque MA, Shehab A. Management dilemmas in patients with mechanical heart valves and warfarin-induced major bleeding. World $\mathrm{J}$ Cardiol. 2012;4(3):54-9.

224. Beyth RJ, Quinn LM, Landefeld CS. Prospective evaluation of an index for predicting the risk of major bleeding in outpatients treated with warfarin. Am J Med. 1998;105(2):91-9.

225. Shireman TI, Mahnken JD, Howard PA, Kresowik TF, Hou Q, Ellerbeck EF. Development of a contemporary bleeding risk model for elderly warfarin recipients. Chest J. 2006;130(5):1390-6.

226. Lip GY, Frison L, Halperin JL, Lane DA. Comparative validation of a novel risk score for predicting bleeding risk in anticoagulated patients with atrial fibrillation: the HAS-BLED (hypertension, abnormal renal/liver function, stroke, bleeding history or predisposition, labile INR, elderly, drugs/alcohol concomitantly) score. J Am Coll Cardiol. 2011;57(2):173-80.

227. Gage BF, Yan Y, Milligan PE, et al. Clinical classification schemes for predicting hemorrhage: results from the National Registry of atrial fibrillation (NRAF). Am Heart J. 2006;151(3):713-9.

228. Fang MC, Chang Y, Hylek EM, et al. Advanced age, anticoagulation intensity, and risk for intracranial hemorrhage among patients taking warfarin for atrial fibrillation. Ann Intern Med. 2004;141(10):745-52.

229. Phan TG, Koh M, Wijdicks EF. Safety of discontinuation of anticoagulation in patients with intracranial hemorrhage at high thromboembolic risk. Arch Neurol. 2000;57(12):1710-3.

230. Wijdicks EF, Schievink WI, Brown RD, Mullany CJ. The dilemma of discontinuation of anticoagulation therapy for patients with intracranial hemorrhage and mechanical heart valves. Neurosurgery. 1998;42(4):769-73.

231. Kaneko T, Aranki SF. Anticoagulation for prosthetic valves. Thrombosis. 2013;2013.

232. Yiu KH, Siu CW, Jim MH, et al. Comparison of the efficacy and safety profiles of intravenous vitamin $\mathrm{K}$ and fresh frozen plasma as treatment of warfarin-related over-anticoagulation in patients with mechanical heart valves. Am J Cardiol. 2006;97(3):409-11.

233. Lubetsky A, Yonath H, Olchovsky D, Loebstein R, Halkin H, Ezra D. Comparison of oral vs intravenous phytonadione (vitamin K1) in patients with excessive anticoagulation: a prospective randomized controlled study. Arch Intern Med. 2003;163(20):2469-73.

234. Patel RJ, Witt DM, Saseen JJ, Tillman DJ, Wilkinson DS. Randomized, placebo-controlled trial of oral phytonadione for excessive anticoagulation. Pharmacotherapy. 2000;20(10):1159-66.

235. Evangelista A, Gonzalez-Alujas MT. Echocardiography in infective endocarditis. Heart. 2004;90(6):614-7.

236. Durack DT, Lukes AS, Bright DK. New criteria for diagnosis of infective endocarditis: utilization of specific echocardiographic findings. Duke Endocarditis Service. Am J Med. 1994;96(3):200-9.

237. Ashley EA, Niebauer J. Cardiology explained. London: Remedica; 2004. Chapter 10, Infective endocarditis. Available from: https://www.ncbi.nlm.nih.gov/books/NBK2208/. Last accessed on 02 Jan 2018

238. Birmingham GD, Rahko PS, Ballantyne F 3rd. Improved detection of infective endocarditis with transesophageal echocardiography. Am Heart J. 1992;123(3):774-81.

239. Daniel WG, Mugge A, Grote J, et al. Comparison of transthoracic and transesophageal echocardiography for detection of abnormalities of prosthetic and bioprosthetic valves in the mitral and aortic positions. Am J Cardiol. 1993;71(2):210-5.

240. Karalis DG, Bansal RC, Hauck AJ, et al. Transesophageal echocardiographic recognition of subaortic complications in aortic valve endocarditis. Clinical and surgical implications. Circulation. 1992;86(2):353-62. 
241. Rozich JD, Edwards WD, Hanna RD, Laffey DM, Johnson GH, Klarich KW. Mechanical prosthetic valve-associated strands: pathologic correlates to transesophageal echocardiography. J Am Soc Echocardiogr. 2003;16(1):97-100.

242. Lengyel M. The impact of transesophageal echocardiography on the management of prosthetic valve endocarditis: experience of 31 cases and review of the literature. J Heart Valve Dis. 1997;6(2):204-11.

243. Daniel WG, Mugge A, Martin RP, et al. Improvement in the diagnosis of abscesses associated with endocarditis by transesophageal echocardiography. N Engl J Med. 1991;324(12):795-800.

244. Mugge A. Echocardiographic detection of cardiac valve vegetations and prognostic implications. Infect Dis Clin N Am. 1993;7(4):877-98.

245. Afridi I, Apostolidou MA, Saad RM, Zoghbi WA. Pseudoaneurysms of the mitral-aortic intervalvular fibrosa: dynamic characterization using transesophageal echocardiographic and Doppler techniques. J Am Coll Cardiol. 1995;25(1):137-45.

246. Lowry RW, Zoghbi WA, Baker WB, Wray RA, Quinones MA. Clinical impact of transesophageal echocardiography in the diagnosis and management of infective endocarditis. Am J Cardiol. 1994;73(15):1089-91.

247. Bayer AS. Infective endocarditis. Clin Infect Dis. 1993;17(3): 313-20.

248. Ali AS, Trivedi V, Lesch M. Culture-negative endocarditis-a historical review and 1990s update. Prog Cardiovasc Dis. 1994;37(3):149-60.

249. Hartnell GG, Spence L, Hughes LA, Cohen MC, Saouaf R, Buff B. Safety of MR imaging in patients who have retained metallic materials after cardiac surgery. AJR Am J Roentgenol. 1997;168(5):1157-9.

250. Davenport J, Hart RG. Prosthetic valve endocarditis 1976-1987. Antibiotics, anticoagulation, and stroke. Stroke. 1990;21(7):993-9.

251. Agarwal S, Rawtani S, Geelani MA, Moharana M, Singh H, Banerjee A. Risk factors for prosthetic valve endocarditis - a case control study. Indian J Thorac Cardiovasc Surg. 2009;25(3):102-6.

252. Vilacosta I, Graupner C, San Roman JA, et al. Risk of embolization after institution of antibiotic therapy for infective endocarditis. J Am Coll Cardiol. 2002;39(9):1489-95.

253. Lieberman A, Hass WK, Pinto R, et al. Intracranial hemorrhage and infarction in anticoagulated patients with prosthetic heart valves. Stroke. 1978;9(1):18-24.

254. Masur H, Johnson WD Jr. Prosthetic valve endocarditis. J Thorac Cardiovasc Surg. 1980;80(1):31-7.

255. Wilson WR, Geraci JE, Danielson GK, et al. Anticoagulant therapy and central nervous system complications in patients with prosthetic valve endocarditis. Circulation. 1978;57(5):1004-7.

256. Carpenter JL, Mcallister CK. Anticoagulation in prosthetic valve endocarditis. South Med J. 1983;76(11):1372-5.

257. Habib G, Badano L, Tribouilloy C, et al. Recommendations for the practice of echocardiography in infective endocarditis. Eur $\mathrm{J}$ Echocardiogr. 2010;11(2):202-19.

258. Baddour LM, Wilson WR, Bayer AS, et al. Infective endocarditis: diagnosis, antimicrobial therapy, and management of complications: a statement for healthcare professionals from the Committee on Rheumatic Fever, Endocarditis, and Kawasaki Disease, Council on Cardiovascular Disease in the Young, and the Councils on Clinical Cardiology, Stroke, and Cardiovascular Surgery and Anesthesia, American Heart Association: endorsed by the Infectious Diseases Society of America. Circulation. 2005;111(23):e394-434.

259. Wilson W, Taubert KA, Gewitz M, et al. Prevention of infective endocarditis: guidelines from the American Heart Association: a guideline from the American Heart Association Rheumatic Fever, Endocarditis, and Kawasaki Disease Committee, Council on Cardiovascular Disease in the Young, and the Council on Clinical Cardiology, Council on Cardiovascular Surgery and Anesthesia, and the Quality of Care and Outcomes Research Interdisciplinary Working Group. Circulation. 2007;116(15):1736-54.

260. Gould FK, Elliott TS, Foweraker J, et al. Guidelines for the prevention of endocarditis: report of the working party of the British Society for antimicrobial chemotherapy. J Antimicrob Chemother. 2006;57(6):1035-42.

261. Groves P. Surgery of valve disease: late results and late complications. Heart. 2001;86(6):715-21.

262. Grubb KJ, Nazif T, Williams MR, George I. Concurrent coronary artery and valvular heart disease-hybrid treatment strategies in 2013. Interv Cardiol Rev. 2013;8(2):127-30.

263. Sourgounis A, Lipiecki J, Lo TS, Hamon M. Coronary stents and chronic anticoagulation. Circulation. 2009;119(12):1682-8.

264. Amsterdam EA, Wenger NK, Brindis RG, et al. 2014 AHA/ACC guideline for the management of patients with non-ST-elevation acute coronary syndromes. J Am Coll Cardiol. 2014;64(24):e139-228.

265. O'Gara PT, Kushner FG, Ascheim DD, et al. 2013 ACCF/AHA guideline for the management of ST-elevation myocardial infarction: a report of the American College of Cardiology Foundation/ American Heart Association task force on practice guidelines. Circulation. 2013;127(4):e362-425.

266. Wang YF, Zhang Y, Liu SX, Chen P. Meta-analysis of drugeluting versus bare metal stents in patients with indications for oral anticoagulation undergoing coronary stenting. Acta Cardiol. 2014;69(3):237-44.

267. Dewilde WJ, Oirbans T, Verheugt FW, et al. Use of clopidogrel with or without aspirin in patients taking oral anticoagulant therapy and undergoing percutaneous coronary intervention: an open-label, randomised, controlled trial. Lancet. 2013;381(9872):1107-15.

268. Schömig A, Sarafoff N, Seyfarth M. Triple antithrombotic management after stent implantation: when and how? Heart. 2009;95(15):1280-5.

269. Zahger D, Ilia R. Coronary stenting in warfarin treated patients. EuroIntervention. 2009;5(2):277-81.

270. Alqahtani AA. Atrial fibrillation post cardiac surgery trends toward management. Heart Views. 2010;11(2):57-63.

271. Filardo G, Hamilton C, Hamman B, Hebeler RF, Adams J, Grayburn P. New-onset postoperative atrial fibrillation and longterm survival after aortic valve replacement surgery. Ann Thorac Surg. 2010;90(2):474-9.

272. Mitchell LB, Exner DV, Wyse DG, et al. Prophylactic oral amiodarone for the prevention of arrhythmias that begin early after revascularization, valve replacement, or repair: PAPABEAR: a randomized controlled trial. JAMA. 2005;294(24):3093-100.

273. Bagshaw SM, Galbraith PD, Mitchell LB, Sauve R, Exner DV, Ghali WA. Prophylactic amiodarone for prevention of atrial fibrillation after cardiac surgery: a meta-analysis. Ann Thorac Surg. 2006;82(5):1927-37.

274. Auer J, Weber T, Berent R, et al. A comparison between oral antiarrhythmic drugs in the prevention of atrial fibrillation after cardiac surgery: the pilot study of prevention of postoperative atrial fibrillation (SPPAF), a randomized, placebo-controlled trial. Am Heart J. 2004;147(4):636-43.

275. Kar SK, Dasgupta CS, Goswami A. Effect of prophylactic amiodarone in patients with rheumatic valve disease undergoing valve replacement surgery. Ann Card Anaesth. 2011;14(3):176-82.

276. Selvaraj T, Kiran U, Das S, Chauhan S, Sahu B, Gharde P. Effect of single intraoperative dose of amiodarone in patients with rheumatic valvular heart disease and atrial fibrillation undergoing valve replacement surgery. Ann Card Anaesth. 2009;12(1):10-6.

277. Dunning J, Treasure T, Versteegh M, Nashef SA. Guidelines on the prevention and management of de novo atrial fibrillation after cardiac and thoracic surgery. Eur J Cardiothorac Surg. 2006;30(6):852-72.

278. Seiler C. Management and follow up of prosthetic heart valves. Heart. 2004;90(7):818-24. 
279. Butchart EG, Gohlke-Bärwolf C, Antunes MJ, et al. Recommendations for the management of patients after heart valve surgery. Eur Heart J. 2005;26(22):2463-71.

280. Shellock FG, Morisoli SM. Ex vivo evaluation of ferromagnetism, heating, and artifacts produced by heart valve prostheses exposed to a 1.5-T MR system. J Magn Reson Imaging. 1994;4(5):756-8.

281. Edwards MB, Taylor KM, Shellock FG. Prosthetic heart valves: evaluation of magnetic field interactions, heating, and artifacts at 1.5 T. J Magn Reson Imaging. 2000;12(2):363-9.

282. Shellock F, Prosthetic G. Heart valves and annuloplasty rings: assessment of magnetic field interactions, heating, and artifacts at 1.5 tesla. J Cardiovasc Magn Reson. 2001;3(4):317-24.

283. Soulen RL, Budinger TF, Higgins CB. Magnetic resonance imaging of prosthetic heart valves. Radiology. 1985;154(3):705-7.
284. Condon B, Hadley DM. Potential MR hazard to patients with metallic heart valves: the Lenz effect. J Magn Reson Imaging. 2000;12(1):171-6.

285. Pruefer D, Kalden P, Schreiber W, Dahm M, Buerke M, Thelen M. In vitro investigation of prosthetic heart valves in magnetic resonance imaging: evaluation of potential hazards. J Heart Valve Dis. 2001;10(3):410-4.

286. Baikoussis NG, Apostolakis E, Papakonstantinou NA, Sarantitis I, Dougenis D. Safety of magnetic resonance imaging in patients with implanted cardiac prostheses and metallic cardiovascular electronic devices. Ann Thorac Surg. 2011;91(6):2006-11.

287. Dill T. Contraindications to magnetic resonance imaging. Heart. 2008;94(7):943-8. 